\title{
Calibration of X-Ray and Gamma-Ray Measuring Instruments
}

NIST

Special

Publication

250-58

Paul J. Lamperti

Michelle O'Brien
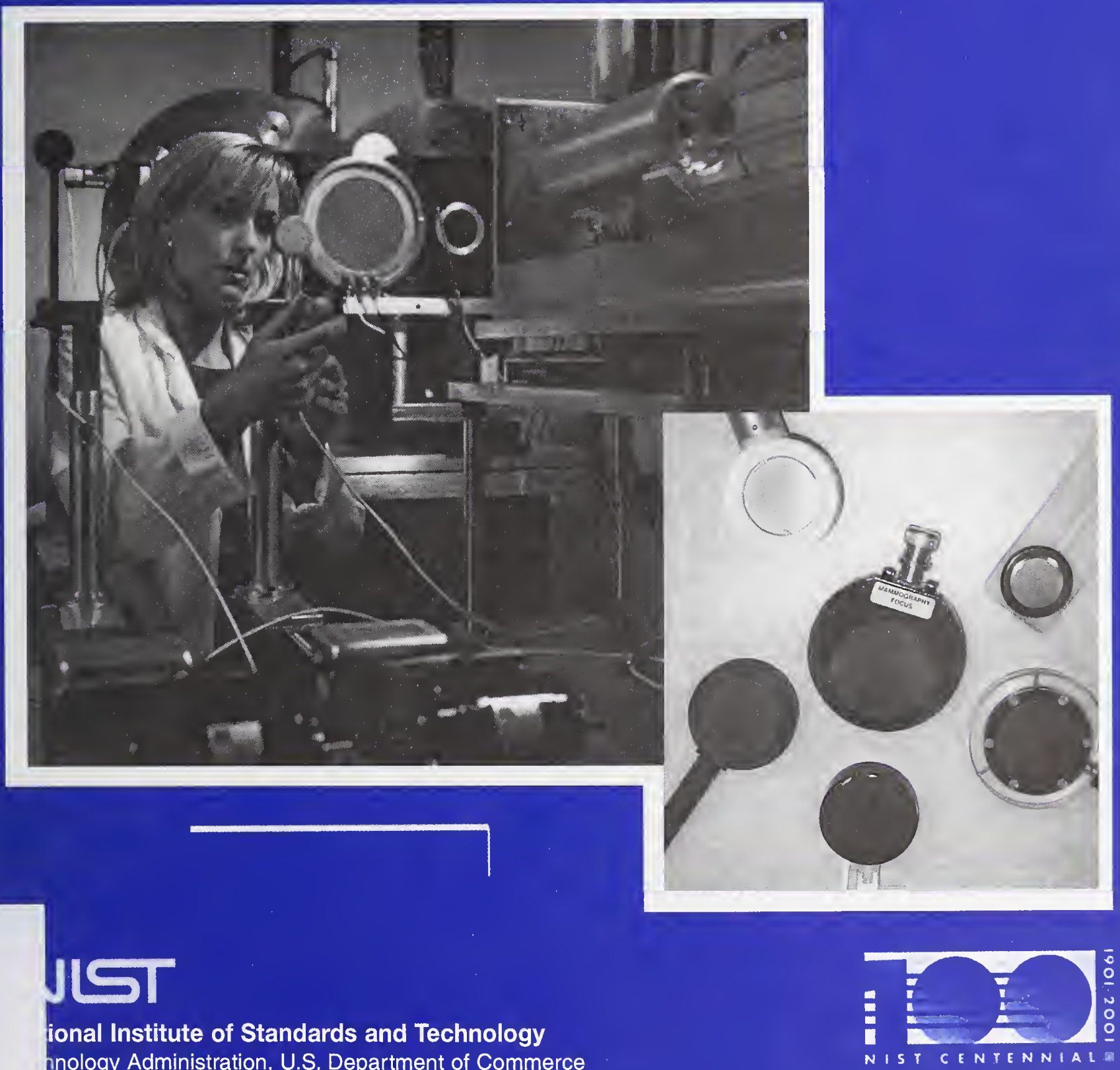
he National Institute of Standards and Technology was established in 1988 by Congress to "assist industry in

the development of technology... needed to improve product quality, to modernize manufacturing processes, to ensure product reliability . . . and to facilitate rapid commercialization . . . of products based on new scientific discoveries."

NIST, originally founded as the National Bureau of Standards in 1901, works to strengthen U.S. industry's competitiveness; advance science and engineering; and improve public health, safety, and the environment. One of the agency's basic functions is to develop, maintain, and retain custody of the national standards of measurement, and provide the means and methods for comparing standards used in science, engineering, manufacturing, commerce, industry, and education with the standards adopted or recognized by the Federal Government.

As an agency of the U.S. Commerce Department's Technology Administration, NIST conducts basic and applied research in the physical sciences and engineering, and develops measurement techniques, test methods, standards, and related services. The Institute does generic and precompetitive work on new and advanced technologies. NIST's research facilities are located at Gaithersburg, MD 20899, and at Boulder, CO 80303. Major technical operating units and their principal activities are listed below. For more information contact the Publications and Program Inquiries Desk, 301-975-3058.

Office of the Director

- National Quality Program

- International and Academic Affairs

\section{Technology Services}

- Standards Services

- Technology Partnerships

- Measurement Services

- Information Services

\section{Advanced Technology Program}

- Economic Assessment

- Information Technology and Applications

- Chemistry and Life Sciences

- Materials and Manufacturing Technology

- Electronics and Photonics Technology

\section{Manufacturing Extension Partnership Program \\ - Regional Programs \\ - National Programs \\ - Program Development}

\section{Electronics and Electrical Engineering Laboratory \\ - Microelectronics \\ - Law Enforcement Standards \\ - Electricity \\ - Semiconductor Electronics \\ - Radio-Frequency Technology ${ }^{1}$ \\ - Electromagnetic Technology ${ }^{1}$ \\ - Optoelectronics ${ }^{1}$}

\section{Materials Science and Engineering Laboratory \\ - Intelligent Processing of Materials \\ - Ceramics \\ - Materials Reliability ${ }^{1}$ \\ - Polymers \\ - Metallurgy \\ - NIST Center for Neutron Research}

Chemical Science and Technology Laboratory

- Biotechnology

- Physical and Chemical Properties ${ }^{2}$

- Analytical Chemistry

- Process Measurements

- Surface and Microanalysis Science

Physics Laboratory

- Electron and Optical Physics

- Atomic Physics

- Optical Technology

- Ionizing Radiation

- Time and Frequency

- Quantum Physics ${ }^{1}$

Manufacturing Engineering Laboratory

- Precision Engineering

- Manufacturing Metrology

- Intelligent Systems

- Fabrication Technology

- Manufacturing Systems Integration

Building and Fire Research

Laboratory

- Applied Economics

- Structures

- Building Materials

- Building Environment

- Fire Safety Engineering

- Fire Science

Information Technology Laboratory

- Mathematical and Computational Sciences ${ }^{2}$

- Advanced Network Technologies

- Computer Security

- Information Access

- High Performance Systems and Services

- Distributed Computing and Information Services

- Software Diagnostics and Conformance Testing

- Statistical Engineering 
NIST Special Publication 250-58

\section{NIST MEASUREMENT SERVICES: Calibration of X-Ray and Gamma-Ray Measuring Instruments}

Paul J. Lamperti

Michelle O'Brien

Ionizing Radiation Division

Physics Laboratory

National Institute of Standards and Technology

Gaithersburg, MD 20899-8460

Supersedes NIST Special Publication 250-16 (March 1988)

April 2001

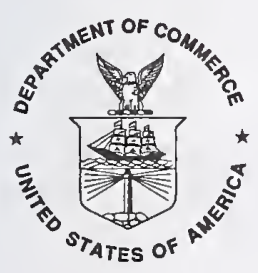

U.S. Department of Commerce

Donald L. Evans, Secretary

Technology Administration

Dr. Karen H. Brown, Acting Under Secretary of Commerce for Technology

National Institute of Standards and Technology

Dr. Karen H. Brown, Acting Director 
Certain commercial entities, equipment, or materials may be identified in this document in order to describe an experimental procedure or concept adequately. Such identification is not intended to imply recommendation or endorsement by the National Institute of Standards and Technology, nor is it intended

to imply that the entities, materials, or equipment are necessarily the best available for the purpose.

\begin{abstract}
The calibration and irradiation of instruments that measure $x$-rays and gammarays are performed in terms of the physical quantity air-kerma. The calibrations are listed in the NIST Special Publication 250 Calibration Service Users Guide as calibrations $46010 \mathrm{C}$ through $46050 \mathrm{~S}$. The process for establishing calibration or correction factors for radiation detectors, charge sensitivity tests for high-gain electrometers, and irradiations of passive dosimeters is explained in this document. Calibrations are performed by comparing the instrument to a NIST primary standard, which include four free-air chambers for x-rays and cavity ionization chambers for cesium- $137\left({ }^{137} \mathrm{Cs}\right)$ and colbalt-60 $\left({ }^{60} \mathrm{Co}\right)$ gamma rays. Details of the design and use of these standards are presented in this document, as well as, a description of the quality assurance checks, which are performed to assure the constancy of the standards and the accuracy of the calibrations and irradiations. The overall uncertainty with a significance of a $95 \%$ confidence limit is given as $0.9 \%$ for the air-kerma rate in the NIST beams, $1 \%$ for the calibration of a cable-connected chamber and irradiation of passive dosimeters, and $1.5 \%$ for the calibration of a condenser chamber.
\end{abstract}

National Institute of Standards and Technology Special Publication 250-58

Natl. Inst. Stand. Technol. Spec. Publ. 250-58, 98 pages (April 2001) CODEN: NSPUE2

\title{
U.S. GOVERNMENT PRINTING OFFICE WASHINGTON: 2001
}




\section{Foreword}

This edition of the National Institute of Standards and Technology (NIST) Special Publication 250 Series is a revision to the NBS Special Publication 250-16 Calibration of X-Ray and Gamma-Ray Measuring Instruments document. The original work has been reorganized, rewritten and supplemented to reflect the changes with the calibration services since 1988. Paul Lamperti and Michelle O'Brien wish to acknowledge the contributions of R. Loevinger, J. Weaver and the late T. Loftus. 
Abstract

2.0 References documents

2.1 International organization for standardization

2.2 National Institute for Standards and Technology

3.0 Terminology

3.1 Descriptions of terms specific to this document

3.2 Key words

4.0 Calibration service

4.1 Description of services

4.2 Beam qualities for calibration of $\mathrm{x}$-ray measuring instruments

5.0 Design philosophy and theory

6.0 X-ray calibration services

$6.1 \quad \mathrm{X}$-ray calibration ranges

6.2 X-ray exposure calibration standards

6.3 Calculation of air kerma

6.4 Wyckoff-Attix (50 kV to $300 \mathrm{kV}$ ) free-air ionization chamber corrections

6.5 Ritz (20 kV to $100 \mathrm{kV})$ free-air ionization chamber corrections

6.6 Lamperti (10 kV to $20 \mathrm{kV}$ ) free-air ionization chamber corrections

6.7 Attix (20 kV to $50 \mathrm{kV})$ free-air ionization chamber corrections

6.8 Comparison of standard free-air ionization chambers

7.0 Gamma-ray air kerma standards and calibration ranges 35

7.1 Cavity-chamber standards 35

7.2 Gamma-ray sources 36

$\begin{array}{ll}7.3 & \text { Calibration of gamma-ray beams } \\ 7.4 & 37\end{array}$

7.4 Useful beam size 39

8.0 Ionization-chamber current-measurement techniques 41

8.1 Background and history 41

8.2 Electrometers 42 
8.3 Ionization current measurement-console equipment 42

8.3.1 X-ray calibration data acquisition system $\quad 42$

8.3.2 Gamma-ray calibration data acquisition system $\quad 45$

8.4 Pre-calibration tests of instruments 46

8.4.1 Charger/reader linearity test 46

8.4.2 Testing of readers for cable-connected probes $\quad 47$

8.4.3 Testing of instruments to be calibrated in electrical units

47

$\begin{array}{lll}9.0 & \text { Support equipment calibrations } & 47\end{array}$

9.1 Capacitor calibrations $\quad 47$

9.2 Temperature indicator calibrations 47

9.3 Pressure indicator calibrations 48

10.0 Operating procedures $\quad 48$

10.1 Administrative procedures 48

10.2 Calibration of integrating-type instruments 49

10.2.1 Condenser chambers 49

10.2.2 Cable-connected instruments 51

10.3 Calibration of current-type instruments 52

10.3.1 X-ray calibrations $\quad 52$

10.3.2 Gamma-ray calibrations $\quad 52$

10.4 In-house calibration checks 52

10.5 Test of high-quality feedback electrometers 53

10.6 Irradiation of passive and electronic dosimeters 54

10.6.1 General considerations and procedures $\quad 54$

10.6.2 Exposure techniques $\quad 54$

11.0 Assessment of uncertainty $\quad 54$

12.0 Safety considerations $\quad 58$

12.1 Radiation safety 58

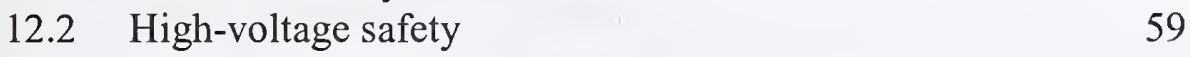

References $\quad 60$

Attachment 1: X-ray beam qualities offered at the NBS prior to $1986 \quad 63$

Attachment 2: Additional references - databooks 65

Attachment 3: Attix chamber schematics 67

Attachment 4: History of the measurement of current $\quad 70$

Attachment 5: Typical ionization chamber calibration report 75

Attachment 6: Typical TLD calibration report $\quad 81$

Attachment 7: Typical electrometer calibration report 84 
List of Tables

Table 4-1. Calibration conditions for x-ray and gamma-ray measuring instruments

Table 4-2. Mammography x-ray beam-quality parameters

Table 4-3. ISO X-Ray Beam Quality Parameters

Table 6-1. Description of the NIST x-ray systems

Table 6-2. Important dimensions and parameters for the NIST standard free-air ionization chambers

Table 6-3. Summary of calculations from ref. [3] for percent loss and gain of ionization due to lack of plate separation and scattered photons in the Wyckoff-Attix free-air ionization chamber

Table 6-4. Comparison of x-ray beam filtrations used for data reported in ref. [3] with filtrations presently used for conventional calibration conditions

Table 6-5. Data used to compute corrections for the Wyckoff-Attix standard free-air chamber for conventional calibration conditions

Table 6-6. Comparison of the ka values currently used to those values computed from the least squares equation

Table 6-7. Products of all air-kerma-rate-independent corrections for the Wyckoff-Attix free-air ionization chamber

Table 6-8. Mass air-attenuation coefficients and air attenuation corrections for the Ritz free-air ionization chamber

Table 6-9. Computation of electron-loss corrections for the Ritz free-air ionization chamber

Table 6-10. Summary of corrections for the Ritz free-air ionization chamber

Table 6-11. Recombination corrections for the Lamperti free-air ionization chamber

Table 6-12. Summary of correction factors for Lamperti free-air ionization chamber 
Table 6-13. Correction factors for the Attix free-air ionization chamber

Table 6-14. Results of the comparison of the Lamperti standard with the BIPM standard

Table 6-15. Results of the comparison of the Ritz standard with the BIPM standard

Table 6-16. Comparison of the Lamperti chamber to the $50 \mathrm{kV}$ NPL standard

Table 6-17. Comparison of the Ritz chamber to the NPL $50 \mathrm{kV}$ standard

Table 6-18. Comparison of the Ritz chamber to the NPL $300 \mathrm{kV}$ standard

Table 6-19. Comparison results for the mammography standard

Table 6-20. Recent "in-house" comparisons standards

Table 7-1. Dimensions of spherical graphite ionization chambers

Table 7-2. Gamma-ray source locations and nominal activities of sources as of January 1, 1999

Table 7-3. Constants for computing exposure rate corrected for decay for the horizontal beam sources

Table 7-4. Data and positioning for calibration of vertical-beam gamma-ray sources in room $\mathrm{B} 036$

Table 7-5. Constants for computing useful beam radii for the horizontal and vertical beam calibration ranges

Table 7-6. Beam size defined by $50 \%$ radiographic density contour for vertical-beam gamma-ray sources, for specific collimator settings

Table 8-1. Parameters of the straight line fits for the temperature probe calibrations used in the $\mathrm{x}$-ray ranges

Table 8-2. Low-energy Pantak unit voltage calibration 
Table 8-3. High-energy Pantak unit voltage calibration

Table 8-4. Temperature probe parameters for the gamma source calibration ranges

Table 10-1. Analysis of three NIST check chambers for the period of 1979 to 1997

Table 11-1. Uncertainty analysis for tungsten $\mathrm{x}$ and gamma-ray air-kerma rates

Table 11-2. Uncertainty analysis for gamma-ray calibrations

Table 11-3. Uncertainty analysis for air-kerma rates with the Attix chamber

Table 11-4. Uncertainty analysis for mammography calibrations

Table 11-5. Explanation of various components of the uncertainty analyses

Table 11.6. Summary of expanded uncertainties 
List of Figures

Fig. 4-1. Graph of generating constant potential against half-value layer for the beam qualities used in the $\mathrm{x}$-ray calibration range

Fig. 4-2. Graph of homogeneity coefficients against aluminum half-value layer for the $\mathrm{L}, \mathrm{M}, \mathrm{H}$ and $\mathrm{S}$ filtrations

Fig. 4-3. Graph of the homogeneity coefficient against the half-value layer measured in copper for the $\mathrm{M}, \mathrm{H}$ and $\mathrm{S}$ beam qualities

Fig. 4-4. Graph of the HVL's of the mammography beam qualities versus constant potential

Fig. 6-1. Schematic of $300 \mathrm{kV}$ x-ray range

Fig. 6-2. Schematic of mammography calibration range

Fig. 6-3. Schematic of Wyckoff-Atix free-air ionization chamber

Fig. 6-4. Sectional view of the Ritz free-air chamber

Fig. 6-5. Schematic cross-sectional views of the Lamperti free-air chamber

Fig. 6-6. Schematic of Attix free-air chamber

Fig. 7-1. Port detail for horizontal ${ }^{60} \mathrm{Co}, 5 \mathrm{~mm}$ diameter source 



\section{Scope}

1.1 This document describes the x-ray and gamma-ray calibration services provided by the Ionizing Radiation Division, Radiation Interactions and Dosimetry Group at the National Institute of Standards and Technology (NIST). The calibration and irradiation of x-ray and gamma-ray instruments are performed in terms of the physical quantity air kerma. The calibrations are listed in NIST Special Publication 250 [1] as calibrations 46010C through 46050 S. Calibration or correction factors are provided for radiation detectors, charge sensitivity is tested for high-gain electrometers, and passive dosimeters are irradiated to known quantities of radiation. Calibrations are performed by comparing the instrument to a NIST primary standard, which include free-air chambers for x-rays and cavity ionization chambers for cesium-137 $\left({ }^{137} \mathrm{Cs}\right)$ and cobalt-60 $\left({ }^{60} \mathrm{Co}\right)$ gamma rays. A variety of quality assurance checks are performed to assure the constancy of the standards and the accuracy of the calibrations and irradiations. The overall uncertainty (considered to have the approximate significance of a $95 \%$ confidence limit) is given as $0.9 \%$ for the air-kerma rate in the NIST beams, $1 \%$ for calibration of a cable-connected chamber and irradiation of passive dosimeters, and $1.5 \%$ for calibration of a condenser chamber.

\section{Referenced documents}

2.1 International Organization for Standardization

ISO/IS 4037-1:1996 X and gamma reference radiations for calibrating dosimeters and dose rate meters and for determining their responses as a function of photon energy - Part 1.: Radiation characteristics and production methods

\subsection{National Institute of Standards and Technology}

NBS Special Publication 250-16 Calibration of X-Ray and Gamma Measuring Instruments SP 250 NIST Calibration Services Users Guide 1998

NBS Handbook 64 Design of Free-Air Ionization Chambers

NBS Handbook 78 Report of the International Commission on Radiological Units and Measurements

NIST Special Publication 811 Guide for the Use of the International System of Units (SI) NIST Technical Note 1297 Guidelines for Evaluating and Expressing the Uncertainty of NIST Measurements

3. Terminology

3.1 Descriptions of terms specific to this document

3.1.1 air kerma - the quotient of $d E_{t r}$ by $d m$, where $d E_{t r}$ is the sum of the initial kinetic energies of all electrons liberated by photons in a volume element of air and $\mathrm{dm}$ is the mass of air in that volume element. The SI unit of air kerma is the gray (Gy). 
3.1.2 beam quality - used to refer to a specific x-ray beam with a characteristic half-value layer and produced by a constant potential kilovoltage.

3.1.3 calibration - the process whereby the response of a dosimeter or measuring instrument is characterized through comparison with an appropriate national standard.

3.1.4 calibration factor - the quotient of the air kerma in the absence of the chamber and the charge generated by that radiation in the ionization chamber, expressed in units of Gy/C.

3.1.5 correction factor - the quotient of the air kerma or exposure in the absence of the chamber and the electrometer reading with the ionization chamber.

3.1.6 effective energy - the energy of monoenergetic x-ray beam which has the same half-value layer as the spectrum in question.

3.1.7 exposure - exposure $(X)$ is the quotient of $d Q$ by $d m$, where $d Q$ is the sum of the electrical charges on all the ions of one sign produced in air when all the electrons are completely stopped in air. The SI unit of exposure is the coulomb per kilogram $(\mathrm{C} / \mathrm{kg})$; the special unit of exposure, the roentgen $(\mathrm{R})$, is equal to exactly $2.58 \mathrm{E}-4 \mathrm{C} / \mathrm{kg}$.

3.1.8 half-value layer - (HVL) the thickness of the specified material added as a beam attenuator that reduces the air kerma rate by one half of the unattenuated beam air kerma rate value.

3.1.9 homogeneity coefficient - $(\mathrm{HC})$ the ratio of the first to the second half-value layer.

3.1.10 monitor instrument - an instrument used to monitor the stability of the air kerma rate during an irradiation.

3.1.11 quarter-value layer - (QVL) the thickness of the specified material added as a beam attenuator that reduces the air kerma rate to one quarter of the unattenuated beam air kerma rate value.

3.1.12 second half-value layer - the difference between the quarter-value layer and the halfvalue layer.

3.1.13 x-ray unit - system comprising of a high voltage generator, an $\mathrm{x}$-ray tube and an $\mathrm{x}$-ray controller.

\subsection{Key words}

air kerma; calibration; cavity chamber; cesium-137 gamma rays; cobalt-60 gamma rays; exposure; free-air chamber; half-value layer; ionization chambers; mammography chamber calibrations; primary standard; standard; uncertainty estimate; $\mathrm{x}$ rays. 
4. Calibration service

This report describes the status of the calibration service for $\mathrm{x}$-ray and gamma-ray measuring instruments, as of January 1999. The physical quantities air-kerma and exposure, calibration by substitution, and the properties of the x-ray and gamma-ray beams used in the NIST services are described in this document. This service guide explains the details of the calibration systems and their measurement standards, the instruments and techniques for measuring current and charge, and the analyses of calibration data. Tests applied to the instruments being calibrated, as well as the tests and calibrations performed on NIST laboratory equipment, and the associated assessment of uncertainty are covered. The operating procedures, including the administrative procedures and methods of handling and calibrating the instruments, and the irradiation of passive dosimeters, are included in this guide. The document concludes with a brief discussion of the necessary safety considerations.

\subsection{Description of service}

The NIST, Ionizing Radiation Division, Radiation Interactions and Dosimetry Group receives a variety of instruments for calibration, test, or irradiation in $\mathrm{x}$ - or gamma-ray beams. These services are assigned test numbers $46010 \mathrm{C}$ through $46050 \mathrm{~S}$ in NIST Publication 250 [1] available from the NIST Technology Services, Office of Measurement Services, Calibration Program Office. Calibration factors or correction factors are provided for radiation detectors. The charge sensitivity of a high-gain electrometer can be tested at any one set of switch positions in conjunction with a calibration factor. Dosimeters can be given known exposures of x-ray or gamma-ray radiation. Calibrations and irradiations are performed in terms of the physical quantities air kerma and exposure.

The quantity air kerma characterizes a beam of photons or neutrons in terms of the energy transferred to any material. For the calibration service described in this document, consideration is limited to photon beams in air. Air kerma is the total energy per unit mass transferred from an x-ray beam to air. Air kerma, $K_{a i r}$, is the quotient of $d E_{t r}$ by $d m$, where $d E_{t r}$ is the sum of the initial kinetic energies of all electrons liberated by photons in a volume element of air and $d m$ is the mass of air in that volume element. Then

$$
K_{\text {air }}=\frac{d E_{t r}}{d m}
$$

The SI unit of air kerma is the gray (Gy), which equals one joule per kilogram; the special unit of air kerma is the rad, which equals $0.01 \mathrm{~Gy}$.

The quantity exposure characterizes an x-ray or gamma-ray beam in terms of the electric charge liberated through the ionization of air. Exposure is defined as the total charge per unit mass liberated in air by a photon beam and is represented by the equation:

$$
X=\frac{d Q}{d m}
$$

where $d Q$ is the sum of the electrical charges on all the ions of one sign produced in air when all the electrons liberated by photons in a volume element of air whose mass is $d m$ are completely 
stopped in air. The SI unit of exposure is the coulomb per kilogram $(\mathrm{C} / \mathrm{kg})$; the special unit of exposure, the roentgen $(\mathrm{R})$, is equal to exactly $2.58 \mathrm{E}-4 \mathrm{C} / \mathrm{kg}$. The ionization arising from the absorption of bremsstrahlung emitted by the secondary electrons is not included in $d Q$. Except for this small difference, significant only at high energies, the exposure as defined above is the ionization equivalent of air kerma. The relationship between exposure and air kerma can be expressed as a simple equation:

$$
X=K_{\text {air }} \frac{1}{2.58 E-4} \frac{(1-g)}{(W / e)}
$$

where $W / e$ is the mean energy per unit charge expended in air by electrons, and $g$ is the fraction of the initial kinetic energy of secondary electrons dissipated in air through radiative processes. The currently accepted value of W/e is $33.97 \mathrm{~J} / \mathrm{C}$ [2] and $g$ is negligible for the $\mathrm{x}$-ray beams of interest. The currently accepted $g$ values for ${ }^{60} \mathrm{Co}$ and ${ }^{137} \mathrm{Cs}$ beams are $0.32 \%$ and $0.16 \%$, respectively.

Only ionization chambers known to be stable and reproducible are accepted for calibration in this program. Institutions submitting ionization chambers for calibration are strongly urged to perform stability checks involving redundant measurements in highly reproducible radiation fields before sending their instruments to NIST, and to repeat those checks after NIST calibration, and again at suitable intervals. Instruments submitted for calibration, and material submitted for irradiation, must be shipped in reusable containers.

An x-ray tube produces bremsstrahlung spectra, inhomogeneous beams with photon energies from very low values to a high-energy cutoff given by the maximum potential applied to the x-ray tube. These beams are customarily filtered with a high purity metal to reduce the unwanted low-energy $\mathrm{x}$-rays. Three $\mathrm{x}$-ray calibration ranges are used for the calibration services. Two of the ranges contain $\mathrm{x}$-ray tubes with tungsten anodes. The $\mathrm{x}$-ray beams from these anodes are filtered with aluminum, copper, tin or lead. Two anode types are offered for the mammography calibration service, molybdenum (Mo) and rhodium (Rh). The Mo generated $\mathrm{x}$ ray beams are filtered with $\mathrm{Mo}, \mathrm{Al}$, or $\mathrm{Rh}$ foils, while the $\mathrm{Rh}$ beams are filtered with $\mathrm{Rh}$ and $\mathrm{Al}$ foils. It is conventional to characterize the "quality" of the filtered x-ray beam in terms of the thickness of aluminum or copper required to reduce the air kerma rate to $50 \%$ and to $25 \%$ of its original value. These thicknesses are called the half-value layer (HVL) and the quarter-value layer (QVL). The HVL and QVL measurements must be made using good-geometry attenuation in order to obtain accurate and reproducible numbers. The homogeneity coefficient (HC) is the ratio of the first to the second HVL, often expressed as a percent. A HC value near 1 (or $100 \%$ ) indicates that the filtration has produced an approximately homogeneous beam that is approaching monoenergetic conditions.

\subsection{Beam qualities for calibration of $\mathrm{x}$-ray and gamma-ray measuring instruments}

The 32 NIST tungsten $x$-ray beam qualities are divided into three groups according to filtration, i.e., light $(\mathrm{L})$, moderate $(\mathrm{M})$, and heavy $(\mathrm{H})$ filtration. The beam codes consist of a letter $\mathrm{L}, \mathrm{M}$, or $\mathrm{H}$, followed by the generating constant potential in kilovolts. For example, M100 indicates moderate filtration and $100 \mathrm{kV}$ constant potential. The special (S) series beam codes, $\mathrm{S} 60$ and S75 have characteristics that are not consistent with those of the $\mathrm{L}, \mathrm{M}$, and $\mathrm{H}$ groups. 
The qualities for each group were chosen so that relativcly smooth curves result for the graph of tube potential versus HVL. Table 4-1 gives a complete listing of beam codes currently available at NIST. The NBS beam codes used prior to January 1986 are listed in Attachment 1. Recent changes to filtration, due to the $\mathrm{x}$-ray tube replacement, are shown in footnote $\mathrm{g}$. Due to changes in the physical setup of the low-energy calibration facility, the L10, L15, H10 and H15 beam qualities are now used with a source-to-detector distance of $50 \mathrm{~cm}$, instead of the previous $25 \mathrm{~cm}$ distance. The resulting changes to the half-value layers are given in Table 4-1. Depending on the energy response and design of the ionization chamber, the calibration factors for a specific ionization chamber often fall on smooth curves when plotted against HVL In this case, all calibration points have been chosen from a single group, $\mathrm{L}, \mathrm{M}$, or $\mathrm{H}$. If calibration points are chosen from more than one group, discontinuities will occur, hence no attempt should be made to interpolate between such calibration factors. Figure 4-1 is a graph of the HVL against the generating constant potential. Figure 4-2 is a graph of the HC against the HVL, measured in aluminum. Figure 4-3 shows the HVL and HC measured in copper against the generating constant potential.

The mammographic beam qualities offered at NIST were chosen to cover the range of HVLs of $x$-ray beams found in clinical settings. The beam codes which name the beam qualities are a combination of the chemical symbol of the anode and the filter respectively, followed by the constant potential in kilovolts. The letter "x" ends the beam codes which name the exit beam qualities. The exit beam qualities, which represent the transmission of the x-rays through the breast, are generated by an additional filtration of $2.0 \mathrm{~mm}$ of Al. The mammographic beam qualities offered are listed in Table 4-2. Figure 4-4 is the graph of the HVL measured in aluminum against generating constant potential.

The ISO $\mathrm{x}$-ray beam qualities are now available at NIST. A list of all ISO beams offered at NIST is found in Table 4-3. The NIST H group of qualities agrees with the ISO narrow spectrum (NS) qualities recommended by the ISO document 4037, referred to in section 2 . The ISO recommendations extend from $300 \mathrm{kV}$ to $40 \mathrm{kV}$, below which the NIST H group has been extended to $10 \mathrm{kV}$ in agreement with practice at the national metrology institute of Germany, Physikalisch-Technische Bundesanstalt (PTB). The NIST M group of qualities is in agreement with the recommendation for radiation therapy calibration in IEC Publication 731.

The selection of beam qualities for instrument calibration depends on the situation of interest. The $\mathrm{H}$ qualities are usually used for calibration for radiation protection instrumentation, since these beams have the narrowest spectrum at each generating potential, and probably most nearly approximate radiation that has penetrated a protective barrier. The $\mathrm{M}$ qualities are usually used for calibration of radiation therapy instruments. The $\mathrm{L}$ qualities are predominately for calibration of instruments used for measurement of unfiltered or lightly filtered beams that give high exposure rates, as is often the case in radiation biology and Grenz-ray therapy. The Mo and Rh beam qualities are offered to simulate the clinical mammographic beams. 
Table 4-1. Calibration conditions for $\mathrm{x}$-ray and gamma-ray measuring instruments

\begin{tabular}{|c|c|c|c|c|c|c|c|c|c|c|}
\hline \multirow{2}{*}{$\begin{array}{l}\text { Beam } \\
\text { code }^{a}\end{array}$} & \multicolumn{4}{|c|}{ Additional Filteration $^{\mathrm{b}}$} & \multicolumn{2}{|c|}{ Half-value layer } & \multicolumn{2}{|c|}{$\begin{array}{l}\text { Homogeneity } \\
\text { coefficient }^{c}\end{array}$} & \multirow{2}{*}{$\begin{array}{c}\text { Effective } \\
\text { energy }^{\mathrm{d}} \\
(\mathrm{keV})\end{array}$} & \multirow{2}{*}{$\begin{array}{c}\text { Distance }^{\mathrm{e}} \\
(\mathrm{cm})\end{array}$} \\
\hline & $\begin{array}{c}\mathrm{Al} \\
(\mathrm{mm})\end{array}$ & $\begin{array}{c}\mathrm{Cu} \\
(\mathrm{mm})\end{array}$ & $\underset{(\mathrm{mm})}{\mathrm{Sn}}$ & $\begin{array}{c}\mathrm{Pb} \\
(\mathrm{mm})\end{array}$ & $\begin{array}{c}\mathrm{Al} \\
(\mathrm{mm})\end{array}$ & $\begin{array}{c}\mathrm{Cu} \\
(\mathrm{mm})\end{array}$ & $\mathrm{Al}$ & $\mathrm{Cu}$ & & \\
\hline
\end{tabular}

X-Ray Beam Qualities

\begin{tabular}{|c|c|c|c|c|c|c|c|c|c|c|}
\hline $\mathrm{L} 10^{\mathrm{f}}$ & & & & & 0.035 & & 89 & & & 50 \\
\hline $\mathrm{L} 15^{\mathrm{f}}$ & & & & & 0.057 & & 68 & & & 50 \\
\hline L20 & & & & & 0.069 & & 73 & & & 50 \\
\hline $\mathrm{L} 30^{\mathrm{g}}$ & 0.30 & & & & 0.22 & & 63 & & & 50 \\
\hline $\mathrm{L} 40^{\mathrm{g}}$ & 0.53 & & & & 0.50 & & 59 & & & 50 \\
\hline $\mathrm{L} 50^{\mathrm{g}}$ & 0.71 & & & & 0.76 & & 60 & & & 50 \\
\hline $\mathrm{L} 80^{\mathrm{g}}$ & 1.45 & & & & 1.83 & & 57 & & & 50 \\
\hline $\mathrm{L} 100$ & 1.98 & & & & 2.77 & & 57 & & & 50 \\
\hline $\mathrm{M} 20^{\mathrm{g}}$ & 0.27 & & & & 0.15 & & 69 & & & 50 \\
\hline M30 & 0.5 & & & & 0.36 & & 65 & & & 50 \\
\hline $\mathrm{M} 40^{\mathrm{g}}$ & 0.89 & & & & 0.73 & & 69 & & & 50 \\
\hline M50 & 1.07 & & & & 1.02 & & 66 & & & 50 \\
\hline M60 & 1.56 & & & & 1.68 & & 66 & & & \\
\hline M80 & 2.61 & & & & 2.97 & & 67 & & & \\
\hline M100 & 5.0 & & & & 5.02 & & 73 & & & \\
\hline M120 & 6.87 & & & & 6.79 & & 77 & & & \\
\hline M150 & 5.0 & 0.25 & & & 10.2 & 0.67 & 87 & 62 & & \\
\hline M200 & 4.1 & 1.12 & & & 14.9 & 1.69 & 95 & 69 & & \\
\hline $\mathrm{M} 250$ & 5.0 & 3.2 & & & 18.5 & 3.2 & 98 & 86 & & \\
\hline M300 & 4.0 & & 6.5 & & 22.0 & 5.3 & 100 & 97 & & \\
\hline $\mathrm{H} 10^{\mathrm{f}}$ & 0.105 & & & & 0.05 & & 91 & & & 50 \\
\hline $\mathrm{H} 15^{\mathrm{f}}$ & 0.5 & & & & 0.153 & & 86 & & & 50 \\
\hline $\mathrm{H} 20^{\mathrm{g}}$ & 1.01 & & & & 0.36 & & 91 & & & 50 \\
\hline $\mathrm{H} 30^{\mathrm{g}}$ & 4.50 & & & & 1.23 & & 93 & & & 50 \\
\hline $\mathrm{H} 40^{\mathrm{g}}$ & 4.53 & 0.26 & & & 2.90 & & 90 & & & 50 \\
\hline H50 & 4.0 & & & 0.1 & 4.2 & 0.142 & 92 & 90 & 38 & \\
\hline H60 & 4.0 & 0.61 & & & 6.0 & 0.24 & 94 & 89 & 46 & \\
\hline $\mathrm{H} 100$ & 4.0 & 5.2 & & & 13.5 & 1.14 & 100 & 94 & 80 & \\
\hline H 150 & 4.0 & 4.0 & 1.51 & & 17.0 & 2.5 & 100 & 95 & 120 & \\
\hline $\mathrm{H} 200$ & 4.0 & 0.6 & 4.16 & 0.77 & 19.8 & 4.1 & 100 & 99 & 166 & \\
\hline $\mathrm{H} 250$ & 4.0 & 0.6 & 1.04 & 2.72 & 22.0 & 5.2 & 100 & 98 & 211 & \\
\hline H300 & 4.1 & & 3.0 & 5.0 & 23.0 & 6.2 & 99 & 98 & 252 & \\
\hline S60 & 4.35 & & & & 2.77 & & 72 & & & \\
\hline S75 & 1.50 & & & & 1.86 & & 63 & & & 50 \\
\hline \multicolumn{11}{|c|}{ Gamma-Ray Beam Qualities } \\
\hline${ }^{137} \mathrm{Cs}$ & & & & & & 10.8 & & & 662 & \\
\hline${ }^{60} \mathrm{Co}$ & & & & & & 14.9 & & & 1250 & \\
\hline
\end{tabular}

a For the $\mathrm{x}$-ray beam codes, the letter indicates light $(\mathrm{L})$, moderate $(\mathrm{M})$, heavy $(\mathrm{H})$ and special filtration $(\mathrm{S})$, and the number is the constant potential in kilovolts.

b The additonal filtration value does not include the inherent filtration. The inherent filtration is approximately $1.0 \mathrm{~mm} \mathrm{Be}$ for beam codes L10-L100, M20-M50, H10-H40 and S75; and 7.0 mm Be for beam codes M60-M300, H50-H300 and S60 plus the filtration resulting from the transmission monitors.

c The homogeneity coefficient is taken as $100(1 \mathrm{st} \mathrm{HVL} / 2$ nd HVL).

d The effective energy is for which it is believed to be a meaningful characterization of the beam quality.

e The distance shown is that between the radiation source and the detector center or the reference line. For the beam codes where no distance is listed, the distance ranges between 78 and $200 \mathrm{~cm}$, depending on the desirable beam size.

f Changes to the HVL from the 1986 value, result from a change in the distance from $25 \mathrm{~cm}$ to $50 \mathrm{~cm}$.

$\mathrm{g}$ To match the previous HVL, changes in the additional filtration value were required with the installation of a new $\mathrm{x}$-ray tube in 1997. 


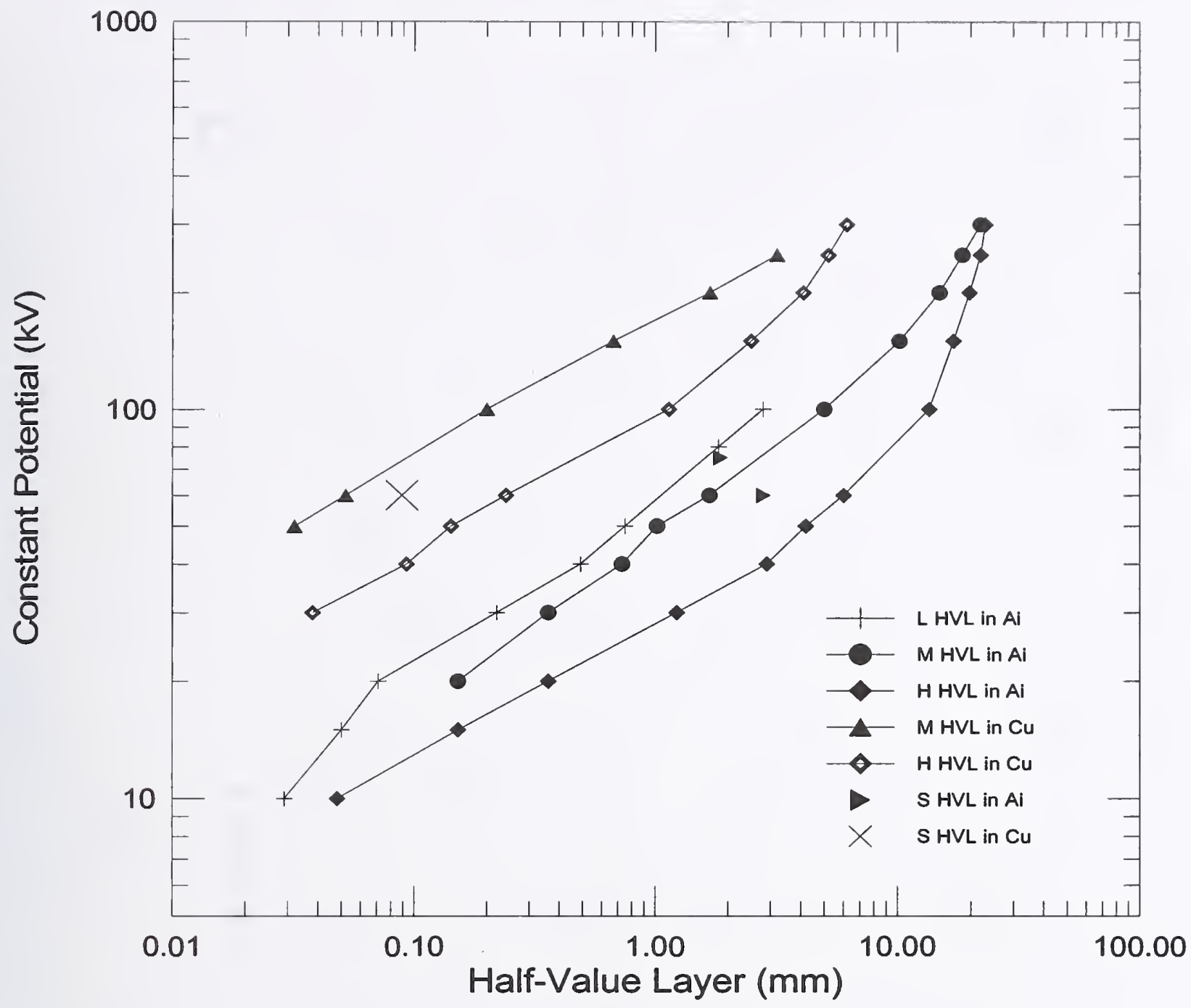

Fig. 4-1 Graph of generating constant potential against half-value layer for the beam qualities used in the x-ray calibration range. The curves for half-value layers measured in copper and aluminum are shown for the light $(\mathrm{L})$, moderate $(\mathrm{M})$, heavy $(\mathrm{H})$ and special $(\mathrm{S})$ filtered beam qualities. The lines connecting the data points are for ease of viewing. 


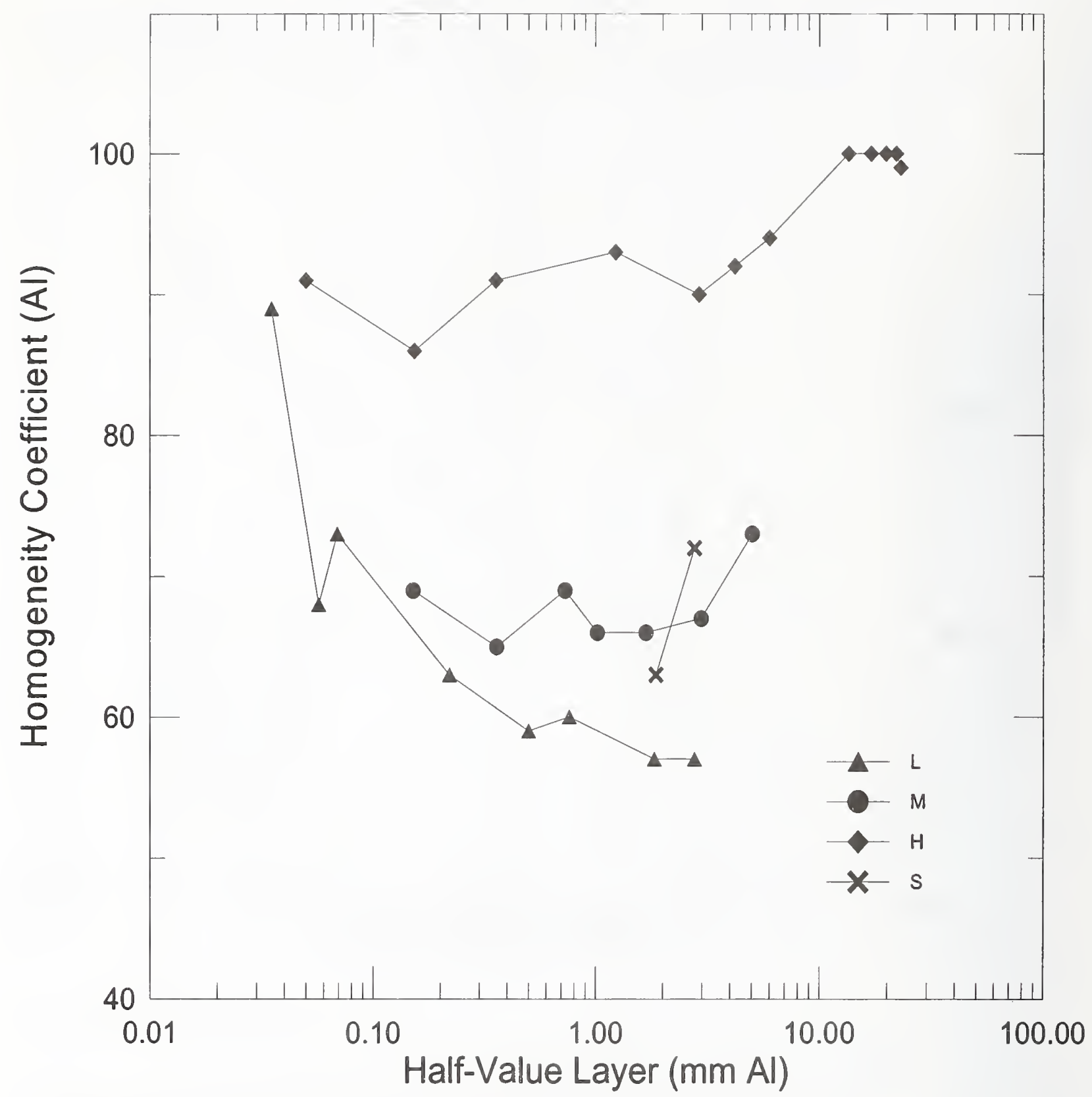

Fig. 4-2. Graph of homogeneity coefficients against aluminum half-value layer for the L, M, H and $\mathrm{S}$ filtrations. The lines connecting the data points are for ease of veiwing. 


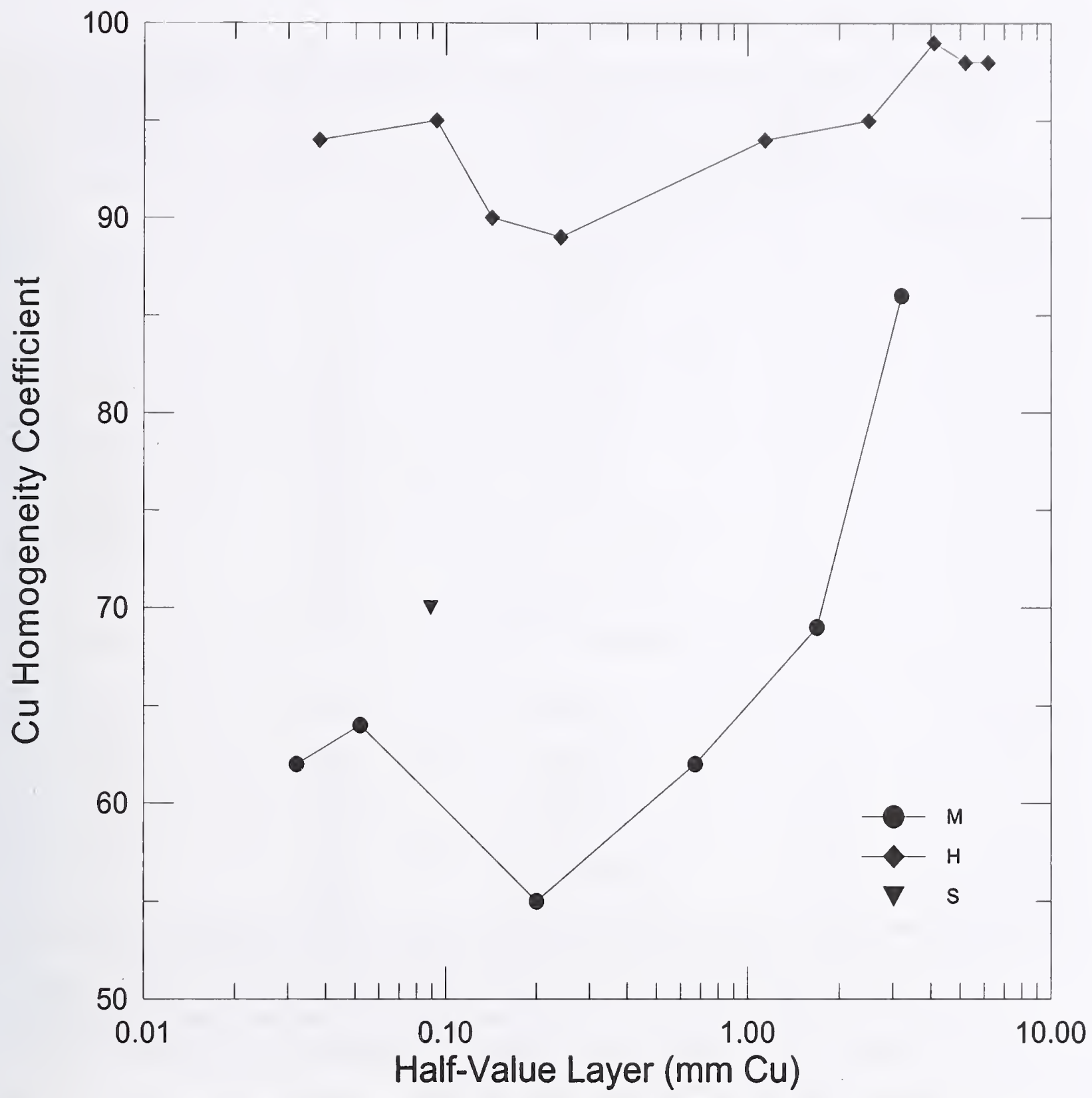

Fig. 4-3. Graph of the homogeneity coefficient against the half-value layer measured in copper for the $\mathrm{M}, \mathrm{H}$ and $\mathrm{S}$ beam qualities. The lines connecting the data points are for ease of viewing. 
Table 4-2. Mammography $\mathrm{x}$-ray beam-quality parameters

\begin{tabular}{|c|c|c|c|c|}
\hline $\begin{array}{l}\text { Beam } \\
\text { Code }^{a}\end{array}$ & $\begin{array}{c}\text { Tube } \\
\text { Voltage } \\
(\mathrm{kVp}) \\
\end{array}$ & $\begin{array}{c}\text { Additional } \\
\text { Filtration }^{\mathrm{b}} \\
(\mathrm{mm})\end{array}$ & $\begin{array}{c}\begin{array}{c}\text { Half-Value } \\
\text { Layer }^{\mathrm{c}} \\
(\mathrm{mm} \mathrm{Al})\end{array} \\
\end{array}$ & $\begin{array}{c}\text { Homogeneity } \\
\text { Coefficient } \\
\text { (Al) }\end{array}$ \\
\hline \multicolumn{5}{|c|}{ Mo Anode } \\
\hline $\mathrm{Mo} / \mathrm{Mo} 23$ & 23 & $0.032 \mathrm{Mo}$ & 0.271 & 70 \\
\hline Mo/Mo25 & 25 & $0.032 \mathrm{Mo}$ & 0.296 & 72 \\
\hline Mo/Mo28 & 28 & $0.032 \mathrm{Mo}$ & 0.332 & 74 \\
\hline $\mathrm{Mo} / \mathrm{Mo} 30$ & 30 & $0.032 \mathrm{Mo}$ & 0.351 & 75 \\
\hline Mo/Mo35 & 35 & $0.032 \mathrm{Mo}$ & 0.392 & 78 \\
\hline Mo/Rh28 & 28 & $0.029 \mathrm{Rh}$ & 0.408 & 80 \\
\hline Mo/Rh32 & 32 & $0.029 \mathrm{Rh}$ & 0.445 & 82 \\
\hline $\mathrm{Mo} / \mathrm{Mo} 25 \mathrm{x}$ & 25 & $0.030 \mathrm{Mo}+2.0 \mathrm{Al}$ & 0.566 & 91 \\
\hline Mo/Mo28x & 28 & $0.030 \mathrm{Mo}+2.0 \mathrm{Al}$ & 0.626 & 96 \\
\hline $\mathrm{Mo} / \mathrm{Mo} 30 \mathrm{x}$ & 30 & $0.030 \mathrm{Mo}+2.0 \mathrm{Al}$ & 0.660 & 95 \\
\hline $\begin{array}{l}\text { Mo/Mo35x } \\
\text { Rh Anod }\end{array}$ & 35 & $0.030 \mathrm{Mo}+2.0 \mathrm{Al}$ & 0.748 & 90 \\
\hline $\mathrm{Rh} / \mathrm{Rh} 25$ & 25 & $0.029 \mathrm{Rh}$ & 0.351 & 76 \\
\hline $\mathrm{Rh} / \mathrm{Rh} 30$ & 30 & $0.029 \mathrm{Rh}$ & 0.438 & 81 \\
\hline $\mathrm{Rh} / \mathrm{Rh} 35$ & 35 & $0.029 \mathrm{Rh}$ & 0.512 & 86 \\
\hline $\mathrm{Rh} / \mathrm{Rh} 40$ & 40 & $0.029 \mathrm{Rh}$ & 0.559 & 90 \\
\hline $\mathrm{Rh} / \mathrm{Rh} 30 \mathrm{x}$ & 30 & $0.029 \mathrm{Rh}+2.0 \mathrm{Al}$ & 0.814 & 96 \\
\hline $\mathrm{Rh} / \mathrm{Rh} 35 \mathrm{x}$ & 35 & $0.029 \mathrm{Rh}+2.0 \mathrm{Al}$ & 0.898 & 95 \\
\hline
\end{tabular}

a The beam codes are a combination of the chemical symbol of the anode and the filter respectively, followed by the constant potential in kilovolts. The letter " $x$ " ends the beam codes which denote "exit" beams. The exit beam qualities, which are intended to represent the transmission of the $\mathrm{x}$-rays through the breast, are generated by an additional filtration of $2.0 \mathrm{~mm}$ of aluminum.

b The inherent filtration is $1 \mathrm{~mm} \mathrm{Be}$ for all qualities plus the filtration due to the transmission monitor.

c The half-value layers listed were determined through direct measurements with the primary standard free-air ionization chamber at a distance of $1 \mathrm{~m}$. 


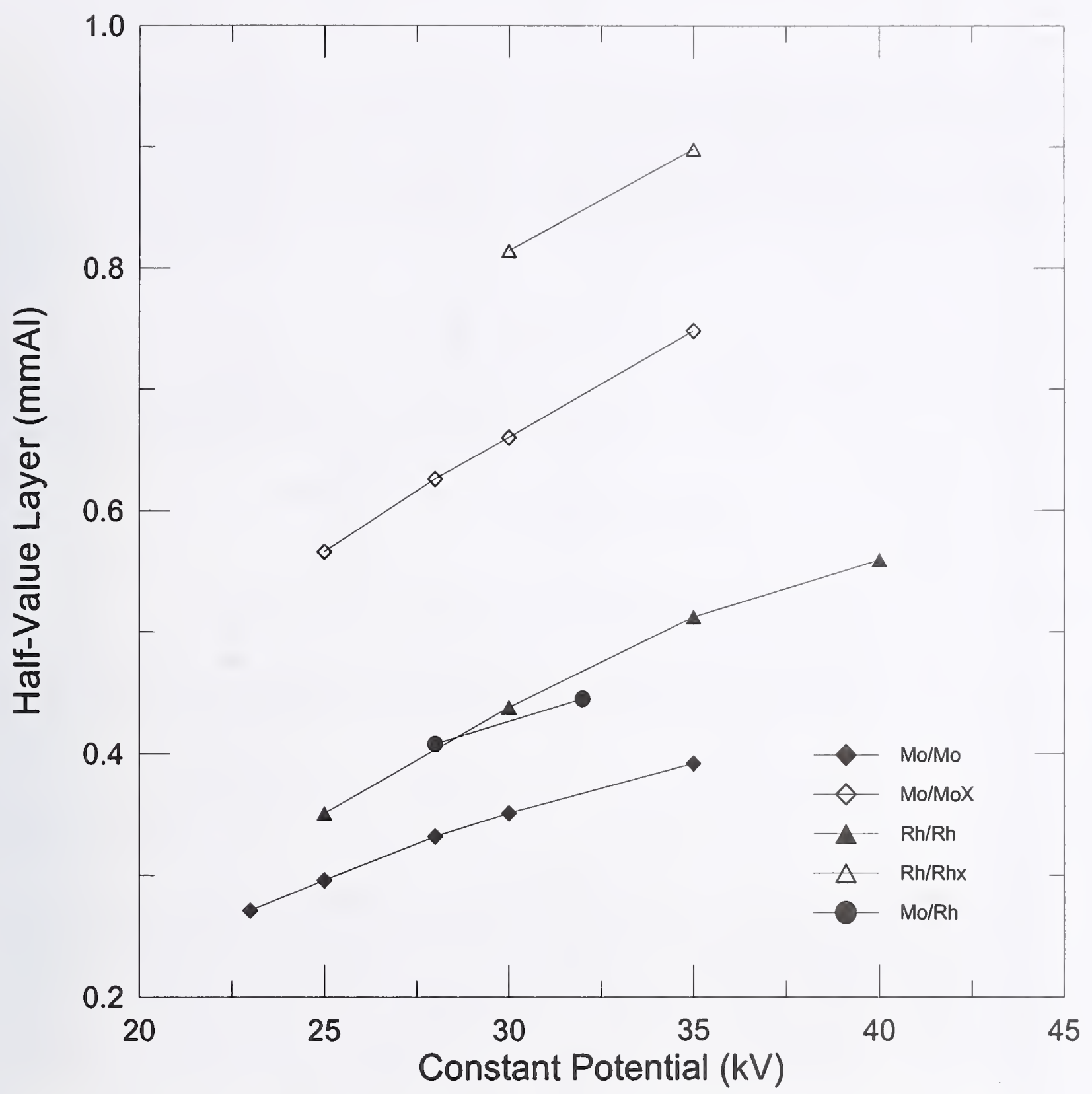

Fig. 4-4. Graph of the HVL's of the mammography beam qualities versus constant potential. 


\begin{tabular}{|c|c|c|c|c|c|c|c|c|}
\hline \multirow{2}{*}{$\begin{array}{l}\text { Beam } \\
\text { Code }^{a}\end{array}$} & \multicolumn{4}{|c|}{ Added Filtration $(\mathrm{mm})^{b}$} & \multicolumn{2}{|c|}{ First HVL } & \multicolumn{2}{|c|}{ Second HVL } \\
\hline & $\mathrm{Al}$ & $\mathrm{Cu}$ & $\mathrm{Sn}$ & $\mathrm{Pb}$ & $\mathrm{mmAl}$ & $\mathrm{mmC}$ & $\mathrm{mmAl}$ & $\mathrm{mmCu}$ \\
\hline HK 10 & & & & & 0.04 & & 0.05 & \\
\hline HK20 & 0.15 & & & & 0.13 & & 0.16 & \\
\hline HK30 & 0.52 & & & & 0.39 & & 0.59 & \\
\hline HK60 & 3.19 & & & & & 0.08 & & 0.11 \\
\hline HK 100 & 3.90 & 0.15 & & & & 0.31 & & 0.46 \\
\hline HK200 & & 1.15 & & & & 1.72 & & 2.43 \\
\hline HK250 & & 1.60 & & & & 2.52 & & 3.37 \\
\hline HK280 & & 3.06 & & & & 3.45 & & 4.07 \\
\hline HK300 & & 2.51 & & & & 3.46 & & 4.21 \\
\hline WS60 & & 0.3 & & & & 0.18 & & 0.21 \\
\hline WS80 & & 0.5 & & & & 0.35 & & 0.44 \\
\hline WS110 & & 2.0 & & & & 0.96 & & \\
\hline WS150 & & & 1.03 & & & 1.88 & & 2.13 \\
\hline WS200 & & & 2.01 & & & 3.09 & & 3.35 \\
\hline WS250 & & & 4.01 & & & 4.30 & & 4.50 \\
\hline WS 300 & & & 6.54 & & & 5.23 & & 5.38 \\
\hline NS10 & 0.095 & & & & 0.051 & & 0.060 & \\
\hline NS15 & 0.49 & & & & 0.15 & & 0.18 & \\
\hline NS20 & 0.90 & & & & 0.32 & & 0.33 & \\
\hline NS25 & 2.04 & & & & 0.69 & & 0.76 & \\
\hline NS30 & 4.02 & & & & 1.16 & & 1.35 & \\
\hline NS40 & & 0.21 & & & & 0.085 & & 0.092 \\
\hline NS60 & & 0.6 & & & & 0.25 & & 0.26 \\
\hline NS80 & & 2.0 & & & & 0.59 & & 0.66 \\
\hline NS100 & & 5.0 & & & & 1.13 & & 1.19 \\
\hline NS120 & & 4.99 & 1.04 & & & 1.70 & & 1.85 \\
\hline NS150 & & & 2.50 & & & 2.40 & & 2.52 \\
\hline NS200 & & 2.04 & 2.98 & & & 4.09 & & 4.20 \\
\hline NS250 & & & 2.01 & 2.97 & & 5.26 & & 5.32 \\
\hline NS300 & & & 2.99 & 4.99 & & 6.17 & & 6.30 \\
\hline LK 10 & 0.30 & & & & 0.062 & & & \\
\hline LK20 & 2.04 & & & & 0.43 & & 0.43 & \\
\hline LK30 & 3.98 & 0.18 & & & 1.48 & & & \\
\hline LK35 & & 0.25 & & & 2.16 & & 2.16 & \\
\hline LK55 & & 1.19 & & & & 0.26 & & \\
\hline LK70 & & 2.64 & & & & 0.51 & & \\
\hline LK100 & & 0.52 & 2.0 & & & 1.27 & & \\
\hline LK125 & & 1.0 & 4.0 & & & 2.04 & & \\
\hline LK170 & & 1.0 & 3.0 & 1.5 & & 3.47 & & \\
\hline LK210 & & 0.5 & 2.0 & 3.5 & & 4.54 & & \\
\hline LK240 & & 0.5 & 2.0 & 5.5 & & 5.26 & & \\
\hline $\begin{array}{l}\text { In th } \\
\text { narro } \\
\text { poter } \\
\text { The i } \\
\text { appro } \\
\text { beloy } \\
\text { inher }\end{array}$ & $\begin{array}{l}\text { seam co } \\
\text { spectru } \\
\text { al in kil } \\
\text { herent fi } \\
\text { imately } \\
\text { approx } \\
\text { it filtrat }\end{array}$ & $\begin{array}{l}\text { the le } \\
\text { (NS), a } \\
\text { lts. } \\
\text { tion is } \\
\text { mm B } \\
\text { tely } 7 . \\
\text { is adiu }\end{array}$ & $\begin{array}{l}\text { indi } \\
\text { xide } \\
\text { mbin } \\
\text { r bea } \\
\mathrm{m} \text { Be } \\
\text { to } 4 \\
\end{array}$ & $\begin{array}{l}\text { of } t \\
\text { des p } \\
\text { KK } 60 \\
\text { Al. }\end{array}$ & $\begin{array}{l}\text { kerma rat } \\
\text { IS); and th } \\
\text { filtration } \\
\text { duced at } \\
\text { nd HK } 10\end{array}$ & $\begin{array}{l}\text { (LK), his } \\
\text { number } \\
\text { de to the } \\
\text { pe potent } \\
\text { nd for al }\end{array}$ & $\begin{array}{l}\text { air kerma } \\
\text { the consta } \\
\text { onitor cha } \\
\mathrm{s} \text { of } 30 \mathrm{k} \\
\text { ther techr }\end{array}$ & $\begin{array}{l}\text { te (HK), } \\
\text { er plus } \\
\text { nd } \\
\text { ues the }\end{array}$ \\
\hline
\end{tabular}


5. Design philosophy and theory

$\mathrm{X}$-ray calibrations are performed by using the substitution method. Using this method, the air kerma or air-kerma rate is determined at some point in space by a free-air chamber. The instrument to be calibrated is then placed at the same point in space as the standard and the response of the instrument is determined. The calibration factor is the quotient of the air kerma, $K_{\text {air }}$ in the absence of the chamber, and the charge, $Q$, generated by that radiation in the ionization chamber:

$$
\text { Calibration Factor }=\frac{K_{\text {air }}}{Q}
$$

The correction factor is the quotient of the air kerma or exposure, in the absence of the chamber, and the electrometer reading with the ionization chamber:

$$
\begin{aligned}
& \text { Correction Factor }=\frac{K_{\text {air }}}{\text { electrometer reading }} \\
& \text { Correction Factor }=\frac{X}{\text { electrometer reading }}
\end{aligned}
$$

Gamma-ray calibrations are performed by using previously calibrated beams and correcting for decay. Details of the calibration of gamma-ray beams are given in Section 7.

6. X-ray calibration services

\section{$6.1 \mathrm{X}$-ray ranges}

Three $\mathrm{x}$-ray calibration ranges are available for instrument calibrations. One range is used for tungsten $\mathrm{x}$-rays generated at constant potentials of $10 \mathrm{kV}$ to $100 \mathrm{kV}$, the other is used for tungsten $\mathrm{x}$-rays generated at potentials of $50 \mathrm{kV}$ to $300 \mathrm{kV}$. The mammography $\mathrm{x}$-rays are generated at constant potentials of $23 \mathrm{kV}$ to $40 \mathrm{kV}$. Table 6-1 describes some of the features of the $\mathrm{x}$-ray systems utilized in each calibration range. A schematic of the $300-\mathrm{kV}$ system is given in Fig. 6-1. A schematic of the mammography range is given in Fig. 6-2.

\subsection{X-ray air kerma calibration standards}

Standardization of x-ray beams for the quantity air kerma or exposure is carried out at NIST by means of four free-air ionization chamber standards. These standards are discussed in Refs. $[3,4,5]$. Figures $6-3$ to $6-5$ show cross-sectional views of the three free-air chambers used in the tungsten $\mathrm{x}$-ray ranges. Figure 6-6 is a schematic of the standard for mammography. The important dimensions of the free-air chambers are given in Table 6-2. With reference to Table 6-2, note that the free-air chambers become larger as the x-ray energy increases. At low x-ray energies, the air attenuation air path between the defining diaphragm and the collector center needs to be minimized. On the other hand, at high x-ray energies a sufficient air path is needed 
Table 6-1. Description of the NIST x-ray systems.

\begin{tabular}{lccc}
\hline \hline \multicolumn{1}{c}{ Features } & Unipolar $^{\mathrm{a}}$ & Bipolar $^{\mathrm{b}}$ & Mammography \\
\hline Manufacturer & Pantak & Pantak & Gulmay \\
Output voltage $(\mathrm{kV})$ & 5 to 100 & 5 to 320 & 5 to 50 \\
Output current $(\mathrm{mA})$ & 0.5 to 80 & 0.5 to 30 & 0.1 to 40 \\
Output power $(\mathrm{kW})$ & up to 3.2 & up to 4.2 & up to 1.2 \\
$\mathrm{kV}$ adjustment $(\mathrm{kV})$ & 0.1 & 0.1 & 0.1 \\
$\mathrm{~mA}$ adjustment $(\mathrm{mA})$ & 0.01 & 0.01 & 0.1 \\
Fixed anode material & $\mathrm{W}$ & $\mathrm{W}$ & Mo or Rh $^{\mathrm{c}}$ \\
Tube window $(\mathrm{mm} \mathrm{Be})$ & 1 & 3 & 1 \\
Focal spot size $(\mathrm{mm})$ & $3 \times 3$ & $4 \times 4$ & $4 \times 4{ }^{\mathrm{d}}$ and $5 \times 5^{\mathrm{e}}$ \\
\hline
\end{tabular}

${ }^{\mathrm{a}}$ Generator and tube were installed in December of 1997.

${ }^{b}$ Generator was installed in February of 1998 with the existing x-ray tube.

${ }^{\mathrm{c}}$ Two $\mathrm{x}$-ray tubes are used in the mammography calibration range with the same generator. ${ }^{\mathrm{d}}$ Size of the Mo anode in tube installed in 1994.

${ }^{\mathrm{e}} \mathrm{Size}$ of the $\mathrm{Rh}$ anode in tube installed in 1994.

Table 6-2. Important dimensions and parameters for the NIST standard free-air ionization chambers

\begin{tabular}{lccccccc}
\hline \hline Chamber & $\begin{array}{c}\text { X-ray tube } \\
\text { potential } \\
(\mathrm{kV})\end{array}$ & $\begin{array}{c}\text { Plate } \\
\text { separation } \\
(\mathrm{mm})\end{array}$ & $\begin{array}{c}\text { Plate } \\
\text { height } \\
(\mathrm{mm})\end{array}$ & $\begin{array}{c}\text { Collector } \\
\text { length } \\
(\mathrm{mm})\end{array}$ & $\begin{array}{c}\text { Diaphragm } \\
\text { diameter/ID } \\
(\mathrm{mm})\end{array}$ & $\begin{array}{c}\text { Air } \\
\text { absorption } \\
\text { length } \\
(\mathrm{mm})\end{array}$ & $\begin{array}{c}\text { Electric } \\
\text { field } \\
\text { strength } \\
(\mathrm{V} / \mathrm{cm})\end{array}$ \\
\hline Lamperti & $10-60$ & 40 & 50 & 10.146 & $4.994 / 5 \mathrm{~s}$ & 39.02 & 750 \\
Attix & $10-50$ & $\begin{array}{c}\text { variable } \\
209 \text { max }\end{array}$ & $87^{\mathrm{a}}$ & variable & $10.00 / 10 \mathrm{u}$ & $212.7^{\mathrm{b}}$ & variable \\
Ritz & $20-100$ & 90 & 90 & 70.030 & $10.00 / 10 \mathrm{~A}$ & 127.39 & 55 \\
$\begin{array}{l}\text { Wyckof } \\
\text { f- Attix }\end{array}$ & $50-300$ & 200 & 268 & 100.80 & $10.00 / 10 \mathrm{~B}$ & 308 & 250 \\
\hline
\end{tabular}

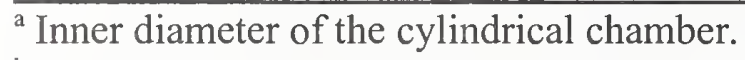

${ }^{\mathrm{b}}$ This is variable; the value shown is what is used for routine use. 


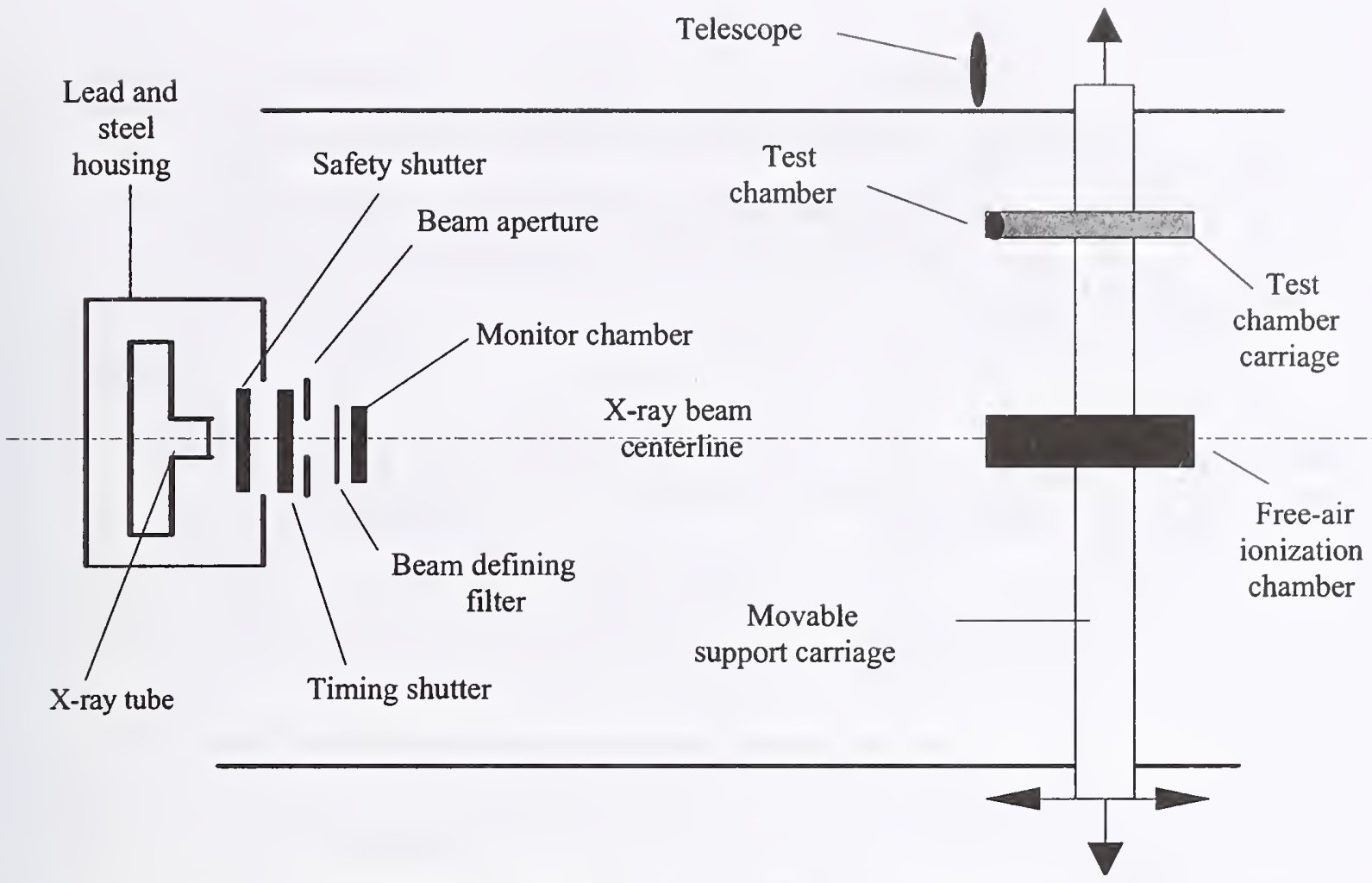

Fig. 6-1. Schematic of $300 \mathrm{kV}$ x-ray range.

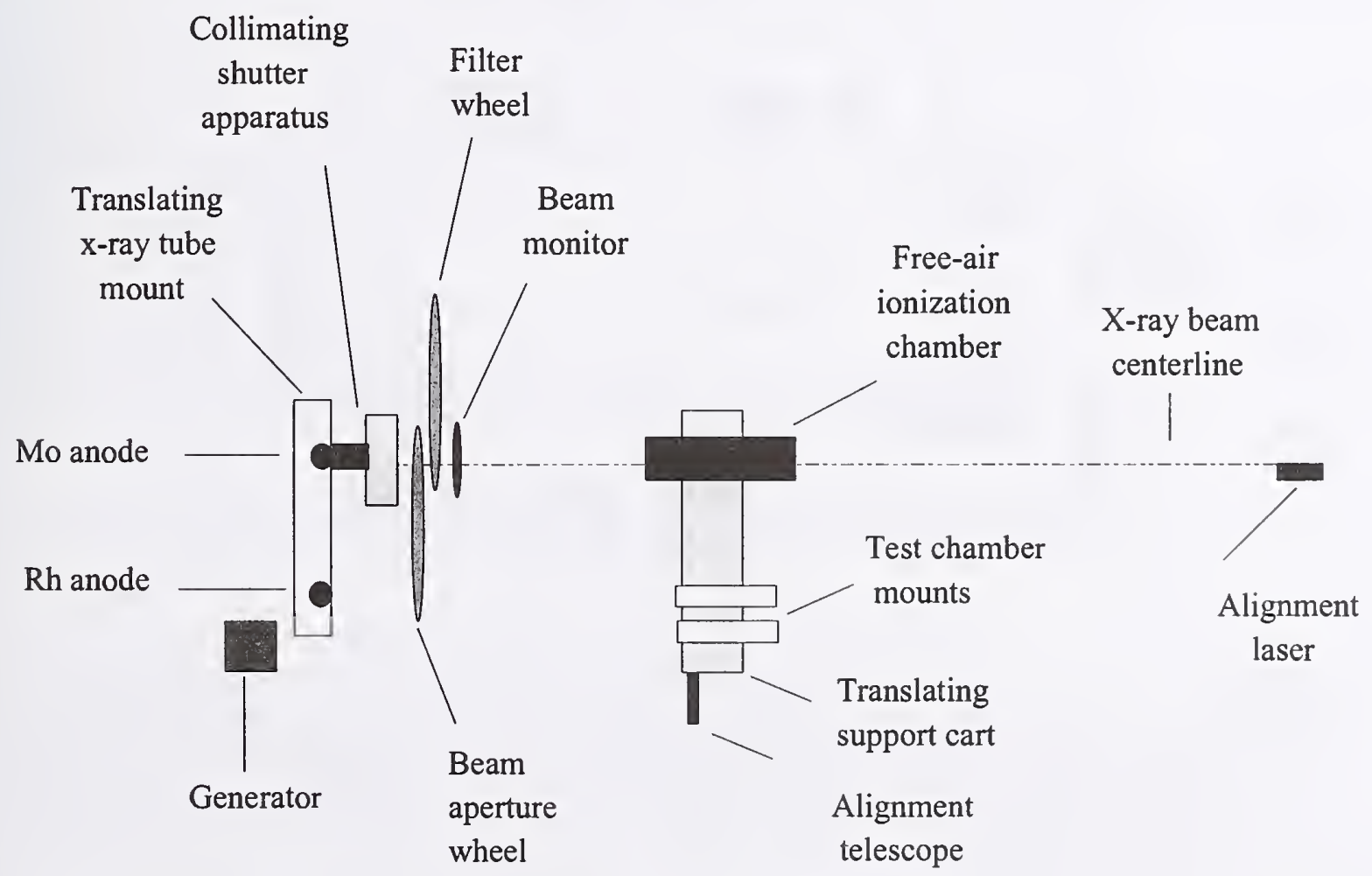

Fig. 6-2. Schematic of mammography calibration range. 


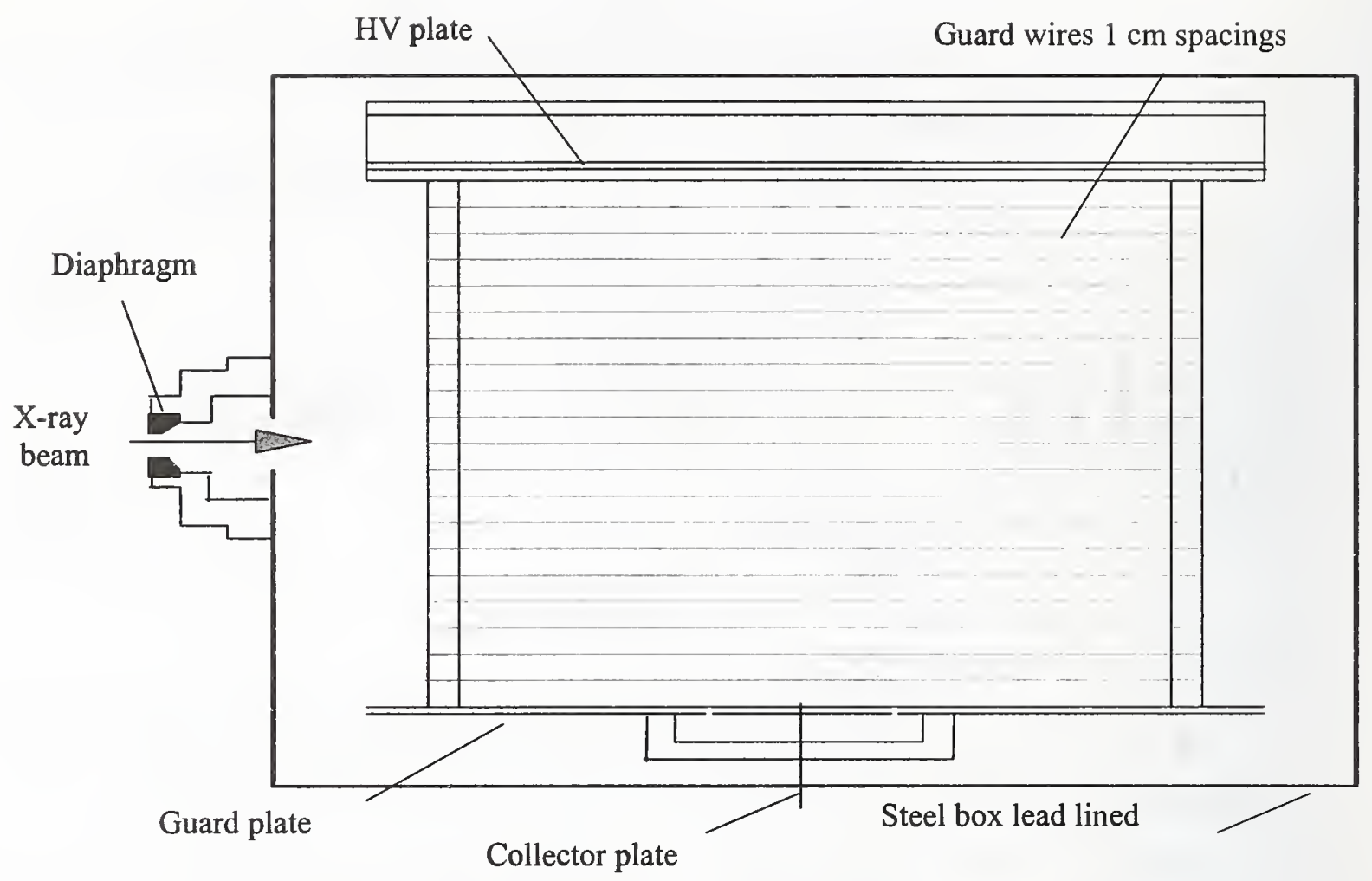

Fig. 6-3. Schematic of Wyckoff-Atix free-air ionization chamber. to electrometer or ground

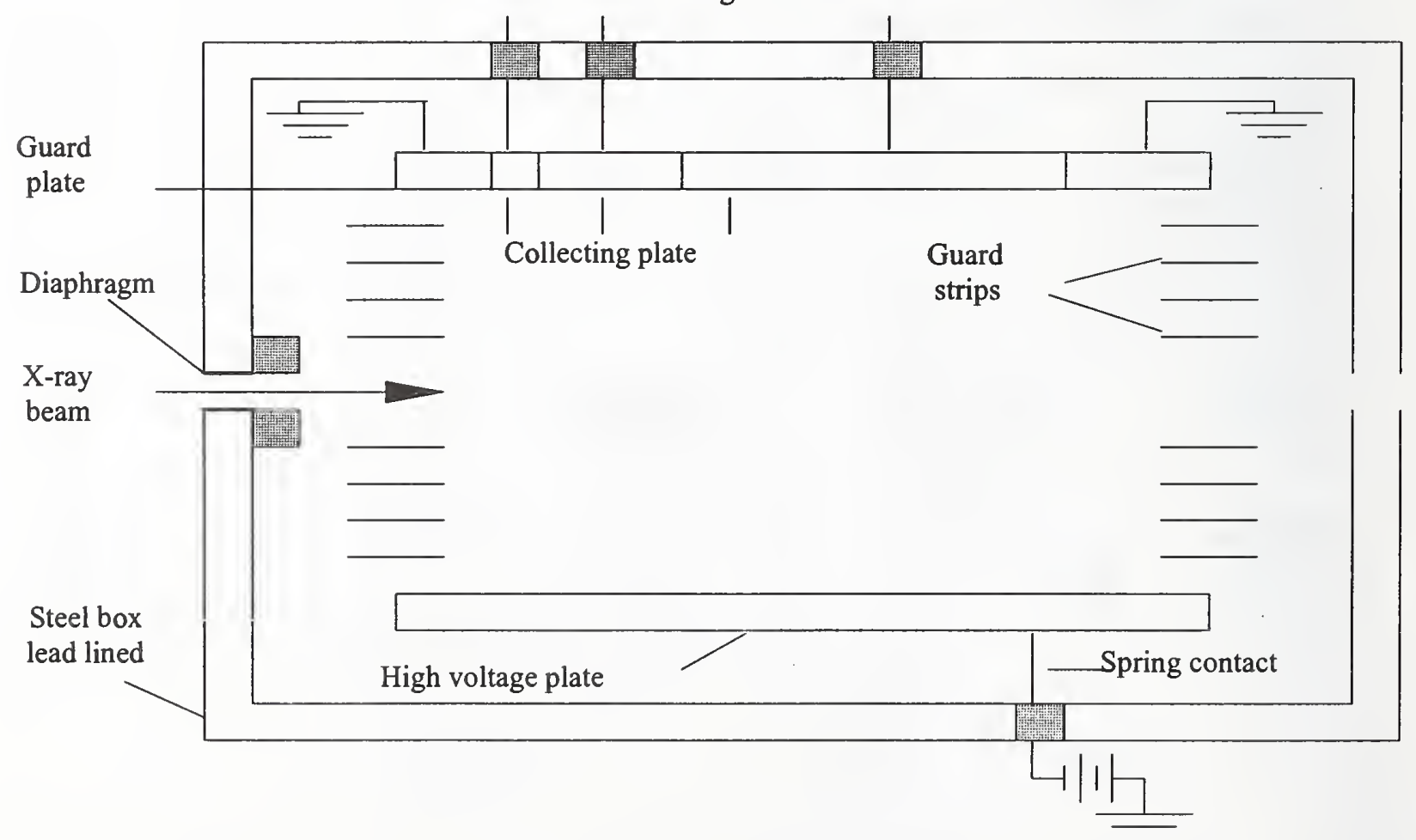

Fig. 6-4. Sectional view of the Ritz free-air chamber. 


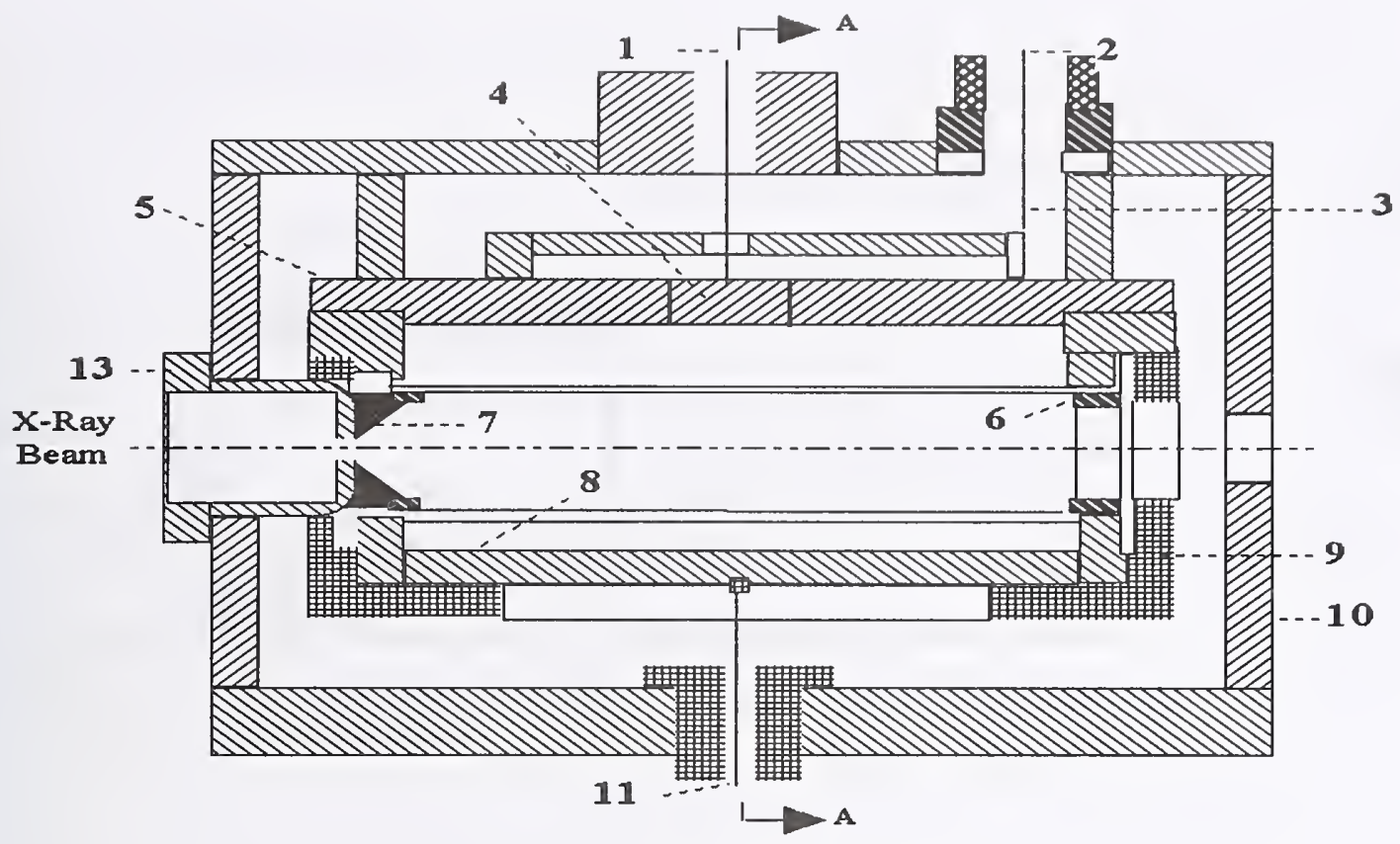

Sectional Side Elevation

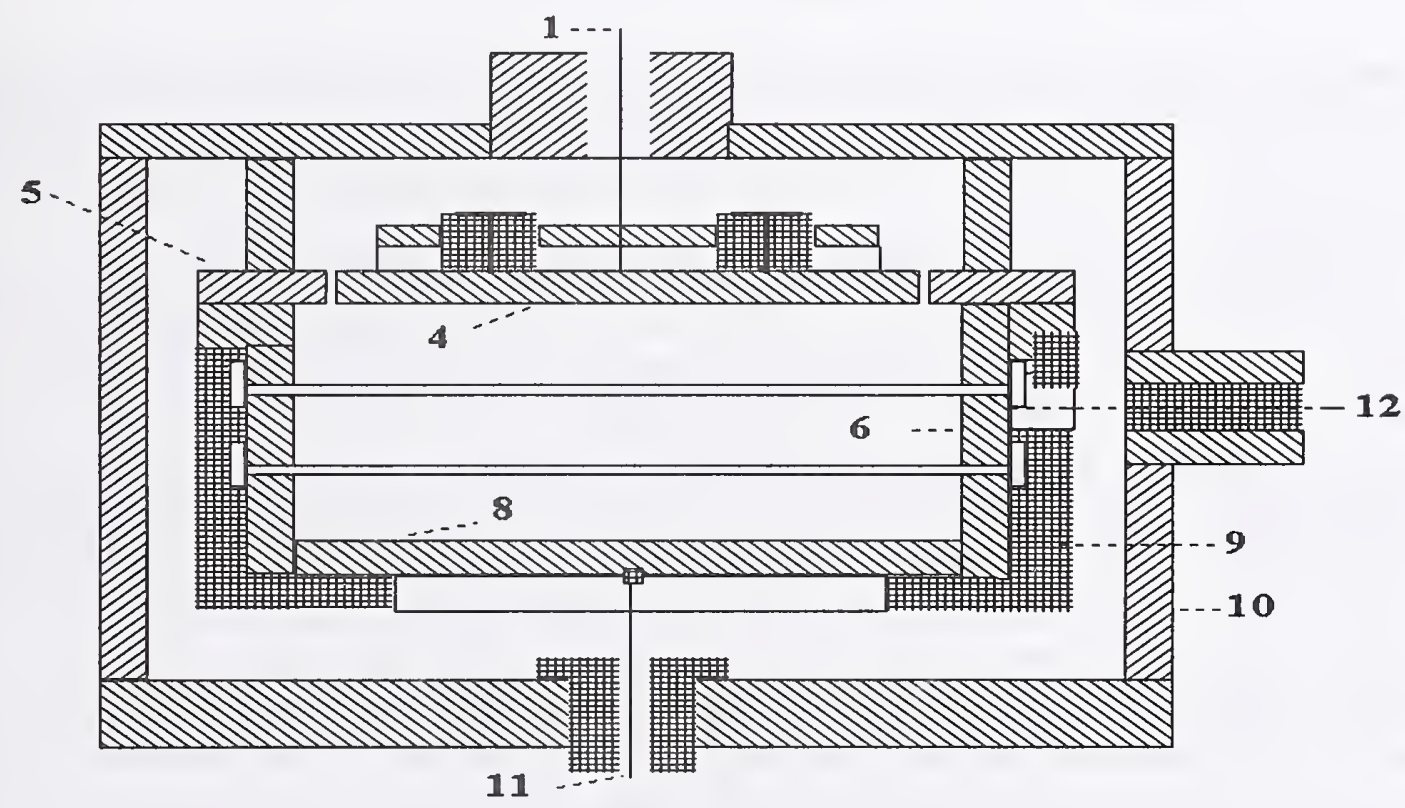

Fig. 6-5. Schematic cross-sectional views of the Lamperti free-air chamber.

1. Lead to measuring system, 2. lead to thermistor readout, 3. thermistor, 4. brass collector plate, 5. brass guard plate, 6 . brass guard ring, 7. tungsten diaphragm, 8. brass high voltage plate, 9 . supporting insulator, 10 . brass ground case, 11 . high voltage lead, 12. lead to midpoint of potential divider, 13. brass radiation shield, A. shows orientation for the second diagram, section A-A. 


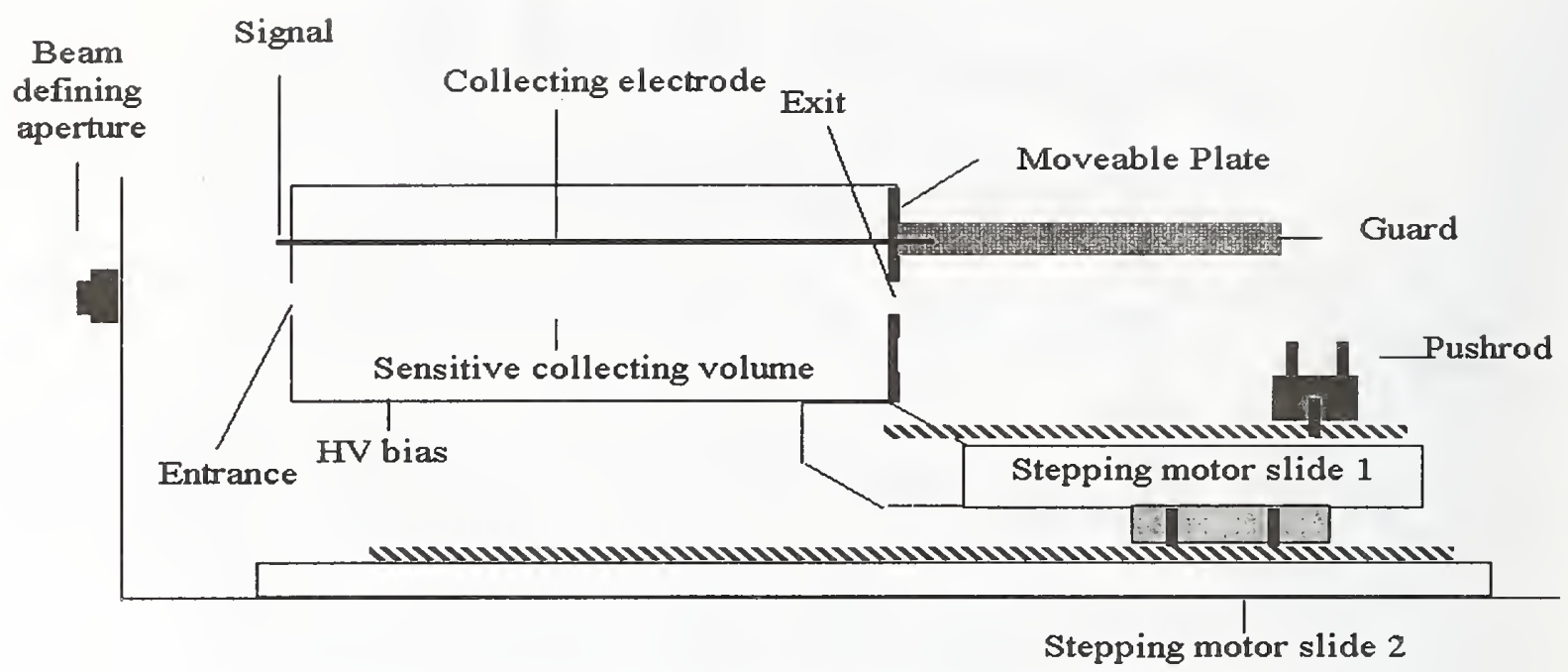

Fig. 6-6. Schematic of Attix free-air chamber.

to compensate for the downstream loss of electrons and eliminate electrons from the diaphragm. In addition, at the higher energies, the plate separation is made larger to allow for complete or nearly complete energy loss for electrons with paths predominately perpendicular to the x-ray beam direction.

Although strenuous efforts were made by the designers of the free-air chambers to realize experimentally the quantity exposure, various corrections are still required. A brief description of the four corrections follow. The area of the beam and the exposure rate are defined at the position of the free-air ionization chamber diaphragm, but the length of the air volume in which the ionizing electrons of interest are produced is defined by the length of the collector plate. Correction must be made for attenuation, $k_{\mathrm{a}}$, of the x-rays in the air path between the diaphram and the position of measurement. The distance for air attenuation measurements is taken to be the distance between the defining plane of the diaphragm and the center of the collector. This correction is energy dependent and at low energies atmospheric temperature and pressure effects become significant. The photon scatter correction, $k_{\mathrm{p}}$, must be made for the ionization that results from photons scattered out of the diaphragm-defined beam. This correction is geometry dependent and needs to be evaluated for each defining aperture. Some energetic electrons leave the collection volume before expending all their energy in the form of ionization. Electron loss corrections, $k_{\mathrm{e}}$, are not required for the Lamperti or the Attix chamber due to the short range of the low energy photons measured with these chambers. The energy dependent electron loss correction must be applied to the Ritz and the Wyckoff-Attix free-air ionization chambers. Since some of the ions recombine before being collected, the air-kerma rate dependent recombination correction, $k_{\mathrm{s}}$, is required. 


\subsection{Calculation of air kerma}

For a free-air ionization chamber with volume $\mathrm{V}$, the air-kerma rate is determined by the relation

$$
\dot{K}=\frac{I}{\rho_{\text {air }} V} \frac{W_{\text {air }}}{e} \frac{1}{1-g_{\text {air }}} \Pi k_{i}
$$

where

$\dot{K}=\quad$ the air-kerma rate $(\mathrm{Gy} / \mathrm{s})$,

$\frac{I}{\rho_{\text {air }} V}=$ the mass ionization current measured by the standard $\left(\mathrm{Cs}^{-1} \mathrm{~kg}^{-1}\right)$,

$V=$ the volume of the standard $\left(\mathrm{m}^{3}\right)$,

$\rho_{\text {air }}=\quad$ the density of air at the ambient conditions of temperature and pressure $\left(\mathrm{kg} \mathrm{m}^{-3}\right)$,

$$
\rho_{\text {air }}=\rho_{\mathrm{o}} \frac{P T_{\mathrm{o}}}{P_{\mathrm{o}} T}
$$

$\rho_{\circ}=$ the density of air at reference conditions, $1.293 \times 10^{-3}\left(\mathrm{~kg} \mathrm{~m}^{-3}\right)$

$\mathrm{T}=$ the ambient temperature $(\mathrm{K})$

$\mathrm{P}=$ the ambient pressure $(\mathrm{Pa})$

$\mathrm{T}_{\mathrm{o}}=$ the reference temperature $(\mathrm{K})$

$\mathrm{P}_{\mathrm{o}}=$ the reference pressure $(\mathrm{Pa})$,

$\frac{W_{\text {air }}}{e}=\quad$ is the mean energy expended by an electron of charge $e$ to produce an ion pair in dry air; the value used at NIST is $33.97 \mathrm{JC}^{-1}$,

$g_{a i r}=\quad$ is the fraction of the initial electron energy lost by radiative processes lost in air; $\mathrm{g}$ is negligible for the $\mathrm{x}$-ray beams of interest and $0.32 \%$ and $0.16 \%$ for the ${ }^{60} \mathrm{Co}$ and ${ }^{137} \mathrm{Cs}$ respectively.

$\Pi \mathrm{k}_{\mathrm{i}}=\quad$ the product of all the necessary non-dimensional corrections.

The largest correction at low energies is that due to the air attenuation of the $\mathrm{x}$-ray fluence along the air path length, $L$ between the reference plane and the center of the collecting volume. The correction factor $k_{\mathrm{a}}$ is calculated using the following equation:

$$
k_{a}=\exp (\mu L)=\exp \left(\frac{\mu}{\rho} \rho L\right)
$$

where

$\frac{\mu}{\rho^{\prime}}=\quad$ the mass air-attenuation coefficient, experimentally determined $\left(\mathrm{m}^{2} \mathrm{~kg}^{-1}\right)$ and

$\rho=$ the density of air at the ambient conditions of temperature and pressure $\left(\mathrm{kg} \mathrm{m}^{-3}\right)$

$\mathrm{L}=\quad$ the air absorption length or air path length $(\mathrm{m})$. 
6.4 Wyckoff-Attix (50 kV to $300 \mathrm{kV}$ ) free-air ionization chamber corrections

The correction for electron loss is

$$
k_{e}=1-\Sigma A_{F} E_{r} / 100
$$

and the correction for scattered photon contribution is

$$
k_{p}=1-\sum A_{F} S_{r} / 100
$$

In equation (6-4), $E_{r}$ is the percent electron contribution, a loss, beyond a radius $r$ of an X-ray beam, $S_{r}$ is the percent scattered photon contribution, a gain, beyond radius $r$, and $A_{F}$ is the fraction of each annular area that contributes to the summation. The calculations of the corrections for electron loss, $k_{\mathrm{e}}$ and photon contribution, $k_{\mathrm{p}}$, are based on data from Ref. [3] and the work of Ritz [6]. One should refer to Ref. [3] if calculations are to be made. A summary of the results of the calculations discussed in Ref. [3] are found in Table 6-3 which lists the percent loss and gain of ionization due to lack of plate separation and scattered photons in the WyckoffAttix chamber. The beam code designations from Table 4-1 are used in Table 6-3 to associate the data derived from Ref. [3] with present-day $\mathrm{x}$-ray beam conditions. The corrections for gain of ionization are calculated from a plot of corrections derived from data in Ref. [3] versus A1 HVL. The corrections for electron loss are calculated from data in Ref. [3] generated for beam conditions very nearly the same as present-day conditions, (see Table 6-4). It is assumed that the differences are not significant. The exceptions to this assumption include the H300, M80 and M120. The correction for electron loss is estimated by interpolation.

Table 6-3. Summary of calculations from ref. [3] for percent loss and gain of ionization due to lack of plate separation and scattered photons in the Wyckoff-Attix free-air ionization chamber

\begin{tabular}{lll}
\hline \hline Beam Code & $\sum \mathrm{A}_{\mathrm{F}} \mathrm{E}_{\mathrm{r}}(\%)$ & $\sum \mathrm{A}_{\mathrm{F}} \mathrm{S}_{\mathrm{r}}(\%)$ \\
\hline M60,H60 & 0 & 0.69 \\
M100 & 0 & 0.56 \\
M150 & -0.16 & 0.41 \\
M200 & -0.36 & 0.39 \\
M250 & -0.48 & 0.36 \\
M300 & -0.81 & 0.33 \\
H100 & -0.08 & 0.56 \\
H150 & -0.77 & 0.41 \\
H200 & -0.81 & 0.39 \\
H250 & -0.23 & 0.36 \\
H300 & & 0.33 \\
\hline
\end{tabular}

${ }^{a}$ The $300-\mathrm{kV}$ filtration of $4 \mathrm{~mm} \mathrm{Cu}$ is not comparable with the $\mathrm{H} 300$ composite filtration. 
Table 6-4. Comparison of x-ray beam filtrations used for data reported in ref. [3] with filtrations presently used for conventional calibration conditions

\begin{tabular}{|c|c|c|c|c|c|c|c|c|c|c|}
\hline \multirow[b]{2}{*}{$\begin{array}{c}\text { X-ray } \\
\text { tube } \\
\text { potential } \\
(\mathrm{kV})\end{array}$} & \multicolumn{5}{|c|}{ Reference [3] } & \multicolumn{5}{|c|}{ NBS SP-250 } \\
\hline & $\begin{array}{c}\text { Inherent } \\
\text { filter } \\
\text { (mm) }\end{array}$ & $\begin{array}{c}\mathrm{Pb} \\
(\mathrm{mm})\end{array}$ & $\begin{array}{c}\text { Addec } \\
\mathrm{Sn} \\
(\mathrm{mm}) \\
\end{array}$ & $\begin{array}{c}\text { Filter } \\
\mathrm{Cu} \\
(\mathrm{mm})\end{array}$ & $\begin{array}{c}\mathrm{Al} \\
(\mathrm{mm})\end{array}$ & $\begin{array}{c}\text { Inherent } \\
\text { filter } \\
\text { (mm) } \\
\end{array}$ & $\begin{array}{c}\mathrm{Pb} \\
(\mathrm{mm})\end{array}$ & $\begin{array}{c}\text { Addec } \\
\text { Sn } \\
(\mathrm{mm})\end{array}$ & $\begin{array}{c}\text { Filter } \\
\mathrm{Cu} \\
(\mathrm{mm})\end{array}$ & $\begin{array}{c}\mathrm{Al} \\
(\mathrm{mm})\end{array}$ \\
\hline \multicolumn{11}{|c|}{ Moderately Filtered Beams (M) } \\
\hline 60 & $3 \mathrm{Al}$ & & & & & $3 \mathrm{Be}$ & & & & 1.51 \\
\hline 100 & $3 \mathrm{Al}$ & & & & 1.0 & $3 \mathrm{Be}$ & & & & 5.0 \\
\hline 150 & $3 \mathrm{Al}$ & & & 0.23 & 1.0 & $3 \mathrm{Be}$ & & & 0.25 & 5.0 \\
\hline 200 & $3 \mathrm{Al}$ & & & 0.50 & 1.0 & $3 \mathrm{Be}$ & & & 1.21 & 4.1 \\
\hline 250 & $3 \mathrm{Al}$ & & & 1.0 & 1.0 & $3 \mathrm{Be}$ & & & 3.20 & 5.0 \\
\hline 300 & $3 \mathrm{Cu}$ & & & & & $3 \mathrm{Be}$ & & 6.5 & & 4.0 \\
\hline \multicolumn{11}{|c|}{ Heavily Filtered Beams $(\mathrm{H})$} \\
\hline 50 & & & ( no & data) & & $3 \mathrm{Be}$ & 0.10 & & & 4.0 \\
\hline 60 & & & (no & data) & & $3 \mathrm{Be}$ & & & 0.61 & 4.0 \\
\hline 100 & $3 \mathrm{Al}$ & 0.53 & & & & $3 \mathrm{Be}$ & & & 5.2 & 4.0 \\
\hline 150 & $3 \mathrm{Al}$ & & 1.53 & 4.0 & & $3 \mathrm{Be}$ & & 1.51 & 4.0 & 4.0 \\
\hline 200 & $3 \mathrm{Al}$ & 0.7 & 4.0 & 0.59 & & $3 \mathrm{Be}$ & 0.77 & 4.16 & 0.60 & 4.0 \\
\hline 250 & $3 \mathrm{Al}$ & 2.7 & 1.0 & 0.59 & & $3 \mathrm{Be}$ & 2.72 & 1.04 & 0.60 & 4.0 \\
\hline 300 & & & (no & data) & & $3 \mathrm{Be}$ & 5.0 & 3.0 & & 4.1 \\
\hline
\end{tabular}

The percent corrections, $\Sigma A_{F} E_{r}$ and $\Sigma A_{F} S_{r}$ used for the Wyckoff-Attix chamber and the products of all exposure-rate-independent corrections for each beam code are given in Table 6-5. Comparison of columns 3 and 4 of Table 6-5 with columns 2 and 3 of Table 6-3 shows there is good agreement, in general, between the data calculated in the review from Ref. [3] and the data presently used. Corrections for electron loss, $\Sigma A_{F} E_{r}$, for beams M300 and H300 are estimated from figure 9 of Ref. [3], and may be slightly in error since the filtration of these reference beams is not the same as that of the present-day M300 and H300 beams. The trends in the corrections in this energy range have been considered and a type $\mathrm{B}$ uncertainty for $\Sigma A_{F} E_{r}$ of 0.07 $\%$ has been estimated for M300 and $0.15 \%$ for $\mathrm{H} 300$.

The corrections given in Table 6-5 for air attenuation, $k_{a}$, in the Wyckoff-Attix free-air ionization appear to be nearly a linear function of the logarithm of the HVL in copper for the beam qualities of interest, see Ref [1] of Attachment 2. The data points cover the range of $\mathrm{Cu}$ HVL's for the M and $\mathrm{H}$ beam qualities except for M60 and H300. The $k_{\mathrm{a}}$ values for those 
Table 6-5. Data used to compute corrections for the Wyckoff-Attix standard free-air chamber for conventional calibration conditions

\begin{tabular}{|c|c|c|c|c|c|}
\hline Beam Code & $\mathrm{k}_{\mathrm{a}}$ & $\begin{array}{l}100(1- \\
\sum A_{F}\end{array}$ & $\begin{array}{l}100\left(1-k_{\mathrm{p}}\right) \\
\sum \mathrm{A}_{\mathrm{F}} \mathrm{S}_{\mathrm{r}}\end{array}$ & $\mathrm{k}_{\rho} \mathrm{k}_{\mathrm{p}}$ & $\Pi \mathrm{k}_{\mathrm{i}}^{\mathrm{a}} / \mathrm{k}_{\mathrm{s}}$ \\
\hline M60 & $1.0203^{b}$ & & 0.77 & 0.9924 & 1.0140 \\
\hline M100 & 1.0097 & & 0.60 & 0.9940 & 1.0052 \\
\hline M150 & 1.0068 & -0.15 & 0.40 & 0.9975 & 1.0058 \\
\hline M200 & $1.0055^{\mathrm{b}}$ & $-0.40^{c}$ & $0.39^{\mathrm{d}}$ & 1.0001 & 1.0071 \\
\hline M250 & 1.0045 & -0.50 & 0.36 & 1.0014 & 1.0074 \\
\hline M300 & $1.0039^{\mathrm{b}}$ & -0.62 & $0.32^{\mathrm{e}}$ & 1.0030 & 1.0084 \\
\hline H50 & 1.0103 & & 0.63 & 0.9937 & 1.0055 \\
\hline $\mathrm{H} 60$ & $1.0088^{b}$ & & $0.55^{\mathrm{e}}$ & 0.9945 & 1.0048 \\
\hline $\mathrm{H} 100$ & $1.0060^{\mathrm{b}}$ & -0.04 & $0.41^{\mathrm{e}}$ & 0.9963 & 1.0038 \\
\hline H150 & 1.0050 & -0.68 & 0.35 & 1.0033 & 1.0098 \\
\hline $\mathrm{H} 200$ & 1.0043 & -0.82 & 0.35 & 1.0047 & 1.0106 \\
\hline $\mathrm{H} 250$ & 1.0040 & -0.26 & 0.35 & 0.9991 & 1.0046 \\
\hline $\mathrm{H} 300$ & $1.0038^{\mathrm{b}}$ & $-0.62^{\mathrm{d}}$ & $0.31^{\mathrm{e}}$ & 1.0031 & 1.0084 \\
\hline S60 & 1.0131 & & 0.70 & 0.9930 & 1.0075 \\
\hline
\end{tabular}

${ }^{a}$ An energy independent correction factor of 1.0015 for non-planarity of the guard-collector plate system is included in the product of $\Pi \mathrm{k}_{\mathrm{i}}$.

${ }^{b}$ Estimated from a graph of $\mathrm{k}_{\mathrm{a}}$ versus $\mathrm{HVL}$ in $\mathrm{mm}$ of $\mathrm{Cu}$.

${ }^{\mathrm{c}}$ Estimated to be essentially the same beam quality as the previous beam code MFC.

${ }^{\mathrm{d}}$ Calculated using figure 9 of reference 1.

${ }^{\mathrm{e}}$ Predicted from the least squares fit: $\Sigma A_{F} S_{r}=0.9912+1.816 \mathrm{E}-3 \log _{\mathrm{e}}(\mathrm{HVL}$ in mm Al).

conditions are estimated from a semilog curve fit.

The data points, found in Ref. [1] of Attachment 2, when fitted to a logarithmic curve using the method of least squares provide the following equation:

$$
k_{a}=1.0067-2.0229 \times 10^{-3} \log _{10}(H V L \mathrm{~mm} \mathrm{Cu})
$$

The correlation coefficient is 0.96 . A comparison of the $k_{\mathrm{a}}$ data, estimated and computed using the least-squares-derived equation is shown in Table 6-6.

The recombination corrections for all the NIST free-air ionization chambers are based on measurements of ionization currents at several collection potentials, with air kerma-rate as a parameter. In accord with the method of Scott and Greening [9], the inverse of the ionization currents are plotted against the inverse of the squares of the collection potentials. Extrapolation of the plotted data to $1 / \mathrm{E}^{2}=0$ predicts the inverse of the saturation ionization current. If the ionization currents are normalized to the current measured at the normal operating collection potential, the inverse of the intercept at $1 / \mathrm{E}^{2}=0$ is the recombination correction for that particular 
Table 6-6. Comparison of the $\mathrm{k}_{\mathrm{a}}$ values currently used to those values computed from the least squares equation

\begin{tabular}{llll}
\hline \hline Beam Code & HVL $(\mathrm{mm} \mathrm{Cu})$ & Present & Least Squares \\
\hline M60 & 0.052 & $1.0203^{\mathrm{a}}$ & 1.0128 \\
M100 & 0.20 & 1.0097 & 1.0100 \\
M150 & 0.67 & 1.0068 & 1.0076 \\
M200 & 1.69 & $1.0055^{\mathrm{a}}$ & 1.0057 \\
M250 & 3.2 & 1.0045 & 1.0044 \\
M300 & 5.3 & $1.0039^{\mathrm{a}}$ & 1.0034 \\
H50 & 0.142 & 1.0103 & 1.0107 \\
H60 & 0.24 & $1.0088^{\mathrm{a}}$ & 1.0096 \\
H100 & 1.14 & $1.0060^{\mathrm{a}}$ & 1.0065 \\
H150 & 2.5 & 1.0050 & 1.0049 \\
H200 & 4.1 & 1.0043 & 1.0039 \\
H250 & 5.2 & 1.0040 & 1.0034 \\
H300 & 6.2 & $1.0038^{\mathrm{a}}$ & 1.0031 \\
\hline
\end{tabular}

${ }^{\mathrm{a} E s t i m a t e d ~ f r o m ~ g r a p h ~ f o u n d ~ i n ~ R e f ~} 1$. of Attachment 2.

air-kerma rate. This same analysis technique can be performed with an abscissa of inverse potential, instead of inverse squared potential, as was the case for the Wyckoff-Attix recombination correction determination. According to Scott and Greening, this procedure exaggerates the effects of recombination and is proper only for very low air-kerma rates. However, the predicted recombination correction for the Wyckoff-Attix chamber is only about $0.2 \%$ for the maximum air-kerma rate tested, $2.9 \mathrm{mGy} / \mathrm{s}$. The result can be represented by the following equation, where the air-kerma rate is in units of Gy/s:

$$
k_{s}=1.00038+2.87 \times 10^{-2} \dot{K}^{0.5},
$$

The product of the currently used correction factors for the Wyckoff-Attix chamber along with the recently reviewed products of the correction factors are listed in Table 6-7. A non-coplanarity correction, based on guard-collector plate assembly measurements, is applied to all free-air chamber measurements. In general, the computations from the most recently reviewed data for the electron-loss and scattered-photon gain corrections are in agreement with the existing data. Two exceptions, which have differences on the order of $0.1 \%$, are the $\Sigma A_{F} S_{r}$ corrections for the M60 and H150 beam qualities. The corrections for M300 assume that the rather large difference in filtration between the experimental conditions $(4 \mathrm{~mm} \mathrm{Cu})$, and the actual filtration for M300 ( $3 \mathrm{~mm} \mathrm{Be}+6.5 \mathrm{~mm} \mathrm{Sn}+4.0 \mathrm{~mm} \mathrm{Al})$, will not significantly affect the magnitude of the corrections. 
Table 6-7. Products of all air-kerma-rate-independent corrections for the Wyckoff-Attix free-air ionization chamber

\begin{tabular}{lllc}
\hline \hline Beam Code & $\begin{array}{l}\Pi \mathrm{k}_{\mathrm{i}} / \mathrm{k}_{\mathrm{s}} \\
\text { Current }\end{array}$ & $\begin{array}{l}\Pi_{\mathrm{i}} / \mathrm{k}_{\mathrm{s}} \\
\text { Review }\end{array}$ & Difference (\%) \\
\hline M60 & 1.0140 & 1.0074 & 0.65 \\
M100 & 1.0052 & 1.0059 & -0.07 \\
M150 & 1.0058 & 1.0066 & -0.08 \\
M200 & 1.0071 & 1.0069 & 0.02 \\
M250 & 1.0074 & 1.0071 & 0.03 \\
M300 & 1.0084 & 1.0097 & -0.13 \\
H50 & 1.0055 & & \\
H60 & 1.0048 & 1.0042 & 0.06 \\
H100 & 1.0038 & 1.0032 & 0.06 \\
H150 & 1.0098 & 1.0100 & -0.12 \\
H200 & 1.0106 & 1.0096 & 0.10 \\
H250 & 1.0046 & 1.0036 & 0.10 \\
H300 & 1.0084 & & \\
\hline
\end{tabular}

6.5 Ritz (20 kV to $100 \mathrm{kV})$ free-air ionization chamber corrections

The Ritz free-air ionization chamber [4] is used for standardization of x-ray beams for $\mathrm{x}$-ray tube potentials from $20 \mathrm{kV}$ to $100 \mathrm{kV}$. The dimensions of interest for purposes of developing corrections for this free-air ionization chamber are the length of the air path between the defining-plane of the diaphragm and the mid-plane of the collection plate and the collection-plate-system separation and height, refer to Table 6-2 for the dimensions.

The largest free-air ionization chamber correction for "low" energy, lightly filtered x-rays is for air attenuation, $k_{\mathrm{a}}$. This correction is determined with the free-air ionization chamber at particular distances from the x-ray tube, since the intervening air acts as a filter and at low energies can influence the measurements. The procedure for determining the correction involves removal of the free-air ionization chamber diaphragm and setting a fixed diaphragm in the beam independent of the free-air ionization chamber. For a particular set of conditions, including the distance from source, the x-ray tube potential, and the filtration, the ionization in the free-air ionization chamber is measured with the mid-plane of the collection plate at the position where the exposure rate is to be determined, position 1, and again with the mid-plane moved away from the source a distance equal to the air path length, position 2. Position 1 places the mid-plane in the normal position of the diaphragm. Position 2 places the mid-plane of the Ritz chamber in the normal position of the collection plate. The diameter of the fixed diaphragm must be such that 
the defined beam in its entirety is intercepted by the free-air ionization chamber at the two measurement positions. The ratio of the currents measured at position 1 and position 2 is the air attenuation correction factor for the conditions of measurement. These conditions include the atmospheric temperature and pressure since the attenuation is dependent on the density of the air. The attenuation correction is computed for a pressure of $99.992 \mathrm{kPa}$ and a temperature of 293.15 $\mathrm{K}$, (dry air density of $1.189 \mathrm{mg} \cdot \mathrm{cm}^{-3}$ ) to provide a correction factor representative of normal room conditions. If the experimentally determined attenuation coefficients, $\mu / \rho$, are so large that normal variations in room conditions produce significant differences in the correction, then the difference in air density from $1.189 \mathrm{mg} \cdot \mathrm{cm}^{-3}$ must be taken into account. The conditions pertain for all $\mathrm{x}$-ray beams with HVLs less than $0.22 \mathrm{~mm} \mathrm{Al}$. The effect on $k_{\mathrm{a}}$ of changes in temperature and pressure from reference conditions must be taken into account using equation 6-3. A list of the air-attenuation coefficients and values for $k_{\mathrm{a}}$ for the Ritz are listed in Table 6-8. See Ref. [7] for a list of calculated mass attenuation coefficients. These have been verified recently using the Attix chamber for a direct determination of the correction.

Table 6-8. Mass air-attenuation coefficients and air attenuation corrections for the Ritz free-air ionization chamber

\begin{tabular}{clcc}
\hline \hline Beam Code & $\begin{array}{c}\text { HVL } \\
(\mathrm{mm} \mathrm{Al})\end{array}$ & $\begin{array}{c}\mu / \rho \\
\left(\mathrm{cm}^{2} / \mathrm{mg}\right)\end{array}$ & $\begin{array}{c}\text { Air Attenuation } \\
\text { Correction }\left(\mathrm{k}_{\mathrm{a}}\right)^{\mathrm{a}}\end{array}$ \\
\hline L20 & 0.071 & $8.2293 \mathrm{E}-3$ & $1.1327^{\mathrm{b}}$ \\
L30 & 0.22 & $3.2392 \mathrm{E}-3$ & $1.0503^{\mathrm{b}}$ \\
L40 & 0.49 & $1.6816 \mathrm{E}-3$ & 1.0258 \\
L50 & 0.75 & $1.2163 \mathrm{E}-3$ & 1.0186 \\
L80 & 1.83 & $7.3175 \mathrm{E}-4$ & 1.0111 \\
L100 & 2.8 & $4.3435 \mathrm{E}-4$ & 1.0066 \\
M20 & 0.152 & $4.0835 \mathrm{E}-3$ & $1.0639^{\mathrm{b}}$ \\
M30 & 0.36 & $1.8811 \mathrm{E}-3$ & 1.0288 \\
M40 & 0.73 & $1.1051 \mathrm{E}-3$ & 1.0169 \\
M50 & 1.02 & $7.4192 \mathrm{E}-4$ & 1.0113 \\
H20 & 0.36 & $1.6190 \mathrm{E}-3$ & 1.0248 \\
H30 & 1.23 & $5.8048 \mathrm{E}-4$ & 1.0088 \\
H40 & 2.9 & $3.9028 \mathrm{E}-4$ & 1.0059 \\
\hline
\end{tabular}

a The air attenuation corrections were determined with the defining plane of the Ritz chamber at $50 \mathrm{~cm}$, for an air-path length of $127.39 \mathrm{~mm}$.

b These corrections vary significantly with changes in atmospheric temperature and pressure. For ambient conditions, $k_{\mathrm{a}}$ is calculated using $k_{\mathrm{a}}=\exp (\mu \mathrm{L})$.

The electron-loss corrections, $k_{\mathrm{e}}$, for the Ritz free-air ionization chamber are taken from data in the 1959 publication on the design of free-air ionization chambers [6]. The dimensions of the Ritz free-air ionization chamber are such that the ionization loss due to loss of electrons 
occurs only at the upper end of the x-ray energy range for which this free-air ionization chamber is used. Therefore, only figures 10 and 14 of Ref. 6 are required for calculation of the corrections for beam codes S75 and L100. These data, used in conjunction with the fractional areas inside the collection-plate system for different radii, provide the required corrections for ionization loss. For this calculation, the plate separation is reduced from $9 \mathrm{~cm}$ to $8 \mathrm{~cm}$ to account for the 1-cm-diameter free-air ionization chamber beam defining diaphragm and to simulate the required zero-beam diameter. The results of the calculations shown in Table 6-9 do not differ by more than $0.1 \%$ from the corrections for electron loss presently used for these conditions. Since no data are published for the L80 $\mathrm{x}$-ray beam condition, the correction for electron-loss is estimated by interpolation following the curvature of the data for $E_{r}$ at 60,75 , and $100 \mathrm{kV}$ with 3 $\mathrm{mm} \mathrm{Al}$ added filtration. The estimated correction is $0.12 \%$, which is not significantly different

Table 6-9. Computation of electron-loss corrections for the Ritz free-air ionization chamber

Radius $\quad$ S75 L100

\begin{tabular}{|c|c|c|c|c|c|c|}
\hline $\begin{array}{l}\text { Inner } \\
(\mathrm{cm})\end{array}$ & $\begin{array}{c}\text { Outer } \\
(\mathrm{cm})\end{array}$ & $\mathrm{A}_{\mathrm{F}}$ & $\begin{array}{c}E_{r} \\
(\%)\end{array}$ & $\begin{array}{c}\mathrm{A}_{\mathrm{F}} \mathrm{E}_{\mathrm{r}} \\
(\%)\end{array}$ & $\begin{array}{c}E_{r} \\
(\%)\end{array}$ & $\begin{array}{c}\mathrm{A}_{\mathrm{F}} \mathrm{E}_{\mathrm{r}} \\
(\%)\end{array}$ \\
\hline 0 & 4.0 & 1.00 & -0.10 & -0.10 & -0.60 & -0.60 \\
\hline 4.0 & 4.5 & 0.58 & 0.035 & 0.02 & 0.20 & 0.12 \\
\hline 4.5 & 5.0 & 0.28 & 0.024 & 0.01 & 0.13 & 0.04 \\
\hline \multicolumn{4}{|c|}{$\mathrm{k}_{\mathrm{e}}=\sum \mathrm{A}_{\mathrm{F}} \mathrm{E}_{\mathrm{r}}$} & -0.07 & & -0.44 \\
\hline
\end{tabular}

from the presently used correction. A detailed analysis of the $k_{\mathrm{e}}$ corrections is currently underway. The calculations, which consider x-ray beam penumbra effects on the magnitude of the corrections can be found in Ref. 3 of Attachment 2.

Corrections for the scattered-photon contribution to the ionization in the free-air ionization chamber are derived from Ritz [6] and Allisy and Roux [9]. The percent scatteredphoton contributions within different radii, and appropriate multipliers for several $\mathrm{x}$-ray beam conditions, are given in Ritz [6], figure 15 and table 1, respectively. The data of Ritz, Allisy and Roux were combined and by means of least-squares fit for $k_{\mathrm{p}} \mathrm{vs}$. HVL measured in Al, the following logarithmic equation was developed:

$$
k_{p}=0.9956+2 \times 10^{-3} \log _{10}(H V L m m A l)
$$

The values of $k_{\mathrm{p}}$ for the Ritz free-air ionization chamber, listed in Table 6-10, are computed from this equation. For convenience, the products of all rate-independent corrections for the Ritz chamber are provided in the last column of Table 6-10.

The recombination corrections for the Ritz free-air ionization chamber are calculated from an equation of the same form as was developed for the Wyckoff-Attix free-air ionization chamber and described in a previous section. The Scott and Greening extrapolation procedure for air-kerma rates ranging from $0.6 \mathrm{mGy} / \mathrm{s}$ to $4.2 \mathrm{mGy} / \mathrm{s}$ yields the following logarithmic equations:

$$
k_{s}=1+8.7136 \times 10^{-2} \dot{K},(G y / s)
$$


Table 6-10. Summary of corrections for the Ritz free-air ionization chamber

\begin{tabular}{lllllll}
\hline \hline $\begin{array}{c}\text { Beam } \\
\text { Code }\end{array}$ & $\begin{array}{c}\text { Added Al } \\
\text { filter } \\
(\mathrm{mm})\end{array}$ & $\begin{array}{c}\mathrm{HVL} \\
(\mathrm{mm} \mathrm{Al})\end{array}$ & $\mathrm{k}_{\mathrm{a}}^{\mathrm{a}}$ & $\mathrm{k}_{\mathrm{p}}$ & $\mathrm{k}_{\mathrm{e}}$ & $\Pi \mathrm{k}_{\mathrm{i}}$ \\
\hline L20 & 0 & 0.071 & & 0.9933 & 1.0000 & $0.9933^{\mathrm{b}}$ \\
L30 & 0.265 & 0.22 & & 0.9942 & 1.0000 & $0.9942^{\mathrm{b}}$ \\
L40 & 0.50 & 0.49 & 1.0257 & 0.9949 & 1.0000 & 1.0205 \\
L50 & 0.639 & 0.75 & 1.0186 & 0.9953 & 1.0000 & 1.0138 \\
L80 & 1.284 & 1.83 & 1.0110 & 0.9960 & 1.0010 & 1.0080 \\
L100 & 1.978 & 2.8 & 1.0065 & 0.9964 & 1.0051 & 1.0080 \\
M20 & 0.230 & 0.152 & & 0.9940 & 1.0000 & $0.9940^{\mathrm{b}}$ \\
M30 & 0.50 & 0.36 & 1.0289 & 0.9947 & 1.0000 & 1.0234 \\
M40 & 0.786 & 0.73 & 1.0170 & 0.9952 & 1.0000 & 1.0121 \\
M50 & 1.021 & 1.02 & 1.0114 & 0.9955 & 1.0000 & 1.0069 \\
S75 & 1.504 & 0.36 & 1.0076 & 0.9960 & 1.0007 & 1.0043 \\
\hline
\end{tabular}

${ }^{\mathrm{a}} \mathrm{The}$ values given for $k_{\mathrm{a}}$ are computed using $\mathrm{P}=750 \mathrm{~mm} \mathrm{Hg}$ and $\mathrm{T}=293.2^{\circ} \mathrm{K}$.

${ }^{\mathrm{b}}$ These products include only $k_{\mathrm{p}}$ and $k_{\mathrm{e}}$ and must be multiplied by $\exp (\mu \mathrm{L})$.

The recombination data was obtained using a $1 \mathrm{~cm}$ diameter free-air ionization chamber diaphragm, which is used for routine calibrations, and from measurements made using a $0.5 \mathrm{~cm}$ diameter diaphragm. There appears to be no significant difference in the data sets. The data used to develop these equations can be found in Ref. 4 of Attachment 2.

\subsection{Lamperti ( $10 \mathrm{kV}$ to $20 \mathrm{kV})$ free-air ionization chamber corrections}

The Lamperti free-air ionization chamber is designed for $\mathrm{x}$-ray air-kerma standardization in the region of $10 \mathrm{kV}$ to $60 \mathrm{kV}$. In practice, the Ritz free-air ionization chamber, with air-kerma measurement capabilities overlapping that of the Lamperti chamber, is used for calibrations down to and including $20 \mathrm{kV} x$ rays. Typically the Lamperti free-air ionization chamber is used only for measurements at $10 \mathrm{kV}$ and $15 \mathrm{kV}$.

The corrections for the Lamperti chamber are discussed in detail by Lamperti and Wyckoff in Ref. [5]. Although many different corrections are identified, the important corrections are for air attenuation, $k_{\mathrm{a}}$ and scattered photon contribution, $k_{\mathrm{p}}$. The corrections for electron loss, $k_{\mathrm{e}}$, in the $10 \mathrm{kV}$ to $60 \mathrm{kV}$ region are given as "much less than $0.1 \%$ "[5]. For $\mathrm{x}$ rays generated at $10 \mathrm{kV}$ and $15 \mathrm{kV}, k_{\mathrm{e}}$ should equal unity since the Lamperti chamber plate separation is $4 \mathrm{~cm}$ and the continuous-slowing-down-approximation (CSDA) range for the $15 \mathrm{keV}$ electrons is only $0.5 \mathrm{~cm}$ in air of density $1.1888 \mathrm{mg} / \mathrm{cm} 3$ ) [10]. Actually, $k_{\mathrm{e}}$ should be unity for the Lamperti chamber for $\mathrm{x}$-rays up to $50 \mathrm{kV}$ since the CSDA range for $50 \mathrm{keV}$ electrons is $4.1 \mathrm{~cm}$ 
for normal room temperature and pressure. This is a very conservative statement because the assumptions are that the entire energy of the highest energy photon is transferred to an electron, and that the CSDA range is equal to the practical range. According to Katz and Penfold [11], the practical electron range would be only $80 \%$ of the CSDA range for $50 \mathrm{keV}$ electrons.

The intercomparison of free-air chambers described by Lamperti and Wyckoff [5] was carried out for $\mathrm{x}$ rays generated by $\mathrm{x}$-ray tube potentials from $20 \mathrm{kV}$ up to $60 \mathrm{kV}$, with corrections for the effect of scattered photons, $k_{\mathrm{p}}$, obtained from Ritz [4] and Allisy and Roux [8]. The data from these two sources differ by about $0.1 \%$ in the region below $30 \mathrm{kV}$ and the two sets of data have been combined using the least squares method to arrive at the following equation:

$$
k_{p}=0.9975+1.034 \times 10^{-3} \log _{10}(H V L \text { mmAl })
$$

Somerwil [12] investigated a systematic difference between several national free-air ionization chamber standards, intercompared at the Bureau Internationale des Poids et Mesures (BIPM), and found that the scattered-photon correction for chambers with $40 \mathrm{~mm}$ diaphragm-tocollection-plate distances should be less than corrections determined from measurements with chambers of $100 \mathrm{~mm}$. The values of $k_{\mathrm{p}}$ were computed for $\mathrm{x}$ rays with beam codes L10, L15, $\mathrm{H} 10$, and $\mathrm{H} 15$ using the above equation. These corrections were reduced by adding $0.15 \%$ at $\mathrm{L} 10$ and $\mathrm{H} 10$ and $0.10 \%$ at L15 and $\mathrm{H} 15$ because the Ritz and Allisy-Roux measurements were for a distance of $100 \mathrm{~mm}$. The adjustments to the corrections are the percentages determined by Somerwil. The air attenuation corrections, $k_{\mathrm{a}}$, for the Lamperti chamber are determined using the Ritz chamber in the two-position, independent-diaphragm technique, previously described. These corrections have recently been directly verified by the Attix chamber. The Ritz and the Attix chambers were used because the Lamperti chamber aperture design is not large enough to encompass the beam defined by the fixed diaphragm. See Ref. 5 of Attachment 2 for data. The recombination corrections, $k_{\mathrm{s}}$, for the Lamperti chamber were determined using the procedure suggested by Scott and Greening. See Ref. 6 of Attachment 2 for Lamperti chamber data. The equation developed from these studies for determining the recombination correction is, where the air-kerma rate is in units of Gy/s:

$$
k_{s}=0.9996+4.573 \times 10^{-3} \dot{K}^{0.5}
$$

Recombination corrections for exposure rates commonly encountered in instrument calibration work are provided in Table 6-11.

Table 6-11. Recombination corrections for the Lamperti free-air ionization chamber

\begin{tabular}{cc}
\hline \hline $\begin{array}{c}\text { Air-kerma rate } \\
(\mathrm{R} / \mathrm{s})\end{array}$ & $\mathrm{k}_{\mathrm{s}}$ \\
\hline 1.5 & 1.0000 \\
15.0 & 1.0002 \\
150 & 1.0014 \\
\hline
\end{tabular}


The corrections presently used for the Lamperti chamber are given in Table 6-12 where most of the air attenuation corrections are shown to be dependent on temperature and pressure and the corrections for photon scatter have been computed from the equation for $k_{\mathrm{p}}$ adjusted for the Somerwil correction. The correction, $k_{\mathrm{e}}$, is equal to unity as are all other exposure-rate independent corrections identified by Lamperti [5].

Table 6-12. Summary of correction factors for Lamperti free-air ionization chamber

\begin{tabular}{cccccc}
\hline $\begin{array}{c}\text { Beam } \\
\text { code }\end{array}$ & $\begin{array}{c}\text { Added filter } \\
(\mathrm{mm} \mathrm{Al})\end{array}$ & $\begin{array}{c}\mathrm{HVL} \\
(\mathrm{mm} \mathrm{Al})\end{array}$ & $\begin{array}{c}\mu / \rho \\
\left(\mathrm{cm}^{2} / \mathrm{mg}\right)\end{array}$ & $k_{\mathrm{p}}$ & $k_{\mathrm{a}}$ \\
\hline L10 & 0.0 & 0.029 & 0.0194 & 0.9972 & $k_{\mathrm{a}}=\exp (\mu \mathrm{L})$ \\
$\mathrm{L} 15$ & 0.0 & 0.050 & 0.0125 & 0.9971 & $k_{\mathrm{a}}=\exp (\mu \mathrm{L})$ \\
$\mathrm{H} 10$ & 0.105 & 0.048 & 0.0140 & 0.9975 & $k_{\mathrm{a}}=\exp (\mu \mathrm{L})$ \\
$\mathrm{H} 15$ & 0.500 & 0.152 & & 0.9976 & 1.0245 \\
\hline
\end{tabular}

6.7 Attix (20 kV to $50 \mathrm{kV})$ free-air ionization chamber corrections

The free-air ionization chamber dedicated for use in the mammography calibration range is the Attix chamber, originally designed by Herb Attix [13] in 1961. The chamber was redesigned [14] and constructed for NIST by the University of Wisconsin Radiation Calibration Laboratory in 1994. The Attix chamber, a variable-length, cylindrical free-air chamber differs in design from the other NIST free-air ionization conventional parallel-plate chambers. The differences contribute to its appropriateness as a standard for the measurement of exposure in the mammography energy region. The chamber design allows a measurement procedure that eliminates the need of a correction for field inhomogeneities near the ends of the chamber. This measurement procedure is based on a subtraction method [13], which involves finding the difference in collected charge for different electrode lengths. The variable-volume design also permits the direct measurement of the air attenuation correction, with relative ease. The Attix chamber has been used to verify air attenuation corrections determined previously for some of the tungsten $\mathrm{x}$-ray beams and eventually will be used to determine all air attenuation corrections for the ISO beams, if possible. Laitano and Toni [15] describe the use of this Attix-style free-air chamber as a national $\mathrm{x}$-ray standard for $100 \mathrm{kVp}$ to $250 \mathrm{kVp} \mathrm{x}$-ray beams.

The Attix chamber is designed for energies up to $50 \mathrm{kVp}$. The chamber is composed of an aluminum cylinder with a fixed front plate and a variable position back plate and an off center electrode. The cylinder and back plate are positioned with precision stepping motor controlled slides. For a detailed description of the chamber see Ref. [14]. As with the conventional parallel-plate free-air chambers, corrections to the air kerma measurements are minimized through the design of the chamber, but three corrections are still necessary: air attenuation, photon scatter, and recombination. The air attenuation $k_{\mathrm{a}}$ and photon scatter corrections $k_{\mathrm{p}}$ are listed in Table 6-13. Although the plate separation is variable for the Attix chamber, a fixed airpath length of $21.27 \mathrm{~cm}$ is maintained for all the measurements. Experimental determination of the photon scatter correction for the Attix chamber would be difficult and time consuming, so previous work by V.H. Ritz [4] was used to determine the appropriate correction for the Attix 
chamber for each available aperture. Table 6-13 lists the photon scatter corrections for a $1 \mathrm{~cm}$ aperture. The recombination correction was determined using the procedure suggested by Scott and Greening [9]. The recombination correction is calculated from the following equation where air-kerma rate is in units of $\mathrm{mGy} / \mathrm{s}$ :

$$
k_{s}=1.0002+0.0019 \dot{K},(m G y / s)
$$

Table 6-13. Correction factors for the Attix free-air ionization chamber

\begin{tabular}{|c|c|c|c|c|c|}
\hline $\begin{array}{l}\text { Beam } \\
\text { Code }\end{array}$ & $\begin{array}{c}\text { Half-Value } \\
\text { Layer } \\
(\mathrm{mm} \mathrm{Al})\end{array}$ & $\begin{array}{c}\text { Air Density } \\
\rho \\
(\mathrm{g} / \mathrm{cm} 3)\end{array}$ & $\begin{array}{c}\mu / \rho \\
\left(\mathrm{cm}^{2} / \mathrm{g}\right)\end{array}$ & $\begin{array}{c}\text { Air } \\
\text { Attenuation } \\
\text { Correction } k_{\mathrm{a}}\end{array}$ & $\begin{array}{c}\text { Photon } \\
\text { Scatter } \\
\text { Correction } k_{\mathrm{p}}\end{array}$ \\
\hline $\mathrm{Mo} / \mathrm{Mo} 23$ & 0.271 & $1.179 \mathrm{E}-3$ & 2.0981 & 1.054 & 0.9949 \\
\hline $\mathrm{Mo} / \mathrm{Mo} 25$ & 0.296 & $1.180 \mathrm{E}-3$ & 1.9819 & 1.051 & 0.9950 \\
\hline Mo/Mo28 & 0.332 & $1.181 \mathrm{E}-3$ & 1.8284 & 1.047 & 0.9950 \\
\hline $\mathrm{Mo} / \mathrm{Mo} 30$ & 0.351 & $1.181 \mathrm{E}-3$ & 1.676 & 1.043 & 0.9951 \\
\hline Mo/Mo35 & 0.392 & $1.175 \mathrm{E}-3$ & 1.5693 & 1.04 & 0.9952 \\
\hline $\mathrm{Mo} / \mathrm{Rh} 28$ & 0.408 & $1.184 \mathrm{E}-3$ & 1.5185 & 1.039 & 0.9952 \\
\hline $\mathrm{Mo} / \mathrm{Rh} 32$ & 3445 & $1.185 \mathrm{E}-3$ & 1.4416 & 1.037 & 0.9953 \\
\hline $\mathrm{Mo} / \mathrm{Mo} 25 \mathrm{x}$ & 0.566 & $1.177 \mathrm{E}-3$ & 0.8304 & 1.021 & 0.9955 \\
\hline $\mathrm{Mo} / \mathrm{Mo} 28 \mathrm{x}$ & 0.626 & $1.177 \mathrm{E}-3$ & 0.908 & 1.023 & 0.9956 \\
\hline $\mathrm{Mo} / \mathrm{Mo} 30 \mathrm{x}$ & 0.66 & $1.179 \mathrm{E}-3$ & 0.8287 & 1.021 & 0.9956 \\
\hline $\mathrm{Mo} / \mathrm{Mo} 35 \mathrm{x}$ & 0.748 & $1.177 \mathrm{E}-3$ & 0.7911 & 1.02 & 0.9957 \\
\hline $\mathrm{Rh} / \mathrm{Rh} 25$ & 0.351 & $1.184 \mathrm{E}-3$ & 1.7098 & 1.044 & 0.9951 \\
\hline $\mathrm{Rh} / \mathrm{Rh} 30$ & 0.438 & $1.189 \mathrm{E}-3$ & 1.5134 & 1.039 & 0.9952 \\
\hline $\mathrm{Rh} / \mathrm{Rh} 35$ & 0.512 & $1.187 \mathrm{E}-3$ & 1.2857 & 1.033 & 0.9954 \\
\hline $\mathrm{Rh} / \mathrm{Rh} 40$ & 0.559 & $1.185 \mathrm{E}-3$ & 1.326 & 1.034 & 0.9954 \\
\hline $\mathrm{Rh} / \mathrm{Rh} 30 \mathrm{x}$ & 0.814 & $1.186 \mathrm{E}-3$ & 0.6684 & 1.017 & 0.9958 \\
\hline $\mathrm{Rh} / \mathrm{Rh} 35 \mathrm{x}$ & 0.898 & $1.181 \mathrm{E}-3$ & 0.6709 & 1.017 & 0.9959 \\
\hline
\end{tabular}

The air kerma determination with the Attix chamber involves the collection of charge with various plate configurations. By changing the volume of the Attix chamber and knowing the corresponding change in length of the collecting electrode, the air kerma can be determined with a minimum of two different plate configurations. Although the minimum number of plate configurations needed to determine the air kerma is two, four measurements are conducted, with the fourth being a repeat of the first position. The electrode length is changed by $5 \mathrm{~cm}$ with each 
plate configuration.

For routine measurements, the defining point of the Attix chambcr, is positioncd at onc meter from the focal spot of the X-ray source. However, for the determination of the HVL's and the air attenuation corrections, the defining point of the aperture is positioned at $78.73 \mathrm{~cm}$ and the chamber center at one meter from the focal spot. A constant plate separation and chamber distance from the focal spot is maintained for the HVL measurements. For the air attenuation correction measurements, a fixed plate separation is maintained, while the center of the chambcr is moved back $21.27 \mathrm{~cm}$, the air path length. The air attenuation correction for the Attix chamber, is the ratio of the charge collected when the chamber center is at $100 \mathrm{~cm}$ to the charge at $121.27 \mathrm{~cm}$ from the focal spot. Attachment 3 contains schematics which show the chambcr configuration for HVL and air attenuation measurements and the chamber position for a routinc measurement procedure. The average of the three resulting ratios of the change in charge to change in electrode length is calculated and used in the air kerma calculation as a component of the mass ionization current.

\subsection{Comparison of standard free-air ionization chambers}

The NIST standard free-air chambers have been compared with each other and with the standards of other nations, to test their congruity where their measurement capabilities overlap. The most recent results from the 1998 BIPM-NIST and the 1998 NPL-NIST comparison are listed in Tables 6-14 to 6-18. Complete details including the uncertainties of the comparison can be found in Ref. [16] and [17].

The Attix chamber was indirectly compared to the German national standard, using a NIST reference-class ionization chamber. The measurment of air kerma was made with both the German and the NIST mammography standards and a calibration factor was established for the NIST reference-class ionization chamber at both institutes. The Attix chamber was also compared indirectly through the use of the Ritz chamber at the NPL, Teddington, UK. The results of this indirect comparison are given in Table 6-19.

The latest "in-house" comparison results for the Attix, Lamperti and Ritz chambers are listed in Table 6-20. The Wyckoff-Attix and Ritz chamber comparisons have been conducted periodically since 1958 . The Lamperti and Ritz chambers have been compared numerous times since 1961. From all previous comparisons, the mean difference between the Lamperti and Ritz chambers in the 20 to $50 \mathrm{kV}$ region was found to be less than $0.4 \%$. The mean difference between the Wyckoff-Attix and Ritz chambers was found to be $0.5 \%$ in the region between 60 and $100 \mathrm{kV}$. No adjustment is made for these differences since they are well within the maximum difference of $1.2 \%$ estimated by the ICRU, and the comparisons give no indication which member of the pair is to be considered the more reliable. Before establishing the Attix chamber as a primary standard it was compared to the Ritz and the Lamperti chambers. The complete details of the Ritz to Attix comparison are given in Ref. [18]. The comparison results are listed in Table 6-20 and show agreement to be better than $0.35 \%$. The unpublished comparison results of the Lamperti to the Attix chamber are also listed. 
Table 6-14. Results of the comparison of the Lamperti standard with the BIPM standard

\begin{tabular}{ccc}
\hline \hline $\begin{array}{c}\text { Generating potential } \\
(\mathrm{kV})\end{array}$ & $\begin{array}{c}\text { Half-value layer } \\
(\mathrm{mm} \mathrm{Al})\end{array}$ & $\begin{array}{c}\text { NIST/BIPM } \\
1998\end{array}$ \\
\hline 10 & 0.036 & 0.9950 \\
30 & 0.176 & 0.9961 \\
25 & 0.250 & 0.9968 \\
$50(\mathrm{~b})$ & 1.021 & 0.9948 \\
$50(\mathrm{a})$ & 2.257 & 0.9938 \\
\hline
\end{tabular}

Table 6-15. Results of the comparison of the Ritz standard with the BIPM standard

\begin{tabular}{ccc}
\hline $\begin{array}{c}\text { Generating potential } \\
(\mathrm{kV})\end{array}$ & $\begin{array}{c}\text { Half-value layer } \\
(\mathrm{mm} \mathrm{Al})\end{array}$ & $\begin{array}{c}\text { NIST/BIPM } \\
1998\end{array}$ \\
\hline 30 & 0.176 & 0.9943 \\
25 & 0.250 & 0.9949 \\
$50(\mathrm{~b})$ & 1.021 & 0.9938 \\
$50(\mathrm{a})$ & 2.257 & 0.9956 \\
80 & 3.01 & 0.9902 \\
100 & 4.00 & 0.9947 \\
\hline
\end{tabular}

Table 6-16. Comparison of the Lamperti chamber to the $50 \mathrm{kV}$ NPL standard

\begin{tabular}{ccc}
\hline \hline $\begin{array}{c}\text { Generating potential } \\
(\mathrm{kV})\end{array}$ & $\begin{array}{c}\text { Half-value layer } \\
(\mathrm{mm} \mathrm{Al})\end{array}$ & $\begin{array}{c}\text { NIST/BIPM } \\
1998\end{array}$ \\
\hline 10 & 0.036 & 0.9951 \\
11.5 & 0.05 & 1.0006 \\
14 & 0.07 & 0.9996 \\
16 & 0.1 & 0.9995 \\
20 & 0.15 & 0.9992 \\
\hline
\end{tabular}


Table 6-17. Comparison of the Ritz chamber to the NPL $50 \mathrm{kV}$ standard

\begin{tabular}{ccc}
\hline \hline $\begin{array}{c}\text { Generating potential } \\
(\mathrm{kV})\end{array}$ & $\begin{array}{c}\text { Half-value layer } \\
(\mathrm{mm} \mathrm{Al})\end{array}$ & $\begin{array}{c}\text { NIST/BIPM } \\
1998\end{array}$ \\
\hline 20 & 0.15 & 0.9977 \\
24 & 0.25 & 0.9978 \\
34 & 0.35 & 0.9989 \\
41 & 0.5 & 0.9973 \\
44 & 0.7 & 0.9983 \\
50 & 1.0 & 0.9983 \\
\hline
\end{tabular}

Table 6-18. Comparison of the Ritz chamber to the NPL $300 \mathrm{kV}$ standard

\begin{tabular}{ccc}
\hline \hline $\begin{array}{c}\text { Generating potential } \\
(\mathrm{kV})\end{array}$ & $\begin{array}{c}\text { Half-value layer } \\
(\mathrm{mm} \mathrm{Al})\end{array}$ & $\begin{array}{c}\text { NIST/BIPM } \\
1998\end{array}$ \\
\hline 50 & 1 & 0.9981 \\
80 & 2.9 & 0.9941 \\
\hline
\end{tabular}

Table 6-19. Comparison results for the mammography standard

\begin{tabular}{cccc}
\hline \hline Beam Quality & $\begin{array}{c}\text { Half-value layer } \\
(\mathrm{mm} \mathrm{Al})\end{array}$ & NIST/PTB $^{\mathrm{a}}$ & NIST/NPL $^{\mathrm{b}}$ \\
\hline Mo/Mo25 & 0.296 & 1.005 & 0.996 \\
Mo/Mo28 & 0.332 & & \\
Mo/Mo30 & 0.351 & 0.999 & \\
Mo/Mo35 & 0.392 & 1.002 & 0.994 \\
Mo/Mo25x & 0.566 & 0.999 & \\
Mo/Mo28x & 0.626 & & \\
Mo/Mo30x & 0.660 & 1.005 & \\
Mo/Mo35x & 0.748 & 1.004 & \\
\hline
\end{tabular}

a These results were obtained through the use of a transfer standard ionization chamber.

b These results were obtained through the use of the Ritz chamber and transfered to the Attix chamber. 
Table 6-20. Recent "in-house" comparisons standards

\begin{tabular}{cccc}
\hline \hline Beam quality & Half-value layer & Ritz/Attix & Lamperti/Attix \\
\hline Mo/Mo23 & 0.271 & 0.998 & \\
Mo/Mo25 & 0.296 & 0.997 & 0.998 \\
Mo/Mo28 & 0.332 & 0.997 & 0.999 \\
Mo/Mo30 & 0.351 & 0.999 & 0.997 \\
Mo/Mo35 & 0.392 & 0.998 & 0.998 \\
Mo/Rh28 & 0.408 & 0.997 & \\
Mo/Rh32 & 0.445 & 0.997 & \\
Mo/Mo25x & 0.566 & 1.001 & \\
Mo/Mo28x & 0.626 & 1.001 & \\
Mo/Mo30x & 0.66 & 1.001 & $1.003^{\mathrm{a}}$ \\
Mo/Mo35x & 0.748 & 1.000 & \\
Rh/Rh25 & 0.351 & 0.997 & $1.004^{\mathrm{a}}$ \\
Rh/Rh30 & 0.438 & 0.997 & \\
Rh/Rh35 & 0.512 & $0.999^{\mathrm{a}}$ \\
Rh/Rh40 & 0.559 & 0.999 & \\
Rh/Rh30x & 0.814 & 0.998 & \\
Rh/Rh35x & 0.898 & 1.000 & \\
L15 & 0.057 & 1.000 & \\
L20 & 0.071 & 0.999 & \\
M20 & 0.152 & 1.002 & \\
L30 & 0.22 & & \\
M30 & 0.36 & 000 & \\
M40 & 0.73 & \\
M50 & 0.09 & \\
\hline
\end{tabular}

${ }^{a}$ This is a comparison of the Lamperti chamber to the Ritz chamber using the new tungsten lowenergy $x$-ray tube. 
7.0 Gamma-ray air kerma standards and calibration ranges

There are seven gamma-ray sources available for the calibration of instruments for the quantity of air kerma and for delivering known exposures to passive dosimeters. The sources are collimated and the beams have been calibrated using the appropriate graphite cavity ionization chamber standard. These chambers have precisely known volumes, so that when exposed to a gamma-ray beam they define the ionization per unit volume of air and, with suitable corrections for wall absorption and other perturbations, the collected charge can be interpreted directly in terms of air kerma.

\subsection{Cavity-chamber standards}

The cavity chambers, used for studies leading to the revised, May $1,1972,{ }^{60} \mathrm{Co}$ and ${ }^{137} \mathrm{Cs}$ air kerma-rate standards, were fabricated from reactor-grade, high-purity graphite, following the design of Wyckoff [19]. A spherical shape was chosen in order to allow the standards to be based on a homogeneous group of chambers of different volumes. The spherical shape also reduces the effect of distance errors and the complexity of set-up for measurements with cylindrical chambers. Additionally, the spherical shape presents a uniform, symmetrical, chamber aspect to the source. The chambers have been carefully compared in the gamma-ray beams, and the NIST standard of air kerma for these radiations is the mean response of seven spherical graphite cavity chambers. The dimensions of the spherical chambers are given in Table 7-1. Additional details on the construction and corrections for these cavity chambers are contained in a report by Loftus and Weaver [20].

Table 7-1. Dimensions of spherical graphite ionization chambers

\begin{tabular}{ccccccc}
\hline $\begin{array}{c}\text { Nominal } \\
\text { volume } \\
\left(\mathrm{cm}^{3}\right)\end{array}$ & Volume & $\begin{array}{c}\text { Net } \\
\text { volume }\end{array}$ & $\begin{array}{c}\text { Outside } \\
\text { diameter }\end{array}$ & $\begin{array}{c}\text { Graphite } \\
\text { density }\end{array}$ & Radial wall thickness \\
\hline 0.5 & 0.440 & 0.431 & 2.078 & 1.72 & 0.563 & 0.968 \\
1 & 1.140 & 1.131 & 2.065 & 1.73 & 0.398 & 0.688 \\
2 & 2.029 & 2.019 & 2.080 & 1.74 & 0.246 & 0.428 \\
10 & 10.088 & 10.069 & 3.428 & 1.72 & 0.3755 & 0.647 \\
30 & 30.262 & 30.24 & 4.607 & 1.74 & 0.3751 & 0.653 \\
$50-1$ & 51.943 & 51.634 & 5.34 & 1.73 & 0.3652 & 0.632 \\
$50-2$ & 50.425 & 50.089 & 5.58 & 1.73 & 0.5085 & 0.880 \\
$50-3$ & 50.460 & 50.155 & 5.80 & 1.73 & 0.6129 & 1.060 \\
\hline
\end{tabular}




\subsection{Gamma-ray sources}

The location, nominal activity, and orientation of the gamma-ray sources used for instrument calibrations are given in Table 7-2. Figure 7-1 is a schematic of a irradiator housing a ${ }^{60} \mathrm{Co}$ gamma-ray source typical of the horizontal gamma-ray source geometries used at NIST.

Table 7-2. Gamma-ray source locations and nominal activities of sources as of January 1, 1999

\begin{tabular}{ccll}
\hline \hline Radionuclide & $\begin{array}{c}\text { Activity } \\
(\mathrm{bq})\end{array}$ & Location & Orientation \\
\hline${ }^{60} \mathrm{Co}$ & $2.7 \mathrm{E} 13$ & $\mathrm{~B} 034$ & vertical \\
${ }^{60} \mathrm{Co}$ & $1.5 \mathrm{E} 14$ & $\mathrm{~B} 036$ & vertical \\
${ }^{60} \mathrm{Co}$ & $1.3 \mathrm{E} 11$ & $\mathrm{~B} 021 \mathrm{~B}$ & horizontal \\
${ }^{60} \mathrm{Co}$ & $9.6 \mathrm{E} 09$ & $\mathrm{~B} 015 \mathrm{~B}$ & horizontal \\
${ }^{137} \mathrm{Cs}$ & $3.1 \mathrm{E} 13$ & $\mathrm{~B} 036$ & vertical \\
${ }^{137} \mathrm{Cs}$ & $5.8 \mathrm{E} 12$ & $\mathrm{~B} 021 \mathrm{~A}$ & horizontal \\
${ }^{137} \mathrm{Cs}$ & $6.3 \mathrm{E} 11$ & $\mathrm{~B} 015 \mathrm{~A}$ & horizontal \\
\hline
\end{tabular}

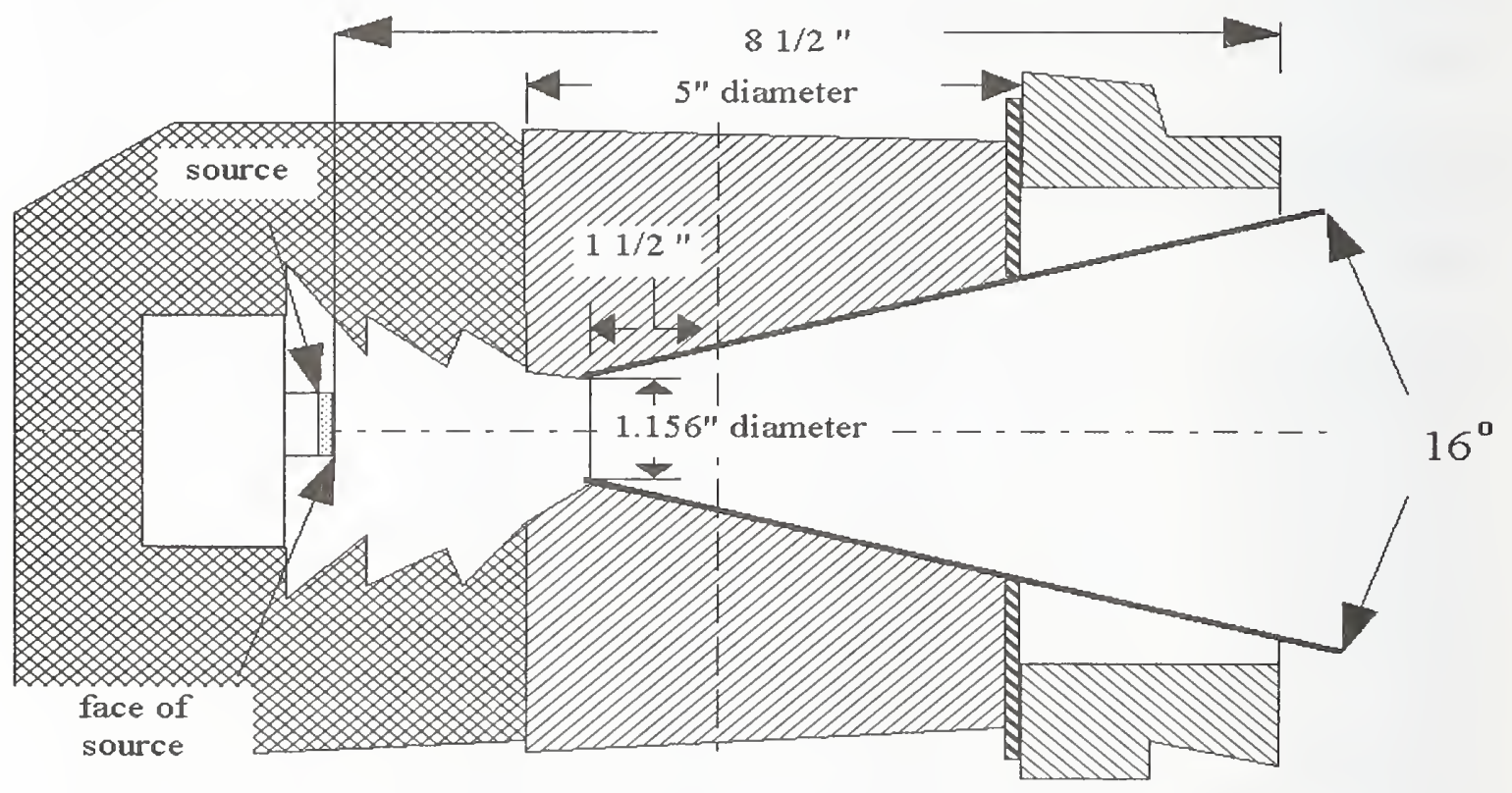

Fig. 7-1. Port detail for horizontal ${ }^{60} \mathrm{Co} 5 \mathrm{~mm}$ diameter source. 


\subsection{Calibration of gamma-ray beams}

The horizontal beam calibration ranges were calibrated at various distances from the sources. The data were fit to a suitable function which allows accurate computation of air kerma rates at selected distances, or of distances for selected air kerma rates. The equation used for this purpose was derived by using the inverse square law with correction for air attenuation and buildup. The equation that was found to adequately predict the air kerma rate to within a few hundredths of one percent at the time of the calibration was in the following form:

$$
\dot{X} D^{2}=K_{1}\left(1+K_{2} D+K_{3} D^{2}+K_{4} D^{3}\right)
$$

where

$$
D=S+S_{0}
$$

and $S$ is the distance from the source to the reference point of the chamber, as read on a scale mounted on an aluminum channel. The $S_{o}$ are offset distances, for each source, introduced to improve the fit of the data to the polynomial in $D$. In practice, the equation is solved for air kerma rate by rearranging the equation as follows:

$$
\dot{X}=\left(A / D^{2}+B / D+C+E D\right) e^{-\lambda T}
$$

where $\lambda$ is the decay constant for the radionuclide, and $T$ is the elapsed time in days since the source was calibrated. Tables of exposure and air-kerma rate for days of decay are available outside each source room. The constants used in equations 7-1 and 7-3 appear in Table 7-3. The constant $E$ used in equation 7-3 is zero for the horizontal gamma sources. The data for the ${ }^{60}$ Co sources in Table 7-3 are derived from the data in table 17 of Loftus and Weaver [20]. Checks on the calibration of these sources through the years show them to be unchanged.

\begin{tabular}{|c|c|c|c|c|c|}
\hline $\begin{array}{c}\text { Source } \\
\text { (Location) }\end{array}$ & $\begin{array}{c}\mathrm{A} \\
\mathrm{K}_{1} \\
\mathrm{~m}^{2} \cdot \mathrm{mR} / \mathrm{s}\end{array}$ & $\begin{array}{c}\mathrm{B} \\
\mathrm{K}_{2} \\
10^{2} \\
\mathrm{~m} \cdot \mathrm{mR} / \mathrm{s}\end{array}$ & $\begin{array}{c}\mathrm{C} \\
\mathrm{K}_{3} \\
10^{4} \mathrm{mR} / \mathrm{s}\end{array}$ & $\begin{array}{c}S_{o}{ }^{\mathrm{b}} \\
\mathrm{K}_{4} \\
10^{2} \mathrm{~m}\end{array}$ & $\begin{array}{c}\lambda^{\mathrm{c}} \\
\mathrm{K}_{5} \\
10^{5} \mathrm{~d}^{-1}\end{array}$ \\
\hline $\mathrm{Cs}^{137}(\mathrm{~B} 015 \mathrm{~A})$ & 2.0323 & -0.943 & -1.8619 & -0.818 & 6.326 \\
\hline $\mathrm{Cs}^{137}(\mathrm{~B} 021 \mathrm{~A})$ & 19.617 & -13.84 & 123.24 & -0.304 & 6.326 \\
\hline $\mathrm{Co}^{60}(\mathrm{~B} 015 \mathrm{~B})$ & 0.5924 & -0.1657 & -1.345 & -0.144 & 36.010 \\
\hline $\mathrm{Co}^{60}(\mathrm{~B} 021 \mathrm{~B})$ & 5.2676 & 0.4764 & 67.33 & -0.528 & 36.010 \\
\hline
\end{tabular}

Table 7-3. Constants ${ }^{\mathrm{a}}$ for computing exposure rate corrected for decay for the horizontal beam sources

${ }^{\mathrm{a}}$ The constant $\mathrm{E}$ equals zero for these four sources.

${ }^{\text {b }}$ The constant $S_{o}$ is the offset distance so distance equals the scale reading plus $S_{o}$.

${ }^{c}$ The reference date is December 31, 1984. See Ref. [7] of Attachment 2.

Calibrations of the vertical-beam sources are limited to one or two sets of conditions. For the 
${ }^{60} \mathrm{Co}$ source located in $\mathrm{B} 034$, the reference distance on the Al-channel mounted scale is $100 \mathrm{~cm}$. The offset of the scale-zero from the source center is $47.9 \mathrm{~cm}$. The highest activity ${ }^{60} \mathrm{Co}$ source available for calibration work is located in B036. At the end of 1989, the effective activity of the source was about $444 \mathrm{~T} \mathrm{~Bq}$ The source was calibrated early in 1990 using the standard graphite ionization chambers. The mean of those measurements corrected for decay is used at the present time. As shown in Table 7-4, a later measurement using the $10 \mathrm{~cm}^{3}$ standard chamber checked the original data.

Table 7-4. Data a and positioning for calibration of vertical-beam gamma-ray sources in room B036

\begin{tabular}{|c|c|c|c|c|c|c|}
\hline \multirow[t]{2}{*}{ Source } & \multirow{2}{*}{$\begin{array}{c}\text { Distance }^{\mathrm{b}} \\
(\mathrm{cm})\end{array}$} & \multirow[t]{2}{*}{$\begin{array}{l}\text { Collimator } \\
\text { setting }\end{array}$} & \multicolumn{3}{|c|}{$\begin{array}{c}\text { Standard chamber and air-kerma } \\
\text { rate } \\
(\mathrm{mGy} / \mathrm{s})\end{array}$} & \multirow[t]{2}{*}{$\begin{array}{c}\text { Calibration } \\
\text { air-kerma rate } \\
(\mathrm{mGy} / \mathrm{s})\end{array}$} \\
\hline & & & $1 \mathrm{~cm}^{3}$ & $10 \mathrm{~cm}^{3}$ & $1-50 \mathrm{~cm}^{3}$ & \\
\hline${ }^{60} \mathrm{Co}$ & 105 & $6 \times 6$ & 4.122 & 4.110 & & 4.117 \\
\hline${ }^{60} \mathrm{Co}$ & 105 & $6 \times 6$ & & 4.109 & & \\
\hline${ }^{137} \mathrm{Cs}$ & 55 & $8 \times 8$ & 0.9233 & & & \\
\hline${ }^{137} \mathrm{Cs}$ & 55 & $8 \times 8$ & 0.9223 & & & \\
\hline${ }^{137} \mathrm{Cs}$ & 55 & $8 \times 8$ & 0.9236 & $(0.9167)$ & $(0.9101)$ & 0.9236 \\
\hline${ }^{137} \mathrm{Cs}$ & 55 & $15 \times 15$ & 0.9517 & & 0.9499 & 0.9508 \\
\hline${ }^{137} \mathrm{Cs}$ & 55 & $15 \times 15$ & 0.9497 & 0.9461 & & \\
\hline${ }^{137} \mathrm{Cs}$ & 38 & $10.5 \times 10.5$ & 1.467 & & & \\
\hline
\end{tabular}

${ }^{a}$ All data is corrected to December 31, 1989, see Ref. [8] of Attachment 2. No data is included for the source in B034 because the source was replaced in the last quarter of 1999 and new parameters have been established.

${ }^{\mathrm{b}}$ Aluminum channel scale.

The ${ }^{137} \mathrm{Cs}$ vertical-beam source in Room B036 is calibrated for several collimator setting and distance conditions. The calibrations rely mainly on measurements with the $1 \mathrm{~cm}^{3}$ standard chamber although some measurements with the $10 \mathrm{~cm}^{3}$ and a $50 \mathrm{~cm}^{3}$ chamber have also been tried. Some of the $10 \mathrm{~cm}^{3}$ and a $50 \mathrm{~cm}^{3}$ data in Table $7-4$ are parenthesized to indicate that they are not included in the source calibration. These data are included in Table 7-4 to call attention to the need for further study of the measurement problems encountered, and data accumulated, over a period of several years for this source. For example, the agreement between the $1 \mathrm{~cm}^{3}$ chamber and a $50 \mathrm{~cm}^{3}$ chamber measurement for the $15 \times 15$ collimator setting show that the standards are consistent for the large field size.

In the course of using the graphite standard ionization chambers for NIST and other-agency source calibrations, the electrodes in the chambers have either loosened and shorted to the chamber wall or excessive voltage has been applied. When this occurs, the 
electrodes are weakened and carbon is deposited on the high-voltage insulator. The $1 \mathrm{~cm}^{3}, 10$ $\mathrm{cm}^{3}$ and $30 \mathrm{~cm}^{3}$ chambers are particularly prone to this problem since the electrodes have diameters less than $1 \mathrm{~mm}$ and, with the present stem design, are difficult to anchor securely in position. It has been necessary on several occasions to straighten or replace these electrodes and to clean or replace the high-voltage insulators and chamber stems. Subsequent checks of source calibrations, in particular using the $1 \mathrm{~cm}^{3}$ chamber, indicate that the relationship of that chamber to the others, established under ideal conditions in 1972, may no longer hold. Measurements of the high-air kerma-rate sources after the last repair of the $1 \mathrm{~cm}^{3}$ chamber were several tenths of one percent higher than the reference data. This is shown to some extent in Table 7-4 where the latest data taken on the ${ }^{137} \mathrm{Cs}$ source for the $8 \times 8$ collimator setting is higher than the previous measurements. Some $1 \mathrm{~cm}^{3}$ chamber exposure data not included in Table 7-4 indicate a difference between present and earlier measurements of as much as $0.4 \%$. On the other hand, measurements at low air kerma rates at 1 meter from the ${ }^{137} \mathrm{Cs}$ source in $\mathrm{Rm}$ B021A show agreement between the $1 \mathrm{~cm}^{3}$ standard and a $50 \mathrm{~cm}^{3}$ or the $10 \mathrm{~cm}^{3}$ standard to be within $0.02 \%$ and $0.01 \%$ respectively. See Ref. [9] of Attachment 2. The net cavity volume for the $1 \mathrm{~cm}^{3}$ chamber was measured to be $1.1297 \mathrm{~cm}^{3}$ following the last repair, which involved the replacement of electrode and refurbishment of the high voltage electrode. See Ref. [10] of Attachment 2.

The main difficulty in reproducing air kerma calibration data involves the $1 \mathrm{~cm}^{3}$ chamber. A small-volume standard chamber is required for high air kerma rate measurements, and in beams that may be uniform only over small areas. See Ref. [11] of Attachment 2 for details. However, small-volume chambers have unwanted extra-cameral volumes in the vicinity of the high voltage insulator and stems that can have a large effect on the chamber response to radiation, therefore data is taken at both polarities. Additional difficulties of another sort arise in comparing data over a period of years when different measurement equipment may be used, see for example Ref. [12] of Attachment 2. The uncertainty statement given by Loftus and Weaver [20] is only representative in the short term and for optimum conditions. In order to maintain the overall uncertainty of $0.7 \%$, the primary standards are carefully preserved and not used as working standards.

\subsection{Useful beam size}

The "useful beam" radius for the gamma-ray sources is defined as the distance from the center of a radiograph of the beam to the point where the density of the film is $90 \%$ of the center density, minus the difference in distance between the $90 \%$ and $50 \%$ density measurements. With $\mathrm{R}_{90}$, the radius of the $90 \%$ density contour, and $\mathrm{R}_{50}$, the radius of the $50 \%$ density contour, the useful beam radius (UB) is computed as follows:

$$
\begin{gathered}
R_{50}=K 6 \times S D+K 7 \\
R_{90}=K 8 \times S D+K 9 \\
U B=R_{90}-\left(R_{50}-R_{90}\right) \\
U B=2 R_{90}-R_{50}
\end{gathered}
$$


In the above equations, the K's are constants and the SD is the aluminum channel scale reading in $\mathrm{cm}$. The constants for each source are listed in Table 7-5. Radiographs of these beams indicate a "hot" spot in the center so a conservative computation for the useful beam is justified. The vertical-beam sources are calibrated at distances listed in Table 7-4 thus the constants K6 and $\mathrm{K} 8$ in Table 7-5 are set to zero. The useful beam radii for these sources is very small, less than $2 \mathrm{~cm}$ for the ${ }^{137} \mathrm{Cs}$ source and $2.5 \mathrm{~cm}$ for the ${ }^{60} \mathrm{Co}$ source.

Table 7-5. Constants for computing useful beam radii for the horizontal and vertical beam calibration ranges

\begin{tabular}{cccccccc}
\hline \hline $\begin{array}{c}\text { Scale } \\
\text { Distance } \\
(\mathrm{cm})\end{array}$ & Source & Location & K6 & K7 & K8 & K9 & $\begin{array}{c}\text { Useful } \\
\text { beam size } \\
(\mathrm{cm})\end{array}$ \\
\hline variable & ${ }^{137} \mathrm{Cs}$ & $\mathrm{B} 015 \mathrm{~A}$ & 0.188 & 0.613 & 0.143 & 0.044 & variable \\
variable & ${ }^{60} \mathrm{Co}$ & $\mathrm{B} 015 \mathrm{~B}$ & 0.157 & 0.237 & 0.112 & -0.106 & variable \\
variable & ${ }^{137} \mathrm{Cs}$ & $\mathrm{B} 021 \mathrm{~A}$ & 0.207 & 0.235 & 0.149 & -1.068 & variable \\
variable & ${ }^{60} \mathrm{Co}$ & $\mathrm{B} 021 \mathrm{~B}$ & 0.191 & 0.682 & 0.124 & -0.236 & variable \\
38 & ${ }^{137} \mathrm{Cs}$ & $\mathrm{B} 036$ & 0 & 6.8 & 0 & 4.3 & 1.8 \\
55 & ${ }^{137} \mathrm{Cs}$ & $\mathrm{B} 036$ & 0 & 6.4 & 0 & 4.05 & 1.7 \\
105 & ${ }^{60} \mathrm{Co}$ & $\mathrm{B} 036$ & 0 & 6.3 & 0 & 4.4 & 2.5 \\
100 & ${ }^{60} \mathrm{Co}$ & $\mathrm{B} 034$ & 0 & 6.8 & 0 & 4.7 & 2.6 \\
\hline
\end{tabular}

Instruments designed for measurement of high-exposure-rate beams are often sensitive to beam size. This effect occurs because the small-volume chambers, used primarily to minimize ion recombination, are subject to the influence of extra-cameral and insulator "soakage" effects, which can constitute a significant fraction of the chamber reading.

Some instruments showing the stem effect are the NPL $0.2 \mathrm{~cm}^{3}$ and the Farmer-NEL 0.6 $\mathrm{cm}^{3}$ chambers, and Victoreen chambers of 100-R range and higher. The difference in calibration factors for a Victoreen 100-R chamber, depending on whether or not its stem is protected from radiation, may be as much as $4 \%$. In order to insure that sensitive chamber stems are protected, calibrations of high-exposure-rate chambers are performed only for certain distance and collimator conditions. These conditions are purposely few in number to reduce the primary standardization work required and to minimize the possibility of error in setup. The beams are nominally square and the dimensions have been determined using radiographic film. The $50 \%$ density contour is taken as defining the beam size for this purpose. The data are given in Table $7-6$. 
Table 7-6. Beam size defined by 50\% radiographic density contour for vertical-beam gammaray sources, for specific collimator settings

\begin{tabular}{ccccc}
\hline \hline Source & $\begin{array}{c}\text { Room } \\
\text { Location }\end{array}$ & $\begin{array}{c}\text { Scale } \\
\text { Distance } \\
(\mathrm{cm})\end{array}$ & $\begin{array}{c}\text { Collimator } \\
\text { settings } \\
\left(\mathrm{cm}^{2}\right)\end{array}$ & $\begin{array}{c}\text { Beam } \\
\text { size } \\
(\mathrm{cm})\end{array}$ \\
\hline${ }^{137} \mathrm{Cs}$ & $\mathrm{B} 036$ & 38 & $10.5 \times 10.5^{\mathrm{a}}$ & $13.6 \times 13.6$ \\
${ }^{137} \mathrm{Cs}$ & $\mathrm{B} 036$ & 55 & $8 \times 8^{\mathrm{a}}$ & $12.8 \times 12.8$ \\
${ }^{60} \mathrm{Co}$ & $\mathrm{B} 036$ & 105 & $6 \times 6$ & $12.6 \times 12.6$ \\
${ }^{60} \mathrm{Co}$ & $\mathrm{B} 034$ & 100 & $6 \times 6^{\mathrm{b}}$ & $6.8 \times 6.8$ \\
\hline \multicolumn{5}{c}{ Approximate settings determined by gauge blocks. } \\
& ${ }^{\mathrm{b}}$ On 100 cm source distance scale in room B034.
\end{tabular}

8.0. Ionization-chamber current-measurement techniques

\subsection{Background and history}

Ionization currents in air-kerma standardization measurements are produced by the irradiation of a gas in an ionization chamber. The ionization chamber may be a free-air chamber, such as one of the national standard chambers, or a cavity chamber, where the gas is surrounded by some wall material. Ionization chambers, regardless of type, consist of electrodes that are insulated from one another and that are polarized in order to collect charge produced in the gas. The ions produced in the air by the beam are swept from the chamber volume by the electric field between the electrodes.

In the normal course of events in dosimetry measurements, ionization currents very rarely reach $50 \mathrm{nA}$. In an ideal ionization chamber, an air-kerma rate of about $9 \mathrm{mGy} / \mathrm{s}$ will produce about $0.3 \mathrm{nA} / \mathrm{cm}^{3}$. Included in the measurement of these currents are currents not produced by the radiation of interest, but by background radiation and insulator leakage. The magnitude and sign of these extraneous currents must be determined and the measured current corrected for their effects in order to determine the true ionization current. The importance of the correction for background and leakage is, of course, relative to the magnitude of the ionization current but good measurement technique requires, prior to attempting radiation measurements, that the background and leakage currents be determined. As a rule of thumb, and without taking special precautions, the leakage current for a good quality ionization chamber should be less than $5 \mathrm{fA}$. The measurement of leakage currents will also include currents due to background radiation so the environment and special circumstances must be considered in evaluating data. For example, if tests are made on a large-volume ionization chamber in a background environment found suitable for small-volume chambers, the extra sensitivity of the large chamber requires separate evaluation of the background environment. For background information on the history of electrometer use refer to Attachment 4. 


\subsection{Electrometers}

The Keithley Model 616 electrometer ${ }^{1}$ was used for many years by the NIST Radiation Interactions and Dosimetry Group due to the versatility and the ability to use external calibrated capacitors. Keithley offers several other models, the 617 and the 6512 , that provide the appropriate features for NIST calibration work. The Radiation Interactions and Dosimetry Group has used NIST calibrated air-dielectric capacitors of nominal capacitance, $100 \mathrm{pF}$ and $1000 \mathrm{pF}$, and good quality $10 \mathrm{nF}$ and $100 \mathrm{nF}$ polystyrene capacitors in a chassis, which were then mounted with electrometers in measurement consoles containing other control and measurement equipment. In recent years, the Keithley $617,617-\mathrm{HiQ}$ and the 6512 with their internal capacitors have been integrated into the measurement control systems, where at one point only Keithley 616 and 642 resided. The accuracy and stability for data collected with the internal capacitors of the newer electrometers in the charge mode, eliminates the need for external capacitors. These electrometers are routinely calibrated using the NIST calibrated capacitors. This is discussed in a later section.

\subsection{Ionization current measurement-console equipment}

$\mathrm{X}$ - and gamma-ray-produced ionization currents are, for the most part, measured automatically, although capability exists to use manual methods. Due to recent upgrades, there are two types of data acquisition systems (DAS) in use in the x-ray and gamma-ray calibration ranges. One system is used exclusively for measurements made with the x-ray sets and the second is a portable system used for measurements made with the gamma-ray sources.

\subsubsection{X-ray calibration data acquisition system}

Data are acquired for $\mathrm{x}$-ray standardization by measurement of all conditions relevant to establishing the $\mathrm{x}$-ray air-kerma rate at a particular distance from the $\mathrm{x}$-ray tube target. The data acquired consists of data for the computation of ionization currents, parameter data, and measurement system test and information data. Data used to determine the ionization currents includes the electrometer charge measurements, the atmospheric pressure and pertinent air temperatures, and the shutter-open time interval. The parameter data includes the $\mathrm{x}$-ray tube current and potential, the x-ray tube target-to-reference point distance, and the beam defining filter thickness and the diaphragm diameters. Test data includes the measurements of the collection potentials on the standard free-air chamber, the monitor chamber, and the chamber being calibrated, if appropriate. All data is acquired through National Instrument's LabView interfacing. All charge measurements are corrected for the temperature and pressure at the time of the charge collection.

The temperature sensors in the $300-\mathrm{kV}$ range used to measure room, free-air chamber, and monitor air temperatures are two-wire thermistors manufactured by Yellow Springs Inc.

\footnotetext{
${ }^{1}$ Certain commercial equipment, instruments, or materials are identified in this paper to foster
} understanding. Such identification does not imply recommendation or endorsement by the National Institute of Standards and Technology, nor does it imply that the materials or equipment identified are necessarily the best available for the purpose. 
(YSI). The sensors are connected to YSI model 43TN readouts. The YSI readout is a bridge circuit which, when unbalanced, provides a voltage proportional to the temperature. There are four YSI temperature probes used in conjunction with measurements on the $100 \mathrm{kV}$ calibration range. The thermistors for the Ritz free-air ionization chamber and the Lamperti free-air ionization chamber are manually switched to a single YSI readout. The parameters of the calibration equations for some of these probes are found in Table 8-1. These probes are calibrated at least annually and the required fit parameters are entered into the data acquisition software. Shown in Table 8-1. are the most recent parameters. In the Mammography Facility the Hart 5613 platinum resistance thermometers and Hart 1502 digital thermometers are used for air temperature measurements in the vicinity of the Attix free-air chamber, the monitor chamber and the test chambers. The calibration correction is applied internally to the 1502 digital meters therefore no calibration equation is given here.

The atmospheric pressure for the low and high-energy tungsten sets is measured by the Setra digital barometer and powered by a NIST power supply serial no. 2561. The output voltage is calibrated for pressure measurements in units of millimeters of $\mathrm{Hg}$. A conversion to the unit of pascal is applied in the calculation of the calibration factor. The equation used for computing the pressure is:

$$
P(m m H g)=-3.483+94.336(\text { voltage })
$$

In the mammography range, a Setra 370 barometer is interfaced through RS232 to the data acquisition software. Any necessary correction is applied directly through software as part of the air kerma calculation.

The low-energy Pantak generator was calibrated in December of 1.997 and the highenergy Pantak in February of 1998, using a calibrated (Test No. 722/G44568) high-voltage divider (Seifert Voltage Divider SN 720479). The procedure for a voltage calibration requires the use of the calibrated voltage divider, a calibrated high precision digital multimeter, and a 10 $000 \mathrm{ohm}$ resistor. The Pantak high resolution voltage display reading, corresponding to the calibrated tube voltage was also determined. Since the calibrations showed some dependence of the voltage on the tube current, the results are given as a function of current for each tube voltage setting. Found in Tables 8-2 and 8-3 are the parameters of each linear fit $(y=m x+b)$ where $x$ is the display reading of the HP voltmeter used to monitor $x$-ray tube current and $y$ is the ratio used to calculate the appropriate voltage HP voltmeter display for the desired nominal voltage.

The tube voltage of the mammography $\mathrm{x}$-ray system has been measured using a Dynalzer voltage divider, and verified with spectrometer measurements. No adjustment is required to be made to the MPl controller $\mathrm{kV}$ display. Without an available NIST calibrated voltage divider, the tube voltage has been established to within $\pm 50 \mathrm{eV}$ of the display setting to the best of our ability.

All time signals are controlled by a National Instrument data acquisition card which contains two 24-bit, $20 \mathrm{MHZ}$ counters/timers. The signal to the timers is a pulse produced by a photodiode when its light beam is interrupted by a flag on the shutter mechanism. Upon initiating the exposure, counting commences only on receipt of the photodiode pulse. At the end of the preset time interval, the shutter is caused to close but the clock continues to count until the edge of the shutter crosses the portal mid-point. The timing shutter operation in both the $100 \mathrm{kV}$ and the $300 \mathrm{kV}$ x-ray range has recently been modified to use air cylinder controlled solonoids. The $300 \mathrm{kV}$ machine also has a safety shutter which opens before, and closes after, the timing 
shutter. The lead thickness in the timing shutter was minimized for mechanical purposes but is of sufficient thickness to prevent significant effects on instrument readings in the interval between operation of the two shutters.

The charge measurements are acquired through the use of Keithley 617, 617-HiQ and 6512 electrometers. The internal capacitors of the electrometers are calibrated annually and any necessary correction is applied as part of the air kerma calculation. Five electrometers, three 6512 and two 617-HiQ, are maintained for use in the low and high-energy range. Four electrometers are maintained in the mammography range, two standard capacitance range electrometers $(20 \mathrm{nC})$, a $617 \mathrm{HIQ}(20 \mu \mathrm{C})$, and a midrange $617(200 \mathrm{nC})$. The HIQ is dedicated for use with the monitor chamber and the midrange 617 is used for collecting charge on the Attix chamber. The two $20 \mathrm{nC}$ capacitance range electrometers are used for the customer chambers.

Table 8-1. Parameters of the straight line fits for the temperature probe calibrations used in the $\mathrm{x}$-ray ranges

\begin{tabular}{lcc}
\hline \hline \multicolumn{1}{c}{$\begin{array}{c}\text { Temperature probe } \\
\text { location }\end{array}$} & slope $^{\mathrm{a}}$ & intercept $^{\mathrm{a}}$ \\
\hline Wyckoff-Attix chamber & -101.384 & 30.252 \\
$300 \mathrm{kV}$ Test chamber & -101.904 & 31.246 \\
Lamperti chamber & -92.611 & 28.740 \\
Ritz chamber & -100.007 & 29.540 \\
$100 \mathrm{kV}$ Test chamber & -105.031 & 30.766 \\
\hline
\end{tabular}

${ }^{a}$ Parameters from calibration performed in September of 1999 .

Table 8-2. Low-energy Pantak unit voltage calibration

\begin{tabular}{ccc}
\hline \hline Nominal Voltage & Slope & Y - Intercept \\
\hline 10 & -0.134 & 12.472 \\
15 & -0.092 & 12.510 \\
20 & -0.068 & 12.09 \\
30 & -0.045 & 12.518 \\
40 & -0.034 & 12.524 \\
50 & -0.026 & 12.513 \\
55 & -0.025 & 12.521 \\
60 & -0.023 & 12.513 \\
70 & -0.021 & 12.513 \\
75 & -0.020 & 12.511 \\
80 & -0.016 & 12.500 \\
100 & -0.024 & 12.502 \\
\hline
\end{tabular}


Table 8-3. High-energy Pantak unit voltage calibration

\begin{tabular}{ccc}
\hline \hline Nominal Voltage & Slope & Y - Intercept \\
\hline 50 & 0.222 & 40.456 \\
55 & 0.193 & 40.503 \\
60 & 0.176 & 40.500 \\
70 & 0.146 & 40.491 \\
80 & 0.129 & 40.455 \\
100 & 0.102 & 40.431 \\
110 & 0.084 & 40.449 \\
120 & 0.084 & 40.432 \\
125 & 0.077 & 40.451 \\
150 & 0.070 & 40.432 \\
170 & 0.062 & 40.417 \\
200 & 0.059 & 40.384 \\
210 & 0.055 & 40.379 \\
240 & 0.059 & 40.333 \\
250 & 0.054 & 40.325 \\
280 & 0062 & 40.260 \\
300 & 0.065 & 40.211 \\
\hline
\end{tabular}

\subsubsection{Gamma-ray calibration data acquisition system}

Calibration and measurements using the gamma-ray sources in rooms B034, B036, B021, and B015 are conducted using a mobile measurement console consisting of all instrumentation required for measurement and standardization of ionization currents. This data acquisition system is a Visual Basic interfacing system, which can automatically acquire all or some of the calibration data for cable-connected instruments and passive or other types of cable-connected instruments, such as those with their own readout. The mobile console contains a Keithley Model 616 electrometer, a Setra Model 350A digital barometer and a Digitec Model 5810 digital thermometer. Each cable connected instrument has as analog output signal. The feedback elements for the electrometer selector switch in the "volts" position are capacitors mounted in a capacitor-selector chassis. The equations for computing temperature are dependent on the thermistor used and, for measurements in control room B019, the signals are taken from YSI readouts mounted in the source control consoles. The equation used for computing atmospheric pressure from the Setra device, and the data for converting the analog signals from the thermistor probes to air temperatures in each calibration range and from the pressure transducer to atmospheric pressure are stored in the computer program. The temperature straight line fit paramaters follow in Table 8-4 . 
Table 8-4. Temperature probe parameters for the gamma source calibration ranges

\begin{tabular}{ccc}
\hline $\begin{array}{c}\text { Temperature probe } \\
\text { location }\end{array}$ & slope & intercept \\
\hline B021-B & -0.201 & 42.830 \\
B021-A & -0.202 & 42.974 \\
B015A & -0.095 & 29.767 \\
B015B & -0.094 & 29.855 \\
B036 & 1.006 & -0.296 \\
B034 & 1.001 & -0.316 \\
\hline
\end{tabular}

\subsection{Pre-calibration tests of instruments}

Other parameters of a device's performance can be best determined at the time of calibration, for example, recombination and leakage. In general, there are two types of instruments submitted for calibration: (a) ionization chambers associated with exposure readers, and (b) ionization chambers to be calibrated in electrical units. Type (a) instruments can be divided into two categories: (1) "condenser" types which consist of a charger/reader and one or more "condenser" probe ionization chambers (probes); and (2) cable-connected types. In general, both types have probes with different ranges, extending the instrument's range from protection-level to therapy-level exposure rates.

\subsubsection{Charger/reader scale linearity test}

For all practical purposes, the only charger/reader sent to NIST for calibration is the Victoreen Model $570 \mathrm{R}$-meter. Once the instrument is allowed to acclimate to the laboratory environment, the charger/reader is tested for scale linearity, the general operation of the charger and the quality of the scale and image of the quartz fiber are evaluated. The image of the string, ideally, should be aligned with the scale markings, and the scale markings and string image should be well-defined from zero to full-scale reading. Evaluation of the image is somewhat subjective, but lack of good focus, double images, or string images with highlights, should be considered as reasons for returning the instrument to the owner for adjustment or repair. Although minor adjustments can be made at NIST, they are done reluctantly since other, unforseen, problems may arise. In no case are adjustments attempted without contacting the owner for permission.

The scale linearity test is carried out using a connector which simulates the stem of a probe and a precision voltage source with a negative polarity on the $1000 \mathrm{~V}$ range. The electrometer is connected to the line, turned on, and allowed to come to equilibrium with temperature changes caused by the light which illuminates the scale. With the precision voltage source warmed up and with all voltage switches turned to zero, the negative polarity output is connected to the probe simulator and the simulator is inserted and locked into the charger recess. The output of the voltage source is then varied while observing the electrometer scale. The 
potential from the voltage source is increased until the image of the string coincides with the zero marking on the scale. The potential is recorded for "V0" on the index card and, decreasing the potential, data are recorded for the $(20,40,50,60,80$ and 100$) \%$ of full-scale reading. This data is then used for the calibration report.

\subsubsection{Testing of readers for cable-connected probes}

While the scale linearity of this type of reader is not tested, it is important to check the collecting potential used for the probe. Some readers have a switch or button that will permit a "self test." For those instruments where this convenience is not available, one needs to turn on the reader alone, then using a high input impedance meter, carefully measure the collecting potential at the probe input connector. Comparison of the observed value should be made with nominal value given in the instruction book for the instrument.

\subsubsection{Testing of instruments to be calibrated in electrical units}

The pre-calibration testing of ionization chambers to be calibrated in electrical units involves only a test for communication to the atmosphere. Experience has shown that rarely does an instrument fail to communicate with the atmosphere due to modern construction techniques. Additional testing of this type of instrument for leakage and settling down time are performed during the course of the calibration. An estimate of the recombination effect is made during calibration, at the highest air-kerma rate, by making measurements at full and half collecting potential.

\subsection{Support equipment calibrations}

\subsection{Capacitor calibrations}

Periodically, since 1956, the reference capacitors are submitted to the NIST Electronics and Electical Engineering Laboratory, Electricity Division for calibration. The capacitors range in capacitance from $(100,1000,10000$ and 100000$) \mathrm{pF}$. Some typical long-term calibration results have an uncertainty stated by the Electricity Division of no more than $\pm 0.05 \%$. The uncertainty is interpreted by the Electricity Division as equivalent to three standard deviations. Typical reproducibility for the last forty years is $0.02 \%$.

\subsection{Temperature indicator calibrations}

A liquid-in-glass thermometer and various probe and meter combinations are periodically calibrated by the NIST Chemical Science and Technology Laboratory, Process Measurements Division. In order to facilitate the temperature indicator calibrations, the calibrated liquid-in-glass thermometer is used to calibrate a quartz crystal thermometer, maintained by the NIST Radiation Interactions and Dosimetry Group. The quartz thermometer is then used to transfer the calibration to other temperature probes and thermistors in a controlled temperature bath annually or whenever the need arises. 


\subsection{Pressure indicator calibrations}

An aneroid barometer, Wallace and Tierman, Model FA 139, Serial Number XX11242, as well as various other laboratory reference barometers are periodically calibrated by the NIST Process Measurments Division. Calibrations of individual pressure indicators used at the various sources are made by placing the calibrated barometer alongside the instrument to be tested and connecting both to a variable pressure device. The instrument readings are compared over a range of pressures that is somewhat larger than normally expected. Data is taken with increasing and with decreasing pressure. The comparisons are made directly or through voltage signals. A correction factor is obtained from this data for each pressure indicator. This calibration procedure is conducted annually or more frequently if the need arises.

\subsection{Operating procedures}

\subsection{Administrative procedures}

The recommended procedure for requesting a NIST calibration service is outlined in NIST Calibration Services Users Guide. In practice, however, customers request calibration service in a variety of ways. Typically a new, or first-time customer will establish contact with the Radiation Interactions and Dosimetry Group by telephone, letter, e-mail or fax requesting information regarding techniques offered, charges, backlog time, turnaround time, and shipping/mailing information. At this stage, there is generally an opportunity to discuss with the prospective customer appropriate qualities of radiation for the type of service being requested and methods of shipment to reduce the risk of damage. The customer is informed that a purchase order must be received at NIST before an official calibration is performed. The purchase order can be sent with the instrument to be calibrated or can be sent separately by fax, mail or e-mail. In addition to an authorization for payment, the purchase order should include a detailed description of the calibration request, including beam quality codes, instrument model and serial numbers, name and telephone number of a technical contact. If an incomplete purchase order is received, every effort is made to get a detailed description of the service requested.

Upon receipt of the purchase order, a checklist, acceptance letter and a customer test folder is generated. A copy of the purchase order, the final copy of the calibration report, the calibration raw data and summary sheets and any documents of correspondence between the customer or the Office of Measurement Services (O.S.), Calibration Program Office are maintained in the customer's calibration report folder filed by the unique dosimetry group (DG) number. After copying the purchase order for the customer folder, the original purchase order, along with a request for a test folder, should be sent to the O.S.. A test folder will be sent by O.S. and will contain the original purchase order and appropriate forms. The test folder's unique number is used as one of the identifiers on the calibration report.

When instruments arrive for calibration, they are unpacked and inspected for damage. Special attention is given to the condition and type of connector. If an adaptor is sent with the chamber this should be noted on the inventory list along with the description of the chamber. Shipping damage is reported to the NIST shipping department. When an instrument arrives in a state of disrepair that is obvious by visual inspection, the customer is notified, and a decision is made whether to return the instrument to the customer, or if the repair is minor, have NIST personnel perform the repair. 
After the instrument has been calibrated the calibration report is generated. Currently the reports are generated in WordPerfect or MicrosoftWord. Templates arc availablc to simplify this procedure and to ensure consistency in the reporting format. Samplc reports arc found as Attachment 5.

The final copy of the calibration report is reviewed and initialed by the preparer and an additional reviewer and then given to the group leader for review. After the group leader approves and initials the report, it is sent to the Division Office for signature. Upon return, two copies are made. The original is mailed to the customer, one copy is filed in the customer folder, and one copy is added to the test folder. After all requested calibration work is completed the fees are computed and NIST form 64 is generated using the ISSC database. One copy is filed in the test folder and one in the customer folder or DG file folder, one copy is kept in the Calibration Log and one copy and the original is sent to the Administrative Officer for the Radiation Interactions and Dosimetry Group. The test folder is then signed and returned to the calibration program. Shipping request forms are prepared after the Division Chief signs off on a calibration report and returns it to the Group office. The instrument is packed either in its original container or in a more suitable one if necessary.

TLD exposure calibration reports are generated in a different manner than the instrument calibration reports. The data are taken and entered in a data book. After review, the data are transferred to a TLD calibration report form, see Attachment 6 and a DG number is assigned. The report is reviewed for correctness, initialed, then sent for signatures and handled in the same manner as the instrument calibration reports.

\subsection{Calibration of integrating-type instruments}

\subsubsection{Condenser chambers}

\subsubsection{General considerations}

This type of instrument consists of a charger/reader and a variety of removable condenser probes. As mentioned previously, the only charger/reader sent to NIST for calibration is the Victoreen Model 570 R-meter along with appropriate condenser chambers (probes). The Victoreen condenser R-meter has been so widely used in radiation dosimetry for such a long period of time, that it merits a special description. A Victoreen condenser chamber consists of an ionization chamber with an air volume of a few cubic centimeters mounted at one end of a shielded stem containing a solid dielectric storage condenser. Connection with the chamber is made through a contact at the other end of the stem, this being covered by a close-fitting cap when the chamber is in use. For charging the chamber, or reading its potential after irradiation, the cap is removed and the stem is plugged into a socket in the charger/reader. This charger/reader contains a quartz-fiber electrometer, which is observed through a low-power microscope having a scale calibrated directly in roentgens. The probes are of various volumes, allowing for a variety of total exposures ranging from $10 \mathrm{mR}$ to $250 \mathrm{R}$ full scale. The wall thickness varies according to probe model. For those models where the wall thickness is insufficient for the energy of the radiation requested, an equilibrium shell must be added. 


\subsubsection{X-ray calibrations}

X-ray calibrations are performed using the substitution method: the standard is used to measure the exposure rate at a given point in space, then the instrument to be calibrated is placed at that point and exposed to the same calibrated $\mathrm{x}$-ray source under the same conditions. The probe's response is normalized to $101.325 \mathrm{kPa}(760 \mathrm{~mm} \mathrm{Hg})$ pressure and $295.15 \mathrm{~K}\left(22^{\circ} \mathrm{C}\right)$.

Prior to calibration, the test chamber is first aligned in the x-ray beam. Generally this can be done while the $\mathrm{x}$-ray set is warming up. A variety of holders are available, depending on the probe being calibrated. The test chamber is placed in a holder and the laser beam is used to determine vertical and horizontal alignment. The cross-hair reticle of a telemicroscope is set to the defining plane of the appropriate free-air chamber prior to final alignment of the probe. For the Wyckoff-Attix (50 kV to $300 \mathrm{kV}$ ) chamber, the defining plane is the white line on the aperture holder. For the Ritz ( $20 \mathrm{kV}$ to $100 \mathrm{kV}$ ) chamber, the defining plane is exactly 15.00 $\mathrm{mm}$ beyond the white line on the aperture holder in the downstream direction from the x-ray source. For the Lamperti ( $10 \mathrm{kV}$ to $20 \mathrm{kV}$ ) chamber, the defining plane is exactly $20.00 \mathrm{~mm}$ downstream from the source from the scribed line on the plastic insert that fits into the removable shield and touches the front face of the aperture. For the Attix $(10 \mathrm{kV}$ to $50 \mathrm{kV})$ chamber, the defining plane is the scribed line in the brass aperture holder. Adjustment of the test chamber position to the defining plane is accomplished by sighting through the telemicroscope which was previously aligned on the defining plane of the free-air chamber. Motorized slides are then used to adjust the test chamber reference point to the standard defining plane. Control of the motorized slides is accomplished using a control box located in the vicinity of each telemicroscope. Condenser-type probes are right cylinders, or have rounded-top cylindrical thimbles or thin end windows. For the first two types, the chamber reference plane is the mid-plane of the thimble. For the latter, the grooved line on the thimble is the reference plane. The thin window chamber is calibrated with its axis parallel to the beam axis, while the other two types are calibrated with the chamber axes perpendicular to the beam axis.

A further consideration in x-ray calibration is choice of an appropriate beam size. For this purpose a parameter called the "beam size" is compared to the largest dimension of the active volume. The general practice is to use a beam size that is only a few centimeters larger than the active volume size so as to minimize irradiation of inappropriate volumes in the probe stem. For x-rays, as opposed to high energy gamma-rays, this is of secondary importance since the chamber stem attenuates the radiation considerably. The beam size of the $\mathrm{x}$-ray beams, for all beam defining apertures for the vertical and horizontal beam position has been determined using an Exradin A1 ion chamber, as well as film. The useful beam size is the point where the ratio of the optical density to the center of the film reveals a change of less than $0.5 \%$. The ratio of the intensity as measured with the ion chamber of the center to the outer point of the useful beam should also change less than $0.5 \%$.

Leakage measurements are taken prior to calibration after a pre-irradiation. If the leakage is a significant fraction of the expected exposure reading, either the probe is cleaned or is not calibrated. In addition, leakage measurements are made at the time of calibration. Again, if the leakage is found to be a significant fraction of the expected reading, the insulators are cleaned using canned dry gas. Since the gas is cold due to expansion, some time must be allowed for the chamber to equilibrate with room temperature. If the cleaning procedure is not successful, the calibration is terminated. 


\subsubsection{Gamma-ray calibrations}

The instruments to be calibrated using gamma-ray beams are calibrated in essentially the same way as in the $\mathrm{x}$-ray beams. The primary difference is that in the gamma-ray beams, a NIST standard is not used at the time of calibration. Instead, a previously determined value of the airkerma rate is corrected for decay to the time of calibration. As with the $\mathrm{x}$-ray calibrations, a check chamber is used. The source-to-chamber distance is set by sighting the telemicroscope on the appropriate scale distance.

All the horizontal sources in rooms B015A, B015B, B021A, and B021B allow scale distances from $35 \mathrm{~cm}$ to $300 \mathrm{~cm}$, and have a fixed collimator size. The probe to be calibrated is adjusted to the beam center-line using the laser beam associated with each source. The chamber is then centered in the telemicroscope scale-reticle. An exception to this technique is when the probe is larger than $10 \mathrm{~cm}$. The technique for set-up then involves measuring the probe in the direction of the beam using metric calipers and determining the radius. The probe is then placed in the beam, aligned as above, and adjusted so that the front or back of the chamber is tangent to the telemicroscope cross-hairs.

\subsubsection{Cable-connected instruments}

\subsubsection{General considerations}

This type of instrument consists of an electrometer-type readout connected by cable to the probe. Details of the theory of operation, measurement techniques, modes of operation, etc., are best described by the instruction manual for each model. All units provide a collecting potential for the probe. The value of the collecting potential can be obtained from the instruction manual; good operating procedure dictates that this parameter be tested prior to calibrating the probe, preferably upon arrival of the instrument at NIST. If the potential is found to be outside specifications, it may require replacement of often unique type batteries or returning the instrument to the customer for repair.

\subsubsection{X-ray calibrations}

Alignment of these types of probes is the same as for condenser chambers. A limited variety of probe holders are on hand for this type of instrument. There are occasions when no specific chamber holder exists for a chamber to be calibrated; on these occasions, available holders must be adapted or modified accordingly. In all instances, care must be taken to reduce or eliminate scattering material from the beam.

The calibration procedure for this type of instrument is only slightly different from that for condenser-type. Having a direct readout makes it convenient to take into account any small leakage/background effects. The procedure used is to unground the reader for the same length of time to be used in the exposure measurements. One can then correct the final value by either adding or subtracting the "leakage." The reason this technique is used for this type of instrument, and not for the condenser-type, is that the readouts on the cable-connected type allow for a more precise reading unlike the electrometers of condenser-types which are generally readable only to $1 \%$. 


\subsubsection{Gamma-ray calibrations}

This type of calibration is basically the same as for x-rays, and essentially no different from the gamma-ray calibration of condenser chambers.

\subsection{Calibration of current-type instruments}

Background information about current-type instruments is given in Section 8.1.

\subsubsection{X-ray calibrations}

Section 8.3.1 gives a description of the data-acquisition system and the ionization current measuring systems. The setup techniques for these types of chambers is basically the same as for both of the integrating-type probes described above, although some additional steps need to be taken. After mounting and aligning the chamber in the fixture and applying the collection potential, the collecting voltage is checked at the chamber. This insures that the voltage connection has been made. Also with certain Triax-to-BNC adapters a short-circuit occurs if the triaxial portion of this adapter (at high voltage) is grounded. It is good practice to insulate this adapter and tape it in place so that movement of the instrument mount does not cause the cable to shift or bind. It is also important to keep all connections out of the radiation beam, thereby reducing errors due to contributions from extra-cameral volumes.

\subsubsection{Gamma-ray calibrations}

The calibration techniques used for current-type instruments are basically the same as the techniques described above for the gamma-ray calibration of integrating type instruments. As with $\mathrm{x}$-ray calibrations, it is necessary to check the chamber collecting potential at the chamber. Care should be taken in shielding the signal lead connections from the beam and from scattered radiation. Errors of as much as $5 \%$ can be introduced, even in the scattered beam, if shielding is not employed.

\subsection{In-house calibration checks}

The long-term reliability of NIST dosimetry calibrations depends on the stability of the NIST air-kerma standards. For gamma rays, the NIST air-kerma standard is the mean response of six spherical graphite ionization chambers, which are periodically compared. For x-rays, the NIST air-kerma standard is the response of the appropriate free-air chamber; the four free-air chambers are also periodically compared. The in-house calibration checks are intended to check both the stability of the NIST standards and the reliability of the calibration procedures.

Two methods are used to verify a calibration. The first is to calibrate a NIST chamber which has a calibration history and is similar to the customer's chamber. The second check is an examination of previous calibrations of the customer's instrument at the same beam quality. If the discrepancy is significant, greater than $0.2 \%$ for current-type probes, and greater than $1 \%$ for integrating-type instruments, an investigation is warranted. When there are several previous calibrations of the customer's instrument at any one beam quality, one can estimate the 
reproducibility and decide whether the current value is acceptable.

For the gamma-ray and x-ray check chambers, a record is maintained of all calibrations, and the previous calibrations are compared with the current calibration to detect any trend or measurement discrepancy. Any discrepancy arising with a NIST check chamber of the order of magnitude mentioned above, gives rise to a thorough investigation of the calibration procedure. Alignment, temperature indications, distance, etc., are to be checked again. If the discrepancy cannot be resolved the complete calibration process is repeated.

The calibration check procedures outlined above carry the danger that a very slight drift in the calibration factor of a check chamber would not be detected, but would accumulate to a significant value over an extended time. In order to investigate this possibility, the entire calibration histories of three different chambers were analyzed for trends using linear regression. The results showed trends in the calibration factors of no more than $0.03 \%$ per year, with an average of $0.01 \%$ per year. See Table $10-1$ for the trends in three NIST check chambers from 1979 to 1997.

Table 10-1. Analysis of three NIST check chambers for the period of 1979 to 1997

\begin{tabular}{|c|c|c|c|c|c|c|}
\hline \multirow{2}{*}{$\begin{array}{l}\text { Chamber } \\
\text { Model }\end{array}$} & \multirow{2}{*}{$\begin{array}{c}\begin{array}{c}\text { Shonka/ } \\
\text { Wyckoff }\end{array} \\
3 \mathrm{~cm}^{3}\end{array}$} & \multicolumn{3}{|c|}{ Exradin } & \multicolumn{2}{|c|}{ Victoreen } \\
\hline & & A4 & A4 & A4 & $415 \mathrm{~A}$ & $415 \mathrm{~A}$ \\
\hline Serial Number & 344 & 117 & 117 & 117 & 121 & 121 \\
\hline Beam Quality Code & ${ }^{137} \mathrm{Cs}$ & ${ }^{137} \mathrm{Cs}$ & ${ }^{60} \mathrm{Co}$ & M100 & M30 & M50 \\
\hline Number of data points & 122 & 37 & 31 & 20 & 45 & 44 \\
\hline$\%$ change / year & 0.001 & 0.003 & 0.004 & 0.005 & 0.02 & 0.03 \\
\hline $\begin{array}{l}\% \text { Standard Error } \\
\text { of Regression }\end{array}$ & 0.0003 & 0.007 & 0.02 & 0.013 & 0.03 & 0.03 \\
\hline$\%$ Standard Deviation $^{\mathrm{a}}$ & 0.11 & 0.09 & 0.17 & 0.21 & 0.71 & 0.6 \\
\hline
\end{tabular}

${ }^{a}$ Standard deviation of average of all calibration factors.

\subsection{Test of high-quality feedback electrometers}

NIST provides a test service for high-quality feedback electrometers that are used in conjunction with current-type ionization chambers. The procedure involves electrically testing the electrometer at one feedback-capacitor position and computing a correction factor, $\mathrm{K}_{\mathrm{Q}}$. A typical report form is found in Attachment 7. As a check on this electrical test, the customer's current-type chamber is calibrated for one beam quality with both the NIST system and with the customer's system. Agreement is usually within $0.2 \%$, if not, the calibration is reviewed and possibly repeated. 
10.6. Irradiation of passive and electronic dosimeters

\subsubsection{General considerations and procedures}

Dosimeters received at NIST for irradiation in terms of air kerma or exposure are the type used for personnel protection. The air kerma from $\mathrm{x}$-rays, ${ }^{137} \mathrm{Cs}$ and/or ${ }^{60} \mathrm{Co}$ requested by the customer can be delivered to passive and electronic dosimeters.

\subsubsection{Exposure techniques}

For both $\mathrm{x}$ - and gamma-ray exposures, the dosimeters are mounted either on a scatter-free frame or a $30 \mathrm{~cm} \times 30 \mathrm{~cm} \times 15 \mathrm{~cm}$ methylmethacrylate phantom at a distance such that the beam is uniform over the area of irradiation. The irradiation distance is the source-to-badge-middle when using the scatter-free frame. When using the phantom, the irradiation distance is the source-to-phantom front surface. No correction is made for the distance of the badge-tophantom offset. Gamma-ray exposures are performed at a scale distance of $195 \mathrm{~cm}$ or $300 \mathrm{~cm}$. The air kerma is obtained from the charts associated with each source, corrected for decay. All irradiation details are recorded in a data book. After review of the results in the data book, the badge identification numbers, air-kerma levels, date of irradiation and a DG number are transferred to a TLD report form, see Attachment 6.

\subsection{Assessment of uncertainty}

The method of uncertainty assessment follows the NIST policy of expressing uncertainty, as outlined in the NIST Technical Note 1297. Conventional statistical estimates are given as standard deviations of the mean, and are designated as "Type A," which can be considered to be objective estimates. All other uncertainty estimates, which are designated "Type B," are subjective estimates, based on extensive experience. The "Type B" uncertainties are estimated so as to correspond approximately to one standard deviation. The Type A and Type B estimates are combined according to the usual rule for combining standard deviations, by taking the square root of the sum of the squares, the quadratic sum. The quadratic sum of the two types of uncertainty is then considered to be the combined uncertainty, which is in turn multiplied by the coverage factor, two, to give an expanded uncertainty. The uncertainty is considered to have the approximate significance of a $95 \%$ confidence limit. Table 11-1. lists the details of the assessment of uncertainty in the air kerma rates determined for the tungsten $\mathrm{x}$-ray beams by the free-air ionization chambers, and as determined for gamma-ray beams by the set of spherical graphite cavity ionization chambers. Table 11-2. lists the details of the assessment of uncertainty in the calibration of current-type ionization chambers and condenser-type chambers used with their electrometers, and also in the irradiation of passive dosimeters, conducted with $\mathrm{x}$ - and gamma-rays. Table 11-3 lists the details of the assessment of uncertainty in air-kerma rates determined for the mammographic $\mathrm{x}$-ray beams by the Attix chamber. Table 11-4 lists the uncertainty components for the calibration of instruments used for mammography. Table 11-5 gives a brief description of some of the uncertainty components. Since the estimates of uncertainty vary lightly with beam qualities, methods of measurement, and rate, in each case the largest value is used for the estimate. In an official calibration, measurements could be repeated 
Table 11-1. Uncertainty analysis for tungsten $\mathrm{x}$ and gamma-ray air-kerma rates, shown in $\%$

Gamma-ray beam X-ray beam

\begin{tabular}{|c|c|c|c|c|c|}
\hline Uncertainty components & Type A & Type B & Type A & & Type B \\
\hline air density & 0.01 & 0.08 & 0.01 & & 0.08 \\
\hline charge & 0.03 & 0.1 & 0.12 & & 0.06 \\
\hline humidity & & 0.07 & & & 0.07 \\
\hline volume & 0.06 & 0.05 & 0.04 & & 0.01 \\
\hline g & & 0.02 & & & 0.02 \\
\hline W/e & & 0.15 & & & 0.15 \\
\hline axial nonuniformity & & 0.02 & & NA & \\
\hline effective measurement point & & 0.05 & & NA & \\
\hline energy-absorption coefficient ratio & & 0.05 & & NA & \\
\hline mean origin of electrons & & 0.1 & & NA & \\
\hline radial nonuniformity & & 0.01 & & NA & \\
\hline stem scatter & & 0.05 & & NA & \\
\hline stopping-power ratio & & 0.25 & & NA & \\
\hline timing & 0.04 & 0.1 & & NA & \\
\hline air attenuation, $\mathrm{k}_{\mathrm{a}}$ & \multicolumn{2}{|c|}{ NA } & & & 0.07 \\
\hline electric field distortion & \multicolumn{2}{|c|}{ NA } & & & 0.2 \\
\hline electron loss, $\mathrm{k}_{\mathrm{e}}$ & \multicolumn{2}{|c|}{ NA } & & & 0.1 \\
\hline penetration of aperture & \multicolumn{2}{|c|}{ NA } & & & 0.04 \\
\hline penetration of chamber face & \multicolumn{2}{|c|}{ NA } & & & 0.01 \\
\hline polarity difference & \multicolumn{2}{|c|}{ NA } & 0.1 & & \\
\hline recombination loss, $\mathrm{k}_{\mathrm{s}}$ & & 0.1 & 0.1 & & \\
\hline scattered photons, $\mathrm{k}_{\mathrm{p}}$ & \multicolumn{2}{|c|}{ NA } & & & 0.2 \\
\hline quadratic sum & 0.08 & 0.38 & 0.19 & & 0.37 \\
\hline combined standard uncertainty & \multicolumn{2}{|c|}{0.39} & \multicolumn{3}{|c|}{0.41} \\
\hline expanded uncertainty & \multicolumn{2}{|c|}{0.78} & \multicolumn{3}{|c|}{0.82} \\
\hline
\end{tabular}


Table 11-2 Uncertainty analysis for gamma-ray calibrations, shown in \%

\begin{tabular}{|c|c|c|c|c|c|c|}
\hline \multirow[b]{2}{*}{ Uncertainty components } & \multicolumn{2}{|c|}{ Current-type } & \multicolumn{2}{|c|}{ Condenser } & \multicolumn{2}{|c|}{ Passive dosimeters } \\
\hline & Type A & Type B & Type A & Type B & Type A & Type B \\
\hline air kerma rate & 0.08 & 0.38 & 0.08 & 0.38 & 0.08 & 0.38 \\
\hline air density & 0.01 & 0.08 & 0.01 & 0.08 & \multicolumn{2}{|c|}{ NA } \\
\hline charge & 0.04 & 0.1 & \multicolumn{2}{|c|}{$\mathrm{NA}$} & \multicolumn{2}{|c|}{ NA } \\
\hline distance & 0.01 & & 0.01 & & & 0.01 \\
\hline humidity & & 0.05 & & 0.05 & & \\
\hline leakage & & 0.02 & & 0.1 & & \\
\hline radiation background & \multicolumn{2}{|c|}{ negligible } & \multicolumn{2}{|c|}{ negligible } & \multicolumn{2}{|c|}{ NA } \\
\hline radial nonuniformity & \multicolumn{2}{|c|}{ NA } & \multicolumn{2}{|c|}{ NA } & \multicolumn{2}{|r|}{0.02} \\
\hline recombination loss & \multicolumn{2}{|c|}{ NA } & & & \multicolumn{2}{|c|}{ NA } \\
\hline scale reading & \multicolumn{2}{|c|}{ NA } & 0.2 & 0.5 & \multicolumn{2}{|c|}{ NA } \\
\hline timing & 0.04 & 0.1 & 0.04 & 0.1 & & 0.1 \\
\hline quadratic sum & 0.1 & 0.4 & 0.22 & 0.64 & 0.08 & 0.44 \\
\hline combined standard & & & & & & \\
\hline uncertainty & \multicolumn{2}{|c|}{0.41} & \multicolumn{2}{|c|}{0.68} & \multicolumn{2}{|c|}{0.45} \\
\hline expanded uncertainty & \multicolumn{2}{|c|}{0.82} & \multicolumn{2}{|c|}{1.36} & \multicolumn{2}{|c|}{0.9} \\
\hline
\end{tabular}

Table 11-3 Uncertainty analysis for air-kerma rates with the Attix chamber, shown in \%

\begin{tabular}{lcc}
\hline \hline Uncertainty components & Type A & Type B \\
\hline air density & 0.01 & 0.08 \\
aperture area & 0.01 & 0.01 \\
charge & 0.20 & 0.06 \\
humidity & & 0.07 \\
plate separation & 0.01 & 0.07 \\
air attenuation & 0.20 & 0.01 \\
g & & 0.02 \\
photon scatter & & 0.20 \\
polarity & 0.1 & \\
recombination & 0.06 & \\
W/e & & \\
\hline quadratic sum & 0.31 & \\
combined standard uncertainty & & 0.15 \\
expanded uncertainty & & 0.29 \\
\hline
\end{tabular}


Table 11-4 Uncertainty analysis for mammography calibrations, shown in $\%$

\begin{tabular}{lcc}
\hline \hline Uncertainty components & Type A & Typc B \\
\hline air kerma rate & 0.31 & 0.29 \\
charge & 0.12 & 0.06 \\
air density & 0.10 & 0.08 \\
humidity & & 0.05 \\
distance & & 0.02 \\
\hline quadratic sum & 0.33 & 0.31 \\
combined standard uncertainty & & 0.46 \\
expanded uncertainty & & 0.91 \\
\hline
\end{tabular}

Table 11-5 Explanation of various components of the uncertainty analyses

\begin{tabular}{|c|c|c|}
\hline $\begin{array}{l}\text { Uncertainty } \\
\text { Component }\end{array}$ & Type & Simplified Description of Component \\
\hline \multirow[t]{2}{*}{ air attenuation } & A & $\begin{array}{l}\text { The average of many air attenuation direct measurements using the Attix } \\
\text { chamber. }\end{array}$ \\
\hline & B & $\begin{array}{l}\text { Obtained by calculating the worst realistic error in air path length. This involves } \\
\text { the uncertainty of establishing a reproducible air path length and the effect on the } \\
\text { air-attenuation correction for a small distance error. }\end{array}$ \\
\hline \multirow[t]{2}{*}{ air density } & A & Based on typical changes in air density during a measurement set. \\
\hline & B & Results from the calibration of the barometers and the thermometers. \\
\hline $\begin{array}{l}\text { aperture } \\
\text { alignment }\end{array}$ & B & $\begin{array}{l}\text { The ability to align aperture to center of volume is considered negligible. Since } \\
\text { the beam is uniform at center, an insignificant change in the positioning would } \\
\text { not result in a measurable change to charge. }\end{array}$ \\
\hline \multirow[t]{2}{*}{ aperture area } & A & The standard deviation of the measurements of each aperture used. \\
\hline & $\mathrm{B}$ & Based on the NIST length standard. \\
\hline \multirow[t]{2}{*}{ charge } & A & $\begin{array}{l}\text { The average standard deviation of the primary chamber charge combined with the } \\
\text { monitor chamber charge standard deviation. }\end{array}$ \\
\hline & $\mathrm{B}$ & Results from the calibration of the electrometers. \\
\hline $\mathrm{g}$ & B & See Ref. 2. \\
\hline humidity & B & Refers to the uncertainty in correcting to dry air. \\
\hline photon scatter & B & $\begin{array}{l}\text { The photon scatter corrections were determined by Ritz with a stated uncertainty } \\
\text { of }+/-0.2 \% \text {, see Ref. } 4 \text {. }\end{array}$ \\
\hline \multirow[t]{2}{*}{$\begin{array}{l}\text { plate } \\
\text { separation }\end{array}$} & A & $\begin{array}{l}\text { For the Attix chamber, the stepper motor accuracy of } 400 \mathrm{steps} / \mathrm{rev} \text { and the lead } \\
\text { screw pitch of } 1 \mathrm{~mm} / \mathrm{rev} \text { leading to } 0.0025 \mathrm{~mm} \text { out of } 50 \mathrm{~mm} \text {. }\end{array}$ \\
\hline & B & Based on the lead screw accuracy of $0.008 \mathrm{in} /$ ftused for the Attix chamber. \\
\hline recombination & A & $\begin{array}{l}\text { The average of the standard error associated with curve fits of the recombination } \\
\text { data. }\end{array}$ \\
\hline \multirow[t]{2}{*}{ timing } & A & The standard deviation of various shutter times. \\
\hline & B & Set by the oscillator in the shutter timer or feature of computer board clock. \\
\hline $\mathrm{W}$ & B & See Ref. 2. \\
\hline
\end{tabular}


to maintain optimal conditions. Table 11-6 gives a summary of expanded uncertainties for each type of calibration.

Table 11.6 Summary of expanded uncertainties

\begin{tabular}{lrll}
\hline \hline \multicolumn{2}{l}{ Tungsten X-rays and Gamma Rays } & Mammography X-rays & \\
\hline air kerma rate & $0.8 \%$ & air kerma rate & $0.9 \%$ \\
cable connected chambers & $1 \%$ & & \\
passive dosimeters & $1 \%$ & ionization chambers & $1 \%$ \\
condenser chambers & $1.5 \%$ & & \\
\hline
\end{tabular}

The Type A components are generally less significant than the Type B components. This arises from the complexity of the interaction of ionizing radiation with matter: it is never possible to account fully for the numerous second-order effects, but it is usual during air-kerma calibrations at NIST to repeat measurements until the Type A component of the uncertainty is smaller than the Type B component. The measurement of volume is an exception, but this is not a routine measurement and both components are small.

\section{Safety considerations}

The main safety consideration is radiation protection. As described below, every effort is made to avoid any possibility of radiation exposure, even though it would be highly unlikely that serious exposures could occur accidentally. Another safety consideration is exposure to high voltage, such as exists on ionization chambers and standard chambers during calibration. There is no danger of high voltage related to the x-ray generators since the equipment now in use has no exposed high voltage in a normal operating mode. All radiation areas in the building are marked with striped tape and dosimeters must be worn by all personnel.

\subsection{Radiation safety}

\subsubsection{X-ray calibration ranges}

First and foremost, the three $\mathrm{x}$-ray source ranges are designed to eliminate any possible exposure to $\mathrm{x}$-radiation. The $100 \mathrm{kV} \mathrm{x}$-ray tube is interlocked with its power supply in such a way that if the tube is moved from a safe position, i.e., away from a lead shutter, the high-voltage is turned off. Recent changes to the shielding of this tube eliminated the leakage radiation that once occurred between the shutter assembly and the tube window at $90^{\circ}$. Flashing red lights signal any malfunction to the shutter and an audible area radiation detector has been recently implemented as a back-up precaution. The $300 \mathrm{kV}$ x-ray tube is enclosed in a housing of $19 \mathrm{~mm}$ $\mathrm{Pb}$ and $6.4 \mathrm{~mm}$ steel. There is a $25 \mathrm{~mm}$ lead safety shutter and a $12.7 \mathrm{~mm}$ lead timing shutter in front of the beam portal. Both x-ray calibration ranges are protected by lead-lined doors that are interlocked in a fail-safe manner with the shutters. This means that the shutter or shutters cannot be opened if the door interlock is open. Where no door exits, as in one area of the $300 \mathrm{kV} \mathrm{x}$-ray 
range, a light beam is used for protection. In addition, a time-delay devicc inside the $300 \mathrm{kV}$ $\mathrm{x}$-ray range must be actuated upon leaving or the shutter cannot be opened. As a further indication of radiation danger, two red lights are turned on whenever the shutter or shutters are open. A flashing red light associated with the $300 \mathrm{kV}$ x-ray set indicates high voltage is on the $\mathrm{x}$-ray tube. The mammography range shielding door is interlocked with the $\mathrm{x}$-ray tube shutter. If the door is opened or is not fully closed, the shutter will return to the shielding position. An audible alarm will sound if the shutter is not fully closed. Red lights illuminate when the shutter is opened. Additional lead shielding surrounds the x-ray tube, which must be in the shielding position for power to be applied to the $\mathrm{x}$-ray tube. No area radiation monitor is used due to the extremely narrow beam and the low scatter conditions resulting from the low energy $\mathrm{x}$-rays used in the mammography range.

\subsubsection{Gamma-ray calibration ranges}

All doors giving access to the gamma-ray calibration ranges have interlocks as required by the Nuclear Regulatory Commission regulations. The vertical-beam rooms have a time-delay device inside the room that must be actuated before leaving the radiation area. Automatic shielding doors protect occupants in the control area of B036 from the sources. In addition to the above safety features, a radiation detector with indicator lights and an audible signal is in each gamma calibration range. A second radiation detector located in the vertical beam area, between the shielding door of the vertical beams and the outer door, alarms whenever the interlock is broken during an irradiation. At each entrance to a gamma-ray calibration range, a set of two red lights indicates a "beam on" condition.

\subsection{High-voltage safety}

The only danger that exists from high voltage comes from the free-air ionization chambers, the customer chamber, and the $\mathrm{x}$-ray calibration range monitor chambers. To prevent dangerous electric shock, almost all power supplies contain current-limiting resistors in the high-voltage circuit. Common sense is dictated when working around ionization chambers that have exposed high-voltage electrodes. Appropriate warning signs are posted. The risk of high voltage from the Attix chamber is minimized by surrounding the chamber with protective cover. 


\section{REFERENCES}

1. Marshal, J.L.,ed. NIST Calibraiton Services Users Gide, NIST (U.S.) Spec. Publ. 250; 1998 January. Available on-line: http://www.ts.nist.gov/calibrations.

2. Boutillon, M. and Perroche-Roux, A.M., Re-evaluation of the $\mathrm{W}$ value for electrons in dry air, Phys. Med. Biol., 32, 213-219 (1987).

3. Wyckoff, H. O. and Attix, F. H., Design of free-air ionization chambers, National Bureau of Standards Handbook 64, 1957.

4. Ritz, V. H., Standard free-air chamber for the measurement of low energy x rays (20-100 kilovolts-constant-potential), J. Res. Nat. Bur. Stand. (U.S.), 64C, 49-53 (1960).

5. Lamperti, P. J. and Wyckoff, H. O., NBS free-air chamber for measurement of 10 to $60 \mathrm{kV} \mathrm{x}$ rays, J. Res. Nat. Bur. Stand. (U.S.), 69C, 39-47 (1965).

6. Ritz, V. H., Design of free-air ionization chambers for the soft $\mathrm{x}$ ray region (20-100 kV), Radiology, 73, 911-922 (1959).

7. Hubbell, J. H., Photon mass attenuation and energy-absorption coefficients from $1 \mathrm{keV}$ to 20 MeV, Int. J. Appl. Radiat. Isot. 33, 1269-1290 (1982).

8. Allisy, A. and Roux, A, M., Contribution a la measure des rayons roentgen dans le domaines de5 a 50 kV, Acta Radiologica, 55, 57-74 (1961).

9. Scott, P. B. and Greening, J. R., The determination of saturation currents in free-air ionization chambers by extrapolation methods, Phys. Med. Biol. 8, 51-57 (1963).

10. Berger, M. J. and Seltzer, S. M., Stopping powers and ranges of electrons and positrons, NBSIR 82-2550-A (2nd Ed.) (1983).

11. Katz, L. and Penfold, A. S., Range-energy relations for electrons and the determination of beta-ray end-point energies by absorption, Rev. Mod. Phys. 24, 28-44 (1952).

12. Somerwil, A., Photon scatter correction in low-energy $\mathrm{x}$ radiation measurements, influence of beam path length in standard free-air chambers, Metrologia 8, 2 (1972).

13. Attix, F. H.,"Electronic equilibrium in free-air chambers and a proposed new chamber design," Naval Research Laboratory Report No. 5646, 1961.

14. Coletti, J.G., Pearson, D. W. and DeWerd, L.A., "Mammography exposure standards: Design and characterization of free-air ionization chamber," Rev. Sci Instrum. 66, 25742577 (1995).

15. Laitano, R.F. and Toni, M.P. "The primary exposure standard of ENEA for medium energy 
x-rays. Characteristics and measurement procedures," Report RT/PROT (83) 27, Laboratorio di Metrologia della Radiazioni Ionizzani ENEA, CRE Casaccia, c.p. 2400 Roma, Italia, 1984.

16. Burns, D.T., Lamperti, P. and O'Brien, M. "Comparison of the NIST and BIPM Air-Kerma Standards for Measurements in the Low-Energy X-Ray Range," J.Res. Natl. Inst. Stand. Technol. 104, 135 (1999).

17. Lamperti, P., O'Brien, M., Sander, T. and Williams, T. "Comparison of the NIST and NPL Air-Kerma Standards for Measurements in the Low-Energy X-Ray Range,"JJ.Res. Natl. Inst. Stand. Technol. 105, 701 (2000).

18. Coletti, J. G., Pearson, D. W., DeWerd, L.A., O'Brien, C. M. and Lamperti, P.J. "Comparison of exposure standards in the mammography x-ray region," Med. Phys. 24(8), 1263-1267 (1997).

19. Report of the International Commission on Radiological Units and Measurements (ICRU), National Bureau of Standards Handbook 78, p. 19, 1959.

20. Loftus, T. P. and Weaver, J. T., Standardization of $60 \mathrm{Co}$ and $137 \mathrm{Cs}$ gamma-ray beams in terms of exposure, J. Res. Nat. Bur. Stand. (U.S.), 78A, 465-476 (1974).

21. Hoag, J. B. and Korff, S. A., Electron and Nuclear Physics, Chap. 17, pages 404-435, D. Van Nostrand Co., Inc. 250 Fourth Ave., New York, NY, (1948).

22. Taylor, L. S. and Singer, G., Note on the guarded-field x-ray ionization chamber. Radiology 26, 322-325 (1936).

23. Taylor, L. S., The precise measurement of x-ray dosage, Radiology 14, 372 (1930).

24. Boag, J. W., Distortion of the electric field in an ionization chamber due to the difference in potential between guard ring and collector, Phys. Med. Biol. 9, 25-32 (1964).

25. Day, F. H. and Attix, F. H., Methods for current measurement with a vibrating reed electrometer. Nat. Bur. Stand. (U.S.), Report 2080 (1952).

26. Loevinger, R., Precision measurement with the total-feedback electrometer. Phys. Med. Biol. 2, 267-279 (1966).

27. Keithley, J. F., Yeager, J. R., and Erdman, R. R., Low Level Measurements, Keithley Instruments, Inc., 28775 Aurora Road, Cleveland, OH 44139 (1984).

28. Frederiksen, T. M., Intuitive IC Op Amps, National Semiconductor Corp., Santa Clara, CA. (1984).

29. Instruction Manual, Model 616 Digital Electrometer, Keithley Instruments, Inc.. 28775 
Aurora Road, Cleveland, OH 44139 (1977).

30. Instruction Manual, Model 642 Electrometer, Keithley Instruments, Inc., 28775 Aurora Road, Cleveland, OH 44139 (1980).

31. Rutkowski, G. B., Handbook of Integrated-Circuit Operational Amplifiers, Prentice-Hall, Inc., Englewood Cliffs, NJ (1975). 
Attachment 1: X-Ray Beam Qualities offered at NBS Prior to 1986 
Table A-1. X-ray beam qualities offered at NBS prior to 1986

\begin{tabular}{|c|c|c|c|c|c|c|c|c|}
\hline \multicolumn{9}{|c|}{ Lightly Filtered X-Rays } \\
\hline $\begin{array}{l}\text { Beam } \\
\text { Code }\end{array}$ & $\begin{array}{c}\text { Constant } \\
\text { Potential } \\
(\mathrm{kV})\end{array}$ & $\begin{array}{l}\text { Distance } \\
(\mathrm{cm})\end{array}$ & \multicolumn{2}{|c|}{$\begin{array}{c}\text { Added } \\
\text { Filter }^{\mathrm{a}} \\
(\mathrm{mm} \mathrm{Al})\end{array}$} & \multicolumn{2}{|c|}{$(\mathrm{mm} \mathrm{Al})$} & \multicolumn{2}{|c|}{$\begin{array}{l}\text { Homogeneity } \\
\text { Coefficient } \\
(\mathrm{Al})\end{array}$} \\
\hline L-B & 10 & 25 & \multicolumn{2}{|c|}{0} & \multicolumn{2}{|c|}{0.03} & \multicolumn{2}{|c|}{0.79} \\
\hline L-C & 15 & 25 & \multicolumn{2}{|c|}{0} & \multicolumn{2}{|c|}{0.05} & \multicolumn{2}{|c|}{0.74} \\
\hline L-D & 20 & 50 & \multicolumn{2}{|c|}{0} & \multicolumn{2}{|c|}{0.07} & \multicolumn{2}{|c|}{0.76} \\
\hline$L-E^{b}$ & 20 & 50 & \multicolumn{2}{|c|}{0.5} & \multicolumn{2}{|c|}{0.23} & \multicolumn{2}{|c|}{0.78} \\
\hline L-G & 30 & 50 & \multicolumn{2}{|c|}{0.5} & \multicolumn{2}{|c|}{0.36} & \multicolumn{2}{|c|}{0.64} \\
\hline L-I & 50 & 50 & \multicolumn{2}{|c|}{1.0} & \multicolumn{2}{|c|}{1.02} & \multicolumn{2}{|c|}{0.66} \\
\hline L-K & 75 & 50 & \multicolumn{2}{|c|}{1.5} & \multirow{2}{*}{\multicolumn{2}{|c|}{$\begin{array}{l}1.86 \\
2.78 \\
\end{array}$}} & \multicolumn{2}{|c|}{0.63} \\
\hline L-M & 100 & 50 & \multicolumn{2}{|c|}{2.0} & & & & \\
\hline \multicolumn{9}{|c|}{ Moderately Filtered X-Rays } \\
\hline & & \multicolumn{3}{|c|}{ Added Filter ${ }^{c}$} & \multicolumn{2}{|c|}{ Half-Value Layer } & Hom & neity \\
\hline Beam & Constant & $\mathrm{Al}$ & $\mathrm{Cu}$ & & $\mathrm{Al}$ & $\mathrm{Cu}$ & $\mathrm{Coe}$ & ient \\
\hline Code & $\begin{array}{c}\text { Potential } \\
(\mathrm{kV})\end{array}$ & $(\mathrm{mm})$ & $(\mathrm{mm})$ & & & $(\mathrm{mm})$ & & \\
\hline MFB & 60 & 0 & 0 & & 1.62 & & & \\
\hline $\mathrm{MFC}^{\mathrm{b}}$ & 60 & 2.50 & 0 & & 2.79 & 0.09 & & \\
\hline $\mathrm{MFE}^{\mathrm{b}}$ & 75 & 2.51 & 0 & & 3.39 & & & \\
\hline MFG & 100 & 3.50 & 0 & & 5.03 & 0.20 & & \\
\hline MFI & 150 & 3.49 & 0.25 & & 10.25 & 0.66 & & \\
\hline MFK & 200 & 3.49 & 0.50 & & 13.20 & 1.24 & & \\
\hline MFM $^{\mathrm{b}}$ & 250 & 3.50 & 1.01 & & 15.80 & 2.23 & & \\
\hline $\mathrm{MFO}$ & 250 & 3.47 & 3.20 & & 18.30 & 3.25 & & \\
\hline & & & $\begin{array}{l}\text { Hea } \\
\text { Add }\end{array}$ & $\begin{array}{l}\text { iltere } \\
\text { ter }\end{array}$ & Rays & Half & ayer & \\
\hline $\begin{array}{l}\text { Beam } \\
\text { Code }\end{array}$ & $\begin{array}{c}\text { Constant } \\
\text { Potential } \\
(\mathrm{kV})\end{array}$ & $\begin{array}{c}\mathrm{Al} \\
(\mathrm{mm})\end{array}$ & $\begin{array}{c}\mathrm{Cu} \\
(\mathrm{mm})\end{array}$ & $\begin{array}{c}\mathrm{Sn} \\
(\mathrm{mm})\end{array}$ & $\begin{array}{c}\mathrm{Pb} \\
(\mathrm{mm})\end{array}$ & $\begin{array}{c}\mathrm{Al} \\
(\mathrm{mm})\end{array}$ & $\begin{array}{c}\mathrm{Cu} \\
(\mathrm{mm})\end{array}$ & $\begin{array}{l}\text { Effective } \\
\text { Energy } \\
(\mathrm{keV})\end{array}$ \\
\hline HFC & 50 & 2.50 & 0 & 0 & 0.10 & 4.20 & 0.14 & 38 \\
\hline $\mathrm{HFE}^{\mathrm{b}}$ & 100 & 2.50 & 0 & 0 & 0.50 & 11.20 & 0.74 & 70 \\
\hline HFG & 150 & 2.50 & 4.00 & 1.51 & 0 & 16.96 & 2.45 & 117 \\
\hline HFI & 200 & 2.47 & 0.60 & 4.16 & 0.77 & 19.60 & 4.09 & 167 \\
\hline HFK & 250 & 2.50 & 0.60 & 1.04 & 2.72 & 21.55 & 5.25 & 210 \\
\hline
\end{tabular}

${ }^{a}$ Inherent filtration approximately $1.0 \mathrm{~mm} \mathrm{Be}$.

${ }^{\mathrm{b}}$ Discontinued beam codes.

${ }^{\mathrm{c}}$ Inherent filtration approximately $1.5 \mathrm{~mm} \mathrm{Al}$. 
Attachment 2: Additional references - data books 
The references listed in this attachment are NIST registered laboratory data books (DB) or binders which are located in $\mathrm{B} 033$ of the Radiation Physics building. The references are identified by the data book identification number and the page number.

1. DB848 page 110 (DB 848:110), DB 331:92-117 and DB 527:081

2. DB852:11

3. A loose-leaf binder entitled "Supplement to DB776, Free-Air Ionization Chamber Comparisons."

4. See DB592, DB624, and DB638. The data plots used for extrapolations are filed in a file cabinet in Rm. B033 under the general title "Free-Air Ionization Chamber Recombination." Further analyses of the data are recorded in a three-ring binder entitled, "Supplement No. 1 to DB 592, DB624 and DB638; 10-60 kV and 20-100 kV Free-Air Ionization Chamber Comparison."

5. DB752:143-162.

6. See DB592, DB624 and DB638. Also found in binder entitled "Supplement No.1 to DB592, DB624 and DB638" and in file folders under the general title "Free-Air Chamber Recombination," all filed in Rm. B-033.

7. DB750:118, DB744:203, DB717:127 and DB717:125.

8. DB799:34, DB817:52, DB750:201, DB799:44 and 60, DB817:121,131 and 141, DB799:70, DB817:138 and DB817:121.

9. DB817:155.

10. DB817:94.

11. DB799:10-11 and DB817:17.

12. DB817:51-52. 
Attachment 3 : Attix chamber schematics 


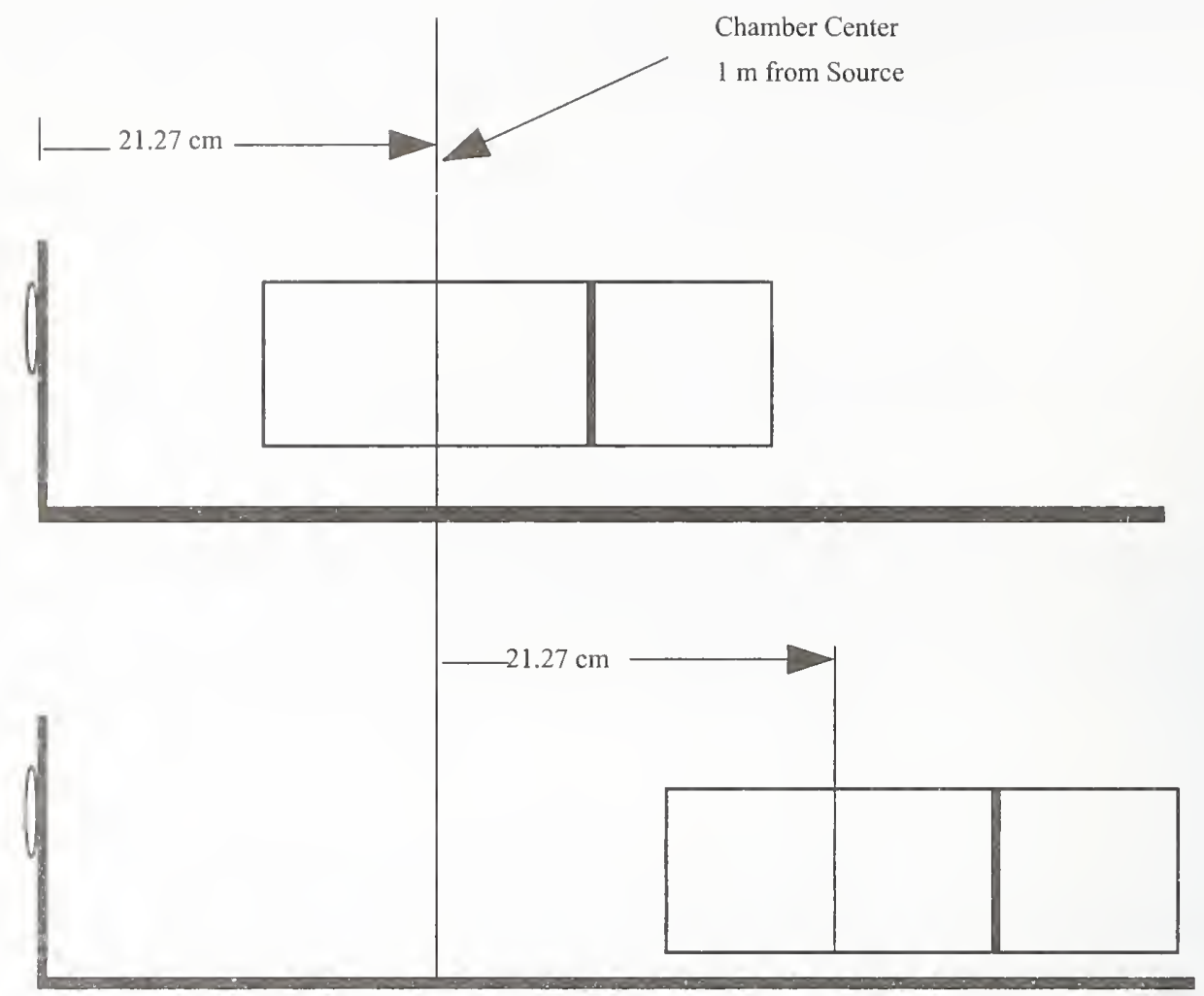

Fig. A3-1. Attix chamber configuration for half-value layer and air attenuation measurements. 


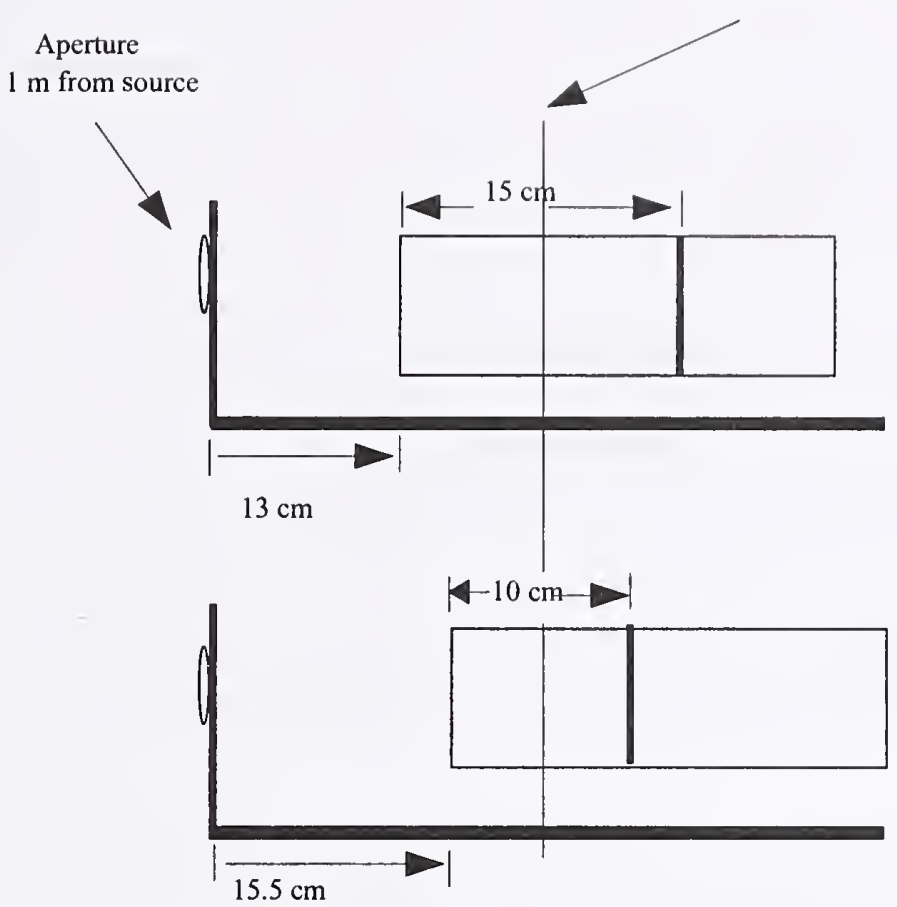

Fig. A3-2. Attix chamber configuration for the two smallest positions of routine calibrations.

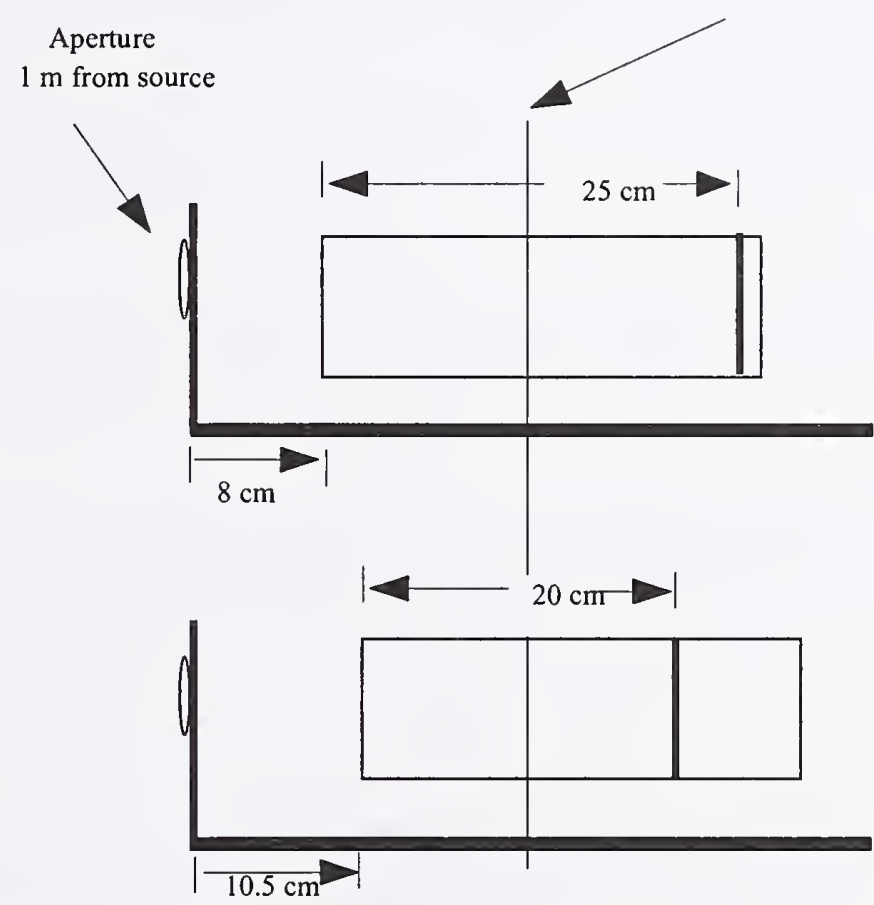

Fig.A3-3 Attix chamber configuration for the two largest positions for an air-kerma measurement. 
Attachment 4 : The history of the measurement of current 
Until high-gain negative-feedback amplifiers were introduced, electrometers used for ionization current measurements were used as null detectors. Charge, or current, was measured by manually nulling the signal on the most sensitive range of the electrometer. In the null method of measurement, determination of stray capacitance in the system and voltage calibration of the electrometer are unnecessary but it is necessary in free-air chambers to maintain the null such that the collector plate potential is very near the guard-plate potential. A difference in potential between the guard and collector plates in a free-air chamber distorts the electric field and deforms the defined air volume. Measurements of exposure will then be in error, see Ref. [21-23] for a more detailed description of this subject.

The VRE was an improvement over direct-current, vacuum-tube electrometers not only because it utilized negative feedback but, being an $\mathrm{AC}$ amplifier, the problem of zero drift was essentially eliminated. Negative feedback automatically maintains the inner electrode of an ionization chamber near the guard potential and minimizes field distortion. For many years, VRE's were used at NIST as null detectors [3,24]. The gain of the VRE's was found on occasion to be much less than the design gain of 1000; gains as low as 250 were found, which could lead to reading errors of up to several percent in the collected charge. Loevinger [25] derived corrections for electrometer current measurements and showed that the gain of several VRE's varied with scale reading and polarity. Sources of information for the following discussion are given in Ref. [25-31].

The high-gain, negative-feedback amplifier is the type of operational amplifier used in electrometers for measurement of small currents from ionization chambers. These amplifiers have a high impedance input and, an essential characteristic for free-air ionization chambers, the input terminal maintains the collector plate virtually at ground potential. A negative-feedback electrometer with resistive feedback element is shown in Fig. A3-1. The signal current $I_{\text {sig }}$ from an ionization chamber impresses a signal on the input terminal of the operational amplifier, which generates an output voltage $V_{O}$. Part or all of $V_{O}$ is fed back (from the load resistor $R_{L}$ ) through the feedback resistor $R_{\mathrm{f}}$ to the input terminal, so as to oppose the input signal. The output voltage is larger than the resultant input voltage $V_{1}$ in the ratio

$$
G=V_{d} V_{I},
$$

where $\mathrm{G}$ is the amplifier gain. In modern electrometers, such as the Keithley $616, \mathrm{G}>104$, so for present purposes $V_{1}$ can be neglected compared to $V_{O}$, and

$$
V_{\text {sig }}=V_{O} \text {. }
$$

For operational amplifiers with large input resistance, for which the input voltage $\mathrm{V}_{1} \approx 0$, there can be no current through the amplifier, and the current through the feedback resistor is equal to the ionization chamber current $I_{\text {sig. }}$. Therefore

$$
V_{\text {sig }}=I_{\text {sig }} R_{f},
$$

and finally

$$
I_{s i g}=V_{O} / R_{f}
$$

This is the relationship used for measuring current when using a resistive feedback element. 


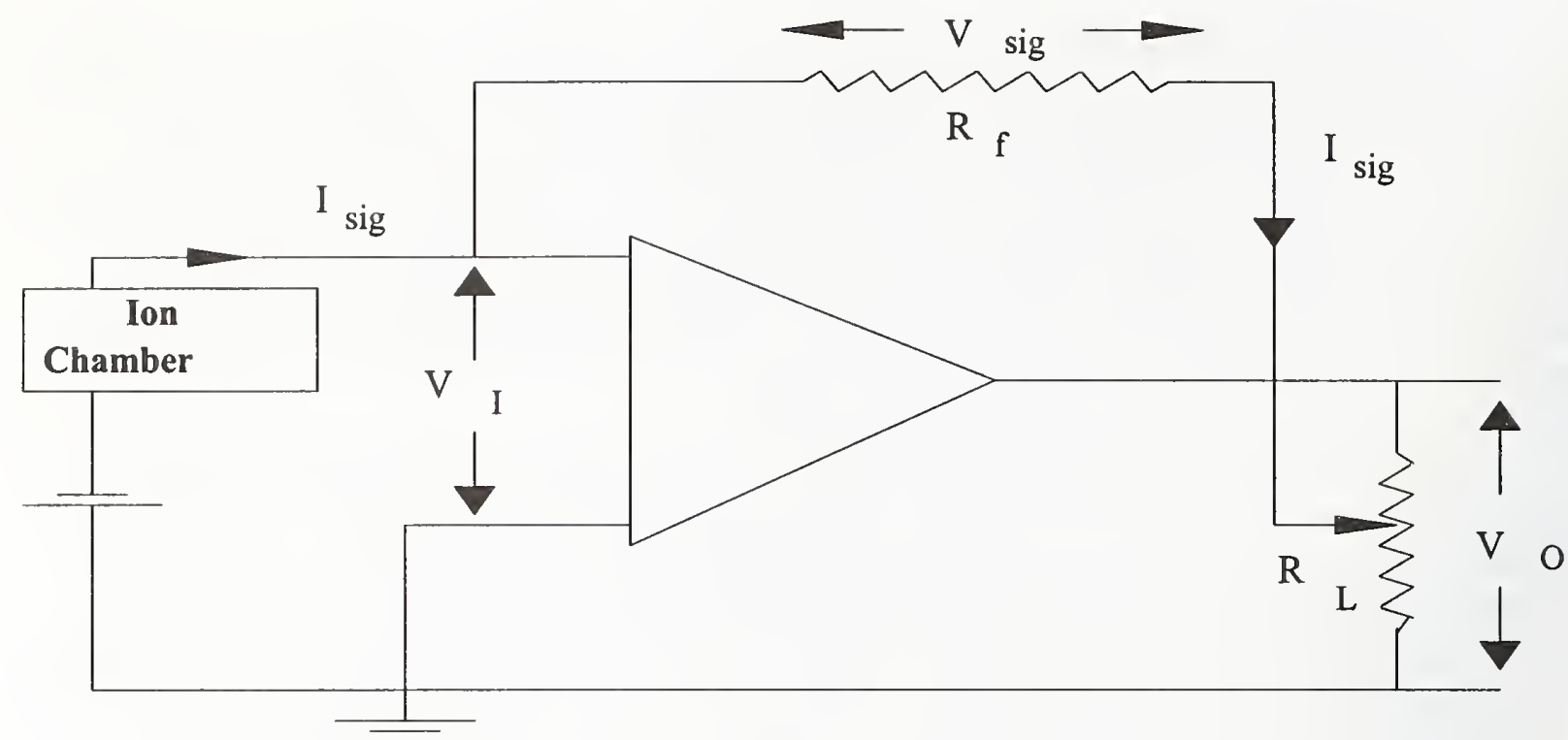

Fig. A3-1. Circuit of a negative-feedback amplifier with resistive feedback. 
For low-current measurements high-megohm $(\mathrm{M} \Omega)$ resistors are required. For example, a feedback resistor of $20 \mathrm{M} \Omega$ is required to develop a feedback voltage of $1 \mathrm{~V}$ for the exceptionally large ionization current of $50 \mathrm{nA}$. Day and Attix [24] found that the high-megohm resistors of several manufacturers changed their values by as much as $1 \%$ over a period of six months. Consequently General Radio Corporation air-dielectric capacitors have been used as feedback elements for dosimetry calibration work for many years. A negative-feedback amplifier with capacitative feedback element $C_{f}$ is shown in Fig. A3-2. In this case,

$$
\Delta V_{\text {sig }}=I_{\text {sig }} \Delta t / C_{f} \text {, }
$$

and results in

$$
I_{s i g}=C_{f} \Delta V_{d} \Delta t
$$

This equation is the basis for all important ionization-current measurements at NIST. The ionization current $\mathrm{I}_{\text {sig }}$ is determined from measurements of $\mathrm{V}_{\mathrm{O}}$ using accurate digital voltmeters which can be commanded to sample-and-hold readings of $\mathrm{V}_{\mathrm{O}}$ at preset time intervals. The inverting operational amplifier has other advantages worthy of mention since they affect the application of these devices to ionization current measurements. These features are the inherent linearity of the change in $\mathrm{V}_{\mathrm{O}}$ with time, giving $\Delta \mathrm{V}_{\mathrm{O}} / \Delta \mathrm{t}=$ constant, and the ability of the device to transfer essentially all of the charge produced in the ionization chamber to the measurement system. The slope $\Delta \mathrm{V}_{\mathrm{O}} / \Delta \mathrm{t}$ is constant because the input terminal being at virtual ground is essentially isolated from the input circuit, i.e., the magnitude of the voltage on $\mathrm{C}_{\mathrm{f}}$ does not affect the ionization current being supplied from the current source. If this were not so, the charge build-up on $\mathrm{C}_{\mathrm{f}}$ would be exponential. The almost complete charge transfer from the current source is accomplished because $\Delta \mathrm{V}_{\mathrm{I}}$, the potential across the capacitance of the current source, is forced to be near zero by the negative feedback and, for an open loop gain of $10000, \Delta V_{I}=$ $\mathrm{V}_{\mathrm{O}} \times 10^{-4}$. Then only $10^{-4} \mathrm{~V}_{\mathrm{O}}$ is across the current source capacitance. Other ways to consider this effect are that the capacitance of the current source is degenerated by the open-loop gain or, that the effective capacitance of the electrometer is increased by the open-loop gain.

Personnel safety in the measurement of radiation requires that measuring instrumentation be located in a radiation-safe environment. In addition, it is good practice not to allow radiation to strike instruments which may be susceptible to generation of extrancous currents. These conditions are made possible through the use of "low-noise" coaxial cables for connection between ionization chambers and electrometers. The "low-noise" characteristic of these cables is accomplished by coating the surface of the coaxial insulator with a conducting material. In this way the metallic braid used as an electrostatic shield, and the coating, are always at the same potential regardless of cable disturbance. Additionally, the capacitance between the coaxial surfaces remains the same even though the braid may not always be in immediate contact with the surface.

The use of long, low-noise cables and the discontinuance of manual null methods were made possible by the use of the high-gain negative-feedback electrometers. For a typical low-noise cable capacitance of $30 \mathrm{pF} / \mathrm{ft}$ the total capacitance is $1.5 \mathrm{nF}$. This cable capacitance is degenerated to $0.15 \mathrm{pF}$ if the electrometer gain is 10,000 . Since, in most measurements, the electrometer feedback capacitors are $1000 \mathrm{pF}$ or greater, the added capacitance in this instance would cause an error of $0.02 \%$. If the feedback capacitance is less than $1000 \mathrm{pF}$, say $100 \mathrm{pF}$, the percent loss of charge trapped on the stray capacitance should be determined. The open-loop 
gain may be as high as 50000 .

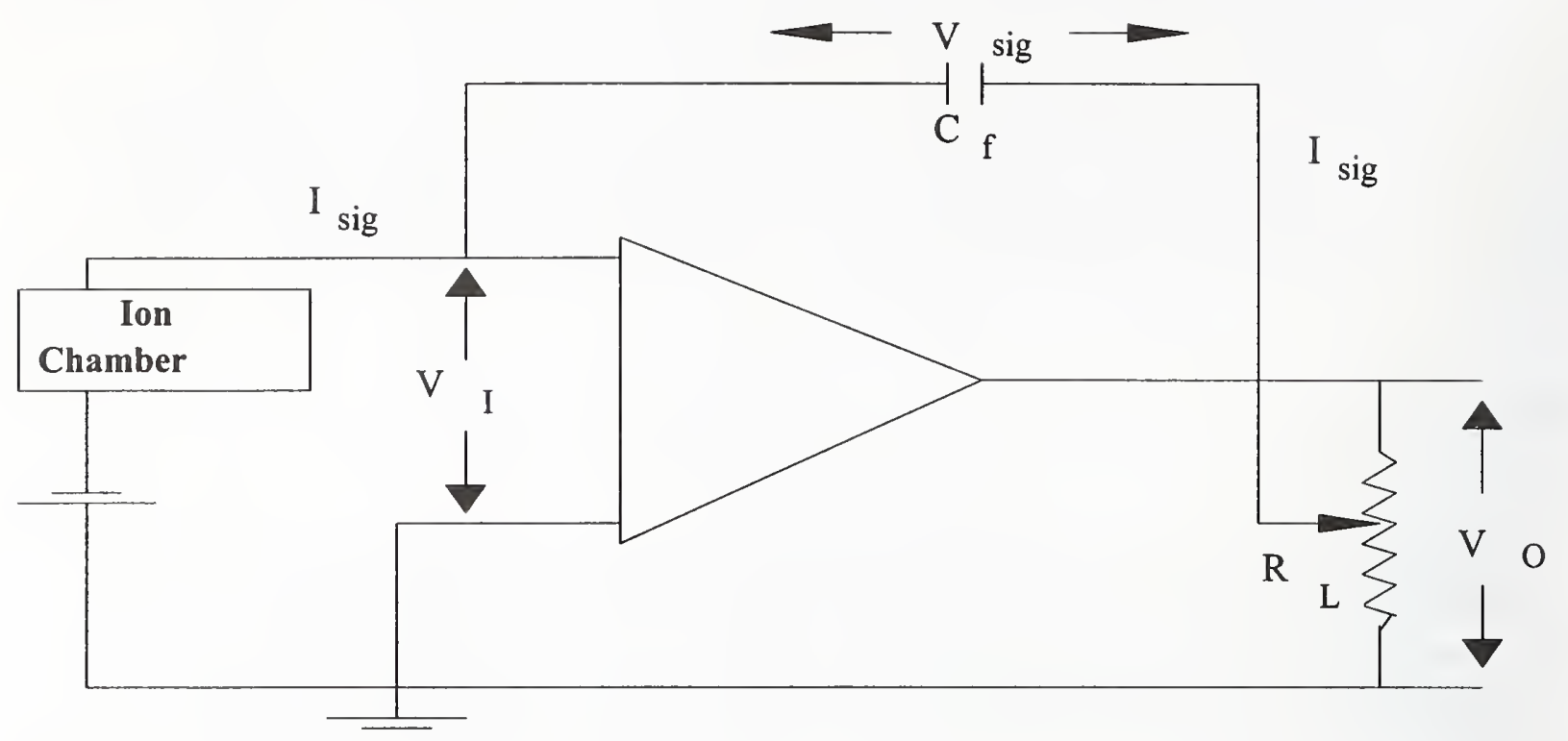

Fig. A3-2. Circuit of a negative feedback amplifier with a capacitive feedback element. 
Attachment 5: Typical ionization chamber calibration report 


\title{
National Institute of Standards and Technology
}

\section{REPORT OF AIR-KERMA CALIBRATION \\ OF}

\author{
ADDRESS 1 \\ ADDRESS 2 \\ ADDRESS 3

\begin{abstract}
Radiation Detection Chamber: Make, Model, SN
\end{abstract}
Measurements performed by Michelle O’Brien

Report reviewed by Paul Lamperti

Report approved by Stephen M. Seltzer

For the Director

National Institute of Standards and Technology

by

\author{
Bert M. Coursey, Chief \\ Ionizing Radiation Division \\ Physics Laboratory
}

Information on technical aspects of this report may be obtained from Michelle O'Brien, National Institute of Standards and Technology, 100 Bureau Drive Stop 8460, Gaithersburg, MD 20899, (301) 975-2014. Report format revised 5/00. 


\title{
National Institute of Standards and Technology
}

\section{REPORT OF AIR-KERMA CALIBRATION}

\author{
OF
}

ADDRESS 1

ADDRESS 2

ADDRESS 3

\section{Radiation Detection Chamber: Make, Model, SN}

Chamber orientation: the cavity was positioned in the center of the beam with the stem of the chamber perpendicular to the beam direction

Chamber collection potential: -000 volts with respect to the inner electrode (- charge was collected)

Chamber rotation: the high voltage wire faced the source of radiation

Environmental conditions: the chamber is assumed to be open to the atmosphere Average leakage: less than $0.02 \%$ of signal

A detailed study of ionization recombination was not performed and no correction was applied to the calibration factor(s). If the chamber is used to measure an air-kerma rate significantly different from that used for the calibration, it may be necessary to correct for recombination loss.

\begin{tabular}{|l|l|l|c|c|c|c||}
\hline $\begin{array}{l}\text { Beam } \\
\text { Code }\end{array}$ & Half -Value Layer & $\begin{array}{c}\text { Equilibrium } \\
\text { Shell } \\
\text { Added }\end{array}$ & $\begin{array}{c}\text { Calibration Factor } \\
(\mathrm{Gy} / \mathrm{C}) \\
295.15 \mathrm{~K}\left(22^{\circ} \mathrm{C}\right) \text { and } \\
101.325 \mathrm{KPa}(1 \mathrm{Atm})\end{array}$ & $\begin{array}{c}\text { Air- Kerma } \\
\text { Rate } \\
(\mathrm{Gy} / \mathrm{s})\end{array}$ & $\begin{array}{c}\text { Calibration } \\
\text { Distance } \\
(\mathrm{cm})\end{array}$ \\
\hline & $\mathrm{mm} \mathrm{Al}$ & $\mathrm{mm} \mathrm{Cu}$ & & & & \\
\hline & & & NO/YES & X.XXX EX & X.XX EX & \\
\hline & & & NO/YES & X.XXX EX & X.XX EX & \\
\hline & & & NO/YES & X.XXX EX & X.XX EX & \\
\hline & & & NO/YES & X.XXX EX & X.XX EX & \\
\hline
\end{tabular}




\section{Conventional Calibration Conditions}

for X-and Gamma-Ray Measuring Instruments

\begin{tabular}{|c|c|c|c|c|c|c|c|c|c|}
\hline \multirow[t]{2}{*}{$\begin{array}{l}\text { Beam } \\
\text { code }\end{array}$} & \multicolumn{4}{|c|}{ Additional Filtration a } & \multicolumn{2}{|c|}{ Half-value layer } & \multicolumn{2}{|c|}{$\begin{array}{l}\text { Homogeneity } \\
\text { coefficient }\end{array}$} & \multirow{2}{*}{$\begin{array}{c}\begin{array}{c}\text { Effective } \\
\text { energy }\end{array} \\
(\mathrm{keV})\end{array}$} \\
\hline & $\begin{array}{c}\mathrm{Al} \\
(\mathrm{mm})\end{array}$ & $\begin{array}{c}\mathrm{Cu} \\
(\mathrm{mm})\end{array}$ & $\begin{array}{c}\mathrm{Sn} \\
(\mathrm{mm})\end{array}$ & $\begin{array}{c}\mathrm{Pb} \\
(\mathrm{mm})\end{array}$ & $\begin{array}{c}\mathrm{Al} \\
(\mathrm{mm})\end{array}$ & $\begin{array}{c}\mathrm{Cu} \\
(\mathrm{mm})\end{array}$ & $\mathrm{Al}$ & $\mathrm{Cu}$ & \\
\hline \multicolumn{10}{|c|}{ X-Ray Beam Qualities } \\
\hline $\mathrm{L} 10$ & & & & & 0.035 & & 69 & & \\
\hline $\mathrm{L} 15$ & & & & & 0.057 & & 66 & & \\
\hline $\mathrm{L} 20$ & & & & & 0.069 & & 73 & & \\
\hline L30 & 0.30 & & & & 0.22 & & 63 & & \\
\hline $\mathrm{L} 40$ & 0.53 & & & & 0.50 & & 59 & & \\
\hline L50 & 0.71 & & & & 0.76 & & 69 & & \\
\hline L80 & 1.45 & & & & 1.83 & & 57 & & \\
\hline L100 & 1.98 & & & & 2.77 & & 57 & & \\
\hline M20 & 0.27 & & & & 0.15 & & 69 & & \\
\hline M30 & 0.5 & & & & 0.36 & & 65 & & \\
\hline M40 & 0.89 & & & & 0.73 & & 69 & & \\
\hline M50 & 1.07 & & & & 1.02 & & 66 & & \\
\hline M60 & 1.50 & & & & 1.68 & & 66 & & \\
\hline M80 & 2.61 & & & & 2.97 & & 67 & & \\
\hline M100 & 5.0 & & & & 5.02 & & 73 & & \\
\hline M120 & 6.87 & & & & 6.79 & & 77 & & \\
\hline M150 & 5.0 & 0.25 & & & 10.2 & 0.67 & 87 & 62 & \\
\hline M200 & 4.1 & 1.12 & & & 14.9 & 1.69 & 99 & 60 & \\
\hline M250 & 5.0 & 3.2 & & & 18.5 & 3.2 & 99 & 66 & \\
\hline M300 & 4.0 & & 6.5 & & 22.0 & 5.3 & 100 & 97 & \\
\hline $\mathrm{H} 10$ & 0.105 & & & & 0.05 & & 91 & & \\
\hline H15 & 0.5 & & & & 0.153 & & 66 & & \\
\hline $\mathrm{H} 20$ & 1.01 & & & & 0.36 & & 91 & & \\
\hline $\mathrm{H} 30$ & 4.50 & & & & 1.23 & & 93 & & \\
\hline $\mathrm{H} 40$ & 0.53 & 0.26 & & & 2.90 & & 99 & & \\
\hline $\mathrm{H} 50$ & 4.0 & & & 0.1 & 4.2 & 0.142 & 92 & 90 & 38 \\
\hline $\mathrm{H} 60$ & 4.0 & 0.61 & & & 6.0 & 0.24 & 99 & 69 & 80 \\
\hline $\mathrm{H} 100$ & 4.0 & 5.2 & & & 13.5 & 1.14 & 100 & 99 & 80 \\
\hline H150 & 4.0 & 4.0 & 1.51 & & 17.0 & 2.5 & 100 & 95 & 120 \\
\hline $\mathrm{H} 200$ & 4.0 & 0.6 & 4.16 & 0.77 & 19.8 & 4.1 & 100 & 99 & 166 \\
\hline $\mathrm{H} 250$ & 4.0 & 0.6 & 1.04 & 2.72 & 22.0 & 5.2 & 100 & 99 & 211 \\
\hline H300 & 4.1 & & 3.0 & 5.0 & 23.0 & 6.2 & 99 & 99 & 252 \\
\hline S60 & 4.35 & & & & 2.77 & & 72 & & \\
\hline S75 & 1.50 & & & & 1.86 & & 63 & & \\
\hline \multicolumn{10}{|c|}{ Gamma-Ray Beam Qualities } \\
\hline $137 \mathrm{Cs}$ & & & & & & 10.8 & & & 662 \\
\hline${ }^{60} \mathrm{Co}$ & & & & & & 14.9 & & & 1250 \\
\hline
\end{tabular}

${ }^{a}$ The additional filtration value does not include the inherent filtration. The inherent filtration is approximately $1.0 \mathrm{~mm}$ Be for beam codes L10-L100, M20-M50, H10-H40 and S75; and 3.0 mm Be for beam codes M60-M300, H50-H300 and S60. 
Air Kerma: The air-kerma rate at the calibration position is measured by a free-air ionization chamber for $\mathrm{x}$ radiation and by graphite cavity ionization chambers for ${ }^{60} \mathrm{Co}$ and ${ }^{137} \mathrm{Cs}$ gamma radiation, and is expressed in units of grays per second (Gy/s). The gamma-ray air-kerma rates are corrected to the date of calibration (from previously measured values) by decay corrections based on half-lives of 5.27 years for ${ }^{60} \mathrm{Co}$ and 30.0 years for ${ }^{137} \mathrm{Cs}$. For a free-air ionization chamber with measuring volume $V$, the air-kerma rate is determined by the relation:

where

$$
\dot{K}=\frac{I}{\rho_{\mathrm{air}} V} \frac{W_{\mathrm{air}}}{e} \frac{1}{1-g_{\mathrm{air}}} \prod_{i} k_{i}
$$

$I /\left(\rho_{\text {air }} V\right)$ is the ionization current, measured by the standard, divided by the mass of air in the measuring volume

$W_{\text {air }}$ is the mean energy expended by an electron of charge $e$ to produce an ion pair in dry air, the value used at NIST is $\mathrm{W}_{\text {air }} / \mathrm{e}=33.97 \mathrm{~J} / \mathrm{C}$

$g_{\text {air }} \quad$ is the fraction of the initial kinetic energy of secondary electrons dissipated in air through radiative processes, the values used at NIST are 0.0032 for ${ }^{60} \mathrm{Co}, 0.0016$ for ${ }^{137} \mathrm{Cs}$ and 0.0 (negligible) for $\mathrm{x}$ rays with energies less than $300 \mathrm{keV}$, and

$\Pi k_{\mathrm{i}}$ is the product of the correction factors to be applied to the standard.

Air kerma in grays $(\mathrm{Gy})$ is related to exposure $(X)$ in roentgens $(\mathrm{R})$ by the equation:

$$
X=\frac{K}{2.58 E-4} \frac{1-g_{\text {air }}}{W_{\text {air }} / e}
$$

To obtain exposure in roentgens, divide air kerma in grays by $8.79 \mathrm{E}-3$ for ${ }^{60} \mathrm{Co}$ gamma rays, $8.78 \mathrm{E}-3$ for ${ }^{137} \mathrm{Cs}$ gamma rays, and $8.76 \mathrm{E}-03$ for $\mathrm{x}$ rays with energies less than $300 \mathrm{keV}$.

Beam Code: The beam code identifies important beam parameters and describes the quality of the radiation field. NIST offers four types of reference beam qualities, as well as the ISO reference radiation qualities. NIST beam codes are referred to as L, M, H, and S beams, which stand for light, moderate, heavy, and special filtration, respectively. The number following the letter is the constant potential across the x-ray tube. For gamma radiation, the beam code identifies the radionuclide.

Calibration Distance: The calibration distance is that between the radiation source and the detector center or the reference line. For thin-window chambers with no reference line, the window surface is the plane of reference. The beam size at the stated distance is appropriate for the chamber dimensions.

Calibration Factor: The calibration factors given in this report are quotients of the air kerma and the charge generated by the radiation in the ionization chamber. The average charge used to compute the calibration factor is based on measurements with the wall of the ionization chamber at the stated polarity

and potential. With the assumption that the chamber is open to the atmosphere, the measurements are normalized to a pressure of one standard atmosphere $(101.325 \mathrm{kPa})$ and a temperature of $295.15 \mathrm{~K}\left(22^{\circ} \mathrm{C}\right)$. 
Use of the chamber at other pressures and temperatures requires normalization of the ion currents to these reference conditions using the normalizing factor $F$ (see below).

Effective Energy: The effective energy is shown for those beams where it is considered a meaningful characterization of the beam quality. The effective energy for gamma radiation is the mean photon energy emitted by the radionuclide, and for $\mathrm{x}$ radiation it is computed from good-geometry copper attenuation data. The initial slope of the attenuation curve is used to determine the attenuation coefficient, and the photon energy associated with this coefficient is given as the "effective energy." The energy vs attenuationcoefficient data used for this purpose were taken from J. H. Hubbell, Int. J. Appl. Radiat. Isot. 33, 1269 (1982). For beam codes $\mathrm{H} 50-\mathrm{H} 300$, the effective energy is well represented by the equation: effective energy $=0.861 V-6.1 \mathrm{keV}$ where $V$ is the constant potential in kilovolts.

Equilibrium Shell: Material added to the nominal wall thickness of the chamber to ensure electronic equilibrium.

Half-Value Layer: The half-value layers (HVL) in aluminum and in copper have been determined by measurements with a free-air chamber for $\mathrm{x}$ radiation, and have been calculated for the copper HVLs of ${ }^{60} \mathrm{Co}$ and ${ }^{137} \mathrm{Cs}$.

Homogeneity Coefficient: The homogeneity coefficient is the quotient of the first HVL and the second HVL, generally expressed as a percent.

Humidity: No correction is made for the effect of water vapor on the instrument being calibrated. It is assumed that both the calibration and the use of that instrument take place in air with a relative humidity between $10 \%$ and $70 \%$, where the humidity correction is nearly constant.

Normalizing Factor $\mathrm{F}$ : The normalizing factor $F$ is computed from the following expression:

$F=(273.15+T) /(295.15 H)$ where $T$ is the temperature in degrees Celsius, and $H$ is the pressure expressed as a fraction of a standard atmosphere. ( 1 standard atmosphere $=101.325$ kilopascals $=1013.25$ millibars $=760$ millimeters of mercury)

Uncertainty: The expanded, combined uncertainty of the calibration described in this report is $1 \%$, of which $0.8 \%$ is assigned to the uncertainty in the air-kerma rate of the NIST beam. The expanded, combined uncertainty is formed by taking two times the square root of the sum of the squares of the standard deviations of the mean for component uncertainties obtained from replicate determinations, and assumed approximations of standard deviations for all other uncertainty components; it is considered to have the approximate significance of a $95 \%$ confidence limit. Details of the uncertainty analysis are given in: Lamperti, P.J., Loftus, T.P., and Loevinger, R., "Calibration of X-Ray and Gamma-Ray Measuring Instruments at the National Bureau of Standards," NBS Special Publication 250-16 (1987). 
Attachment 6: Typical TLD calibration report 


\title{
National Institute of Standards and Technology
}

\section{REPORT OF ${ }^{137}$ Cs IRRADIATION \\ OF}

\author{
ADDRESS 1 \\ ADDRESS 2 \\ ADDRESS 3
}

Measurements performed by Ronnie Minniti

Report reviewed by Paul Lamperti

Report approved by Stephen M. Seltzer

For the Director

National Institute of Standards and Technology

by

Bert M. Coursey, Chief

Ionizing Radiation Division

Physics Laboratory

Information on technical aspects of this report may be obtained from Michelle O'Brien, National Institute of Standards and Technology, 100 Bureau Drive Stop 8460, Gaithersburg, MD 20899, (301) 975-5586. Report format revised 5/00. 


\section{National Institute of Standards and Technology}

\section{REPORT OF ${ }^{137}$ Cs IRRADIATION \\ $\mathrm{OF}$}

ADDRESS 1
ADDRESS 2
ADDRESS 3

Dosimeter Type:

Badge Orientation: front face normal to the incident radiation.

Air Kerma Rate: X.XX E0 Gy/s.

\begin{tabular}{|c|c|c|c|c|c|}
\hline \multicolumn{2}{|c|}{ TLD Identification } & \multirow{2}{*}{$\begin{array}{l}\text { Exposed } \\
\text { on } \\
\text { Phantom }\end{array}$} & \multirow{2}{*}{$\begin{array}{c}\text { Total } \\
\text { Exposure } \\
(\mathrm{mR})\end{array}$} & \multirow{2}{*}{$\begin{array}{l}\text { Total } \\
\text { Air- } \\
\text { Kerma } \\
(\mathrm{mGy})\end{array}$} & \multirow{2}{*}{$\begin{array}{c}\text { Irradiation } \\
\text { Distance } \\
\text { (cm) }\end{array}$} \\
\hline Model & Number & & & & \\
\hline & & YES/NO & X.XXX E0 & X.XX E0 & 000 \\
\hline & & YES/NO & X.XXX E0 & X.XX E0 & 000 \\
\hline
\end{tabular}

See the last three pages of attachment 5 for an example of the remainder of this report. 
Attachment 7: Typical electrometer calibration report 


\title{
National Institute of Standards and Technology
}

\section{REPORT OF TEST}

\author{
$\mathrm{OF}$
}

ADDRESS 1

ADDRESS 2

ADDRESS 3

Electrometer: Make, Model SN

Measurements performed by Michelle O'Brien

Report reviewed by Paul Lamperti

Report approved by Stephen M. Seltzer

For the Director

National Institute of Standards and Technology

by

Bert M. Coursey, Chief

Ionizing Radiation Division

Physics Laboratory

Information on technical aspects of this report may be obtained from Michelle O'Brien, National Institute of Standards and Technology, 100 Bureau Drive Stop 8460, Gaithersburg, MD 20899, (301) 975-2014. Report format revised 5/00. 


\section{THE SP 250 SERIES ON NIST MEASUREMENT SERVICES*}

SP 250-1 Spectral Radiance Calibrations

PB87179883

SP 250-2 Far Ultraviolet Detector Standards PB87227609

SP 250-3 Radiometric Standards in the Vacuum Ultraviolet PB87227625

SP 250-4 Fricke Dosimetry in High-Energy Electron Beams PB88110374

SP 250-5 Alpha-Particle Calibrations PB88168620

SP 250-6 Regular Spectral Transmittance PB88108550

SP 250-7 Radiance Temperature Calibrations PB88123674

SP 250-8 Spectral Reflectance PB88109905

SP 250-9 Calibration of Beta-Particle-Emitting Ophthalmic Applicators

PB88108535

SP 250-10 Radioactivity Calibrations with the " $4 \pi$ " Gamma Ionization Chamber and Other Radioactivity Calibration Capabilities PB88123708

SP 250-11 Dosimetry for High Dose Applications PB88201587

SP 250-12 Neutron Personnel Dosimetry PB87227617

SP 250-13 Activation Foil Irradiation with Californium Fission Sources PB88217443

SP 250-14 Activation Foil Irradiation by Reactor Cavity Fission Sources PB88217435

SP 250-15 Photometric Calibrations PB88153747

SP 250-16 Calibration of X-Ray and Gamma-Ray Measuring Instruments PB88211826

SP 250-17 The NBS Photodetector Spectral Response Calibration Transfer Program PB88201595

SP 250-18 Neutron Source Strength Calibrations PB88211818

SP 250-19 Calibration of Gamma-Ray-Emitting Brachytherapy Sources PB89193858

SP 250-20 Spectral Irradiance Calibrations PB88123781

SP 250-21 Calibration of Beta-Particle Radiation Instrumentation PB88201579

SP 250-22 Platinum Resistance Thermometer Calibrations PB88138367

SP 250-23 Liquid-in-Glass Thermometer Calibration Service PB89128888
SP 250-24 Standard Cell Calibrations PB88123690

SP 250-25 Calibration Senvice for Inductive Voltage Dividers

SP 250-26 NBS Phase Angle Calibration Services PB88225636

SP 250-27 AC-DC Difference Calibrations PB892222616

SP 250-28 Solid-State DC Voltage Standard Calibrations PB88168703

SP 250-29 Traceable Frequency Calibrations PB88168364

SP 250-30 GOES Satellite Time Code Dissemination: Description and Operation PB88168760

SP 250-31 Mass Calibrations PB89153894

SP 250-32 A Calibration Service for $30 \mathrm{MHz}$ Attenuation and Phase Shift PB88238324

SP 250-33 A Calibration Service for Voltage Transformers and High-Voltage Capacitors PB882252903

SP 250-34 High Vacuum Standard and Its Use PB89193841

SP 250-35 The Calibration of Thermocouples and Thermocouple Materials PB89209340

SP 250-36 A Calibration Service for Current Transformers PB91216770

SP 250-37 Photometric Calibrations PB97148472

SP 250-38 NIST Leak Calibration Service PB92149772

SP 250-39 NIST Pressure Calibration Service PB94164043

SP 250-40 Absorbed-Dose Calibration of Ionization Chambers in a ${ }^{60} \mathrm{Co}$ Gamma-Ray Beam

No PB number

SP 250-41 Spectroradiometric Detector Measurements: Part I - Ultraviolet Detectors and Part II - Visible to Near-Infrared Detectors PB98-149073

SP 250-42 Sprectroradiometric Detector Measurements: Part III-Infrared Detectors PB99-134371

SP 250-43 Radiance Temperature Calibrations PB98-141047

SP 250-44 Radiation Processing Dosimetry Calibration Services and Measurement Assurance Program PB98-140973

* Entries containing a stock number (SN003-003-) can be purchased from the Superintendent of Documents, U.S. Government

Printing Office, Washington, DC 20402-9325. GPO will accept checks, money orders, VISA, and MasterCard. For more infomation, or to place an order, call (202) 512-1800. Be sure to cite the stock number on all orders.

Entries containing PB numbers can be purchased from the National Technical Information Service, Springfield, VA 22161. NTIS will accept American Express in addition to the payment methods listed for GPO. For more information or to place an order call (800) 553-6487. Fax: (703) 321-8547. Be sure to cite the PB number on all orders.

Entries without stock or PB numbers are in preparation. 
SP 250-45 Radiation Processing Dosimetry Calibration Services: Manual of Calibration Procedures SN003-003-03514-9, PB98-140981

SP 250-46 NIST Multifunction Calibration System SN003-003-03515-7, PB98-131279

SP 250-47 NIST Calibration Service for Capacitance Standards at Low Frequencies SN003-003-03549-1, PB98-144687

SP 250-48 Spectral Reflectance SN003-003-03545-9, PB98-149016

SP 250-49 NIST Calibration Services for Gas Flow Meters: Piston Prover and Bell Prover Gas Flow Facilities SN003-003-03560-2, PB99-107260

SP 250-51 Calibration Service of Optoelectronic Frequency Response at $1319 \mathrm{~nm}$ for Combined Photodiode/rf Power Sensor Transfer Standards SN003-003-03623-4, PB2000-103300

SP 250-52 Error Analysis and Calibration Uncertainty of Capacitance Standards at NIST SN003-003-03633-1, PB2000-103674

SP 250-53 Calibration Service for Spectral Responsivity of Laser and Optical-Fiber Power Meters at Wavelengths Between $0.4 \mu \mathrm{m}$ and $1.8 \mu \mathrm{m}$ SN003-003-03624-2, PB2000-102878

SP 250-54 Optical Fiber Power Meter Calibrations at NIST SN003-003-03652-8, PB2000-106986

SP 250-56 Optical Fiber Power Meter Nonlinearity Calibrations at NIST SN003-003-03653-6, PB2000-106987

SP 250-57 Measurement Assurance Program for the Spectral Density of Relative Intensity Noise of Optical Fiber Sources Near $1550 \mathrm{~nm}$ SN003-003-03658-7, PB2000-108256

* Entries containing a stock number (SN003-003-) can be purchased from the Superintendent of Documents, U.S. Government Printing Office, Washington, DC 20402-9325. GPO will accept checks, money orders, VISA, and MasterCard. For more infomation, or to place an order, call (202) 512-1800. Be sure to cite the stock number on all orders.

Entries containing PB numbers can be purchased from the National Technical Information Service, Springfield, VA 22161. NTIS will accept American Express in addition to the payment methods listed for GPO. For more information or to place an order call (800) $553-6487$. Fax: (703) 321-8547. Be sure to cite the PB number on all orders.

Entries without stock or PB numbers are in preparation. 



\section{Technical Publications}

\section{Periodical}

Journal of Research of the National Institute of Standards and Technology-Reports NIST research and development in those disciplines of the physical and engineering sciences in which the Institute is active. These include physics, chemistry, engineering, mathematics, and computer sciences. Papers cover a broad range of subjects, with major emphasis on measurement methodology and the basic technology underlying standardization. Also included from time to time are survey articles on topics closely related to the Institute's technical and scientific programs. Issued six times a year.

\section{Nonperiodicals}

Monographs-Major contributions to the technical literature on various subjects related to the Institute's scientific and technical activities.

Handbooks-Recommended codes of engineering and industrial practice (including safety codes) developed in cooperation with interested industries, professional organizations, and regulatory bodies.

Special Publications-Include proceedings of conferences sponsored by NIST, NIST annual reports, and other special publications appropriate to this grouping such as wall charts, pocket cards, and bibliographies. National Standard Reference Data Series-Provides quantitative data on the physical and chemical properties of materials, compiled from the world's literature and critically evaluated. Developed under a worldwide program coordinated by NIST under the authority of the National Standard Data Act (Public Law 90-396). NOTE: The Journal of Physical and Chemical Reference Data (JPCRD) is published bimonthly for NIST by the American Institute of Physics (AIP). Subscription orders and renewals are available from AIP, P.O. Box 503284, St. Louis, MO 63150-3284.

Building Science Series-Disseminates technical information developed at the Institute on building materials, components, systems, and whole structures. The series presents research results, test methods, and performance criteria related to the structural and environmental functions and the durability and safety characteristics of building elements and systems.

Technical Notes-Studies or reports which are complete in themselves but restrictive in their treatment of a subject. Analogous to monographs but not so comprehensive in scope or definitive in treatment of the subject area. Often serve as a vehicle for final reports of work performed at NIST under the sponsorship of other government agencies.

Voluntary Product Standards-Developed under procedures published by the Department of Commerce in Part 10, Title 15, of the Code of Federal Regulations. The standards establish nationally recognized requirements for products, and provide all concerned interests with a basis for common understanding of the characteristics of the products. NIST administers this program in support of the efforts of private-sector standardizing organizations.

Order the following NIST publications_FIPS and NISTIRs-from the National Technical Information Service, Springfield, VA 22161.

Federal Information Processing Standards Publications (FIPS PUB)_Publications in this series collectively constitute the Federal Information Processing Standards Register. The Register serves as the official source of information in the Federal Government regarding standards issued by NIST pursuant to the Federal Property and Administrative Services Act of 1949 as amended, Public Law 89-306 (79 Stat. 1127), and as implemented by Executive Order 11717 (38 FR 12315, dated May 11, 1973) and Part 6 of Title 15 CFR (Code of Federal Regulations).

NIST Interagency or Internal Reports (NISTIR)-The series includes interim or final reports on work performed by NIST for outside sponsors (both government and nongovernment). In general, initial distribution is handled by the sponsor; public distribution is handled by sales through the National Technical Information Service, Springfield, VA 22161, in hard copy, electronic media, or microfiche form. NISTIR's may also report results of NIST projects of transitory or limited interest, including those that will be published subsequently in more comprehensive form. 


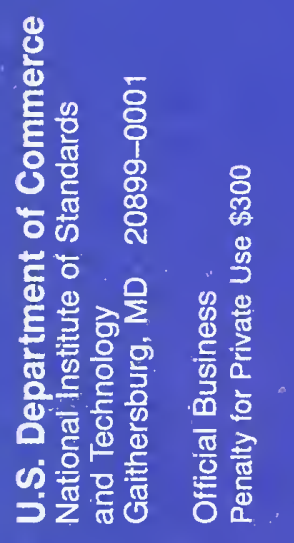

